\title{
Burden of Breast Cancer and Associated Health and Economic Outcomes in Elderly Women in West Virginia: Comparison with National Estimates
}

Ami Maulik Vyas

Follow this and additional works at: https://researchrepository.wvu.edu/etd

\section{Recommended Citation}

Vyas, Ami Maulik, "Burden of Breast Cancer and Associated Health and Economic Outcomes in Elderly Women in West Virginia: Comparison with National Estimates" (2014). Graduate Theses, Dissertations, and Problem Reports. 7141.

https://researchrepository.wvu.edu/etd/7141

This Dissertation is protected by copyright and/or related rights. It has been brought to you by the The Research Repository @ WVU with permission from the rights-holder(s). You are free to use this Dissertation in any way that is permitted by the copyright and related rights legislation that applies to your use. For other uses you must obtain permission from the rights-holder(s) directly, unless additional rights are indicated by a Creative Commons license in the record and/ or on the work itself. This Dissertation has been accepted for inclusion in WVU Graduate Theses, Dissertations, and Problem Reports collection by an authorized administrator of The Research Repository @ WVU.

For more information, please contact researchrepository@mail.wvu.edu. 
"Burden of Breast Cancer and Associated Health and Economic Outcomes in Elderly Women in West Virginia: Comparison with National Estimates"

$$
\text { Ami Maulik Vyas }{ }^{1}
$$

Dissertation submitted to the School of Pharmacy

at West Virginia University

in partial fulfillment of the requirements

for the degree of

Doctor of Philosophy

in

Health Outcomes Research

Suresh Madhavan, M.B.A., Ph.D. Chair ${ }^{1}$

Usha Sambamoorthi, Ph.D. ${ }^{1}$

Xiaoyun (Lucy) Pan, Ph.D. ${ }^{1}$

Michael Regier, Ph.D. ${ }^{2}$

Hannah Hazard, M.D. ${ }^{3}$

${ }^{1}$ Department of Pharmaceutical Systems and Policy, School of Pharmacy, West Virginia University

${ }^{2}$ Department of Biostatistics, School of Public Health, West Virginia University

${ }^{3}$ Department of Surgery, School of Medicine, Mary Babb Randolph Cancer Center, West Virginia University

Morgantown, West Virginia

2014

Keywords: Breast Cancer; Surveillance, Epidemiology, and End Results (SEER); West Virginia Cancer Registry; Medicare; Mammography Screening; Persistence; Timeliness of Care; Blinder-Oaxaca Linear Decomposition; Generalized Linear Modeling; Logistic Regression

Copyright 2014 Ami Maulik Vyas 


\title{
ABSTRACT \\ "Burden of Breast Cancer and Associated Health and Economic Outcomes in Elderly Women in West Virginia: Comparison with National Estimates"
}

\author{
Ami Maulik Vyas
}

\begin{abstract}
West Virginia (WV) which is the only state which lies entirely in Appalachia and which is predominantly rural and medically underserved region, has lower incidence of breast cancer (BC) but a higher BC-related mortality as compared to the national averages in elderly women age 65 and above. This may be due to lower mammography utilization in these rural elderly women, limited physical access to services, shortage of healthcare professionals and services, and untimely and/or inappropriate care. This is dearth of epidemiological studies that have focused on understanding the factors associated with these disparities among these rural and underserved population such as WV. The purpose of this project was to do a detailed evaluation of burden of BC and its associated health and economic outcomes in elderly women in WV, and to compare these estimates with the national estimates. Three retrospective observational studies were conducted using West Virginia Cancer Registry-Medicare and Surveillance, Epidemiology, and End Results (SEER)-Medicare linked datasets for the years 2002-2007. In the first study, persistence with mammography screening and its effect on stage at $\mathrm{BC}$ diagnosis was investigated for the elderly rural $\mathrm{WV}$ women and was compared to the national estimates from SEER-Medicare data. The study found no significant differences in the representation of disease between WV-Medicare and SEER-Medicare cohorts even after controlling for persistence with mammography screening. In the second study, timeliness of BC care in regards to diagnosis and treatment as per the published opinion-based recommendations and its effect on chances of being alive at the follow-up period was determined for the WV-Medicare cohort and then was compared to the SEER-Medicare cohort. The study found that the WV-Medicare cohort was significantly less likely to receive timely diagnosis of BC as per recommendations when compared to the SEER-Medicare cohort. However, there were no significant differences between these cohorts for the timely treatment of BC. Also, delayed diagnosis was not associated with poorer prognosis in the WV-Medicare cohort. In the third study, average total healthcare costs in the initial phase of 12-months following BC diagnosis and costs by types of specific services were estimated for the WV-Medicare cohort and these were compared to the national estimates derived from the SEER-Medicare cohort. This study reported that average total healthcare costs, inpatient costs and physician services costs were significantly lower for the WV-Medicare cohort as compared to the SEER-Medicare cohort. Also, the decomposition analyses only explained total $16 \%$ of the differences in the average costs due to the cohorts' characteristics. Overall, the findings of this project highlight the importance of persistence with mammography screening and timely BC care in the elderly, rural and underserved women diagnosed with BC. Moreover, these studies can serve as a foundation for larger studies aimed at decreasing $\mathrm{BC}$ disparities in a rural and geographically challenged state such as WV, through the development of strategies and interventions to foster early detection and timely treatment of BC among rural populations.
\end{abstract}




\section{DEDICATION}

I dedicate this dissertation to my husband, Maulik, my mom, Kanta, my dad, Prabhudas, my two sisters, Pinky and Bansary, for their continued love and support. 


\section{ACKNOWLEDGEMENTS}

I want to acknowledge that this project was conducted at the WV-CoHORTS center with the support of Agency for Healthcare Research and Quality grant 1-R24-HS018622-03 and the National Institute of General Medicine Sciences grant U54GM104942.

I am highly grateful to everyone who helped me in the completion of my dissertation. I would like to heartily acknowledge my major advisor, mentor and committee chair, Dr. Suresh Madhavan for his continuous guidance and providing me with tremendous support during the entire $\mathrm{Ph} . \mathrm{D}$ program and my dissertation project. I would not have been blessed with this outstanding achievement of my life without his support. Special thanks to Dr. Usha Sambamoorthi without whose help and guidance, this project would not have been completed. I also want to thank my other committee members Dr. Xiaoyun (Lucy) Pan, Dr. Michael Regier, and Dr. Hannah Hazard for their valuable feedback and inputs during the course of my dissertation project. I want to acknowledge Sita Kalidindi for her programming tutorial sessions during the earlier phase of my dissertation project.

I also want to acknowledge my PSP family: Faculty, Angie Frame, and all the graduate students for their continued support.

Finally, special appreciation to my husband, Maulik, for his continued love, support, sacrifices, and encouragement during my 4.5 years of fruitful journey at West Virginia University. I am very grateful to my family - my mom, my dad, my two sisters for encouraging me to achieve all of my goals all my life. And thank you God! 


\section{TABLE OF CONTENTS}

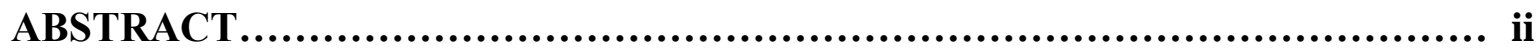

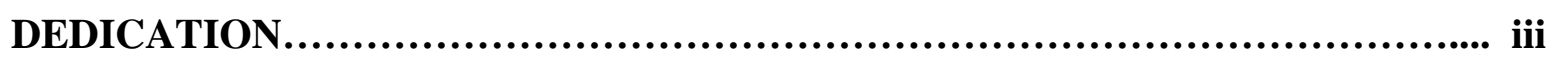

ACKOWLEDGEMENTS.......................................................... iv

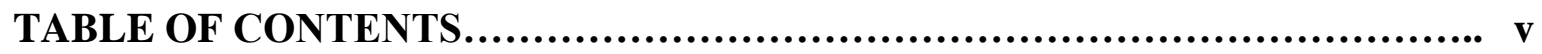

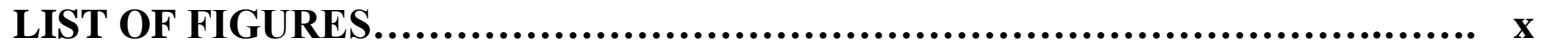

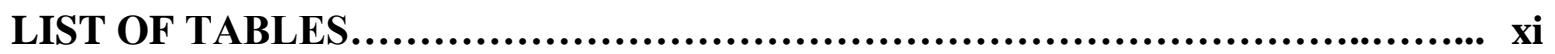

CHAPTER 1: INTRODUCTION..................................................... 1

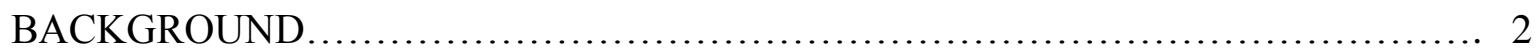

Breast Cancer Overview.......................................................... 2

Risk Factors for Breast Cancer............................................. 2

Breast Cancer Epidemiology ............................................. 3

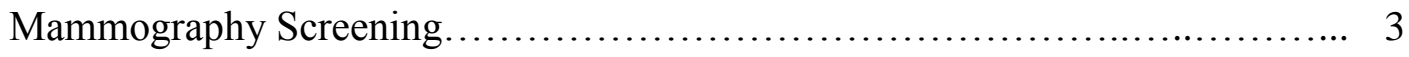

Breast Cancer and Mammography Screening in West Virginia................... 4

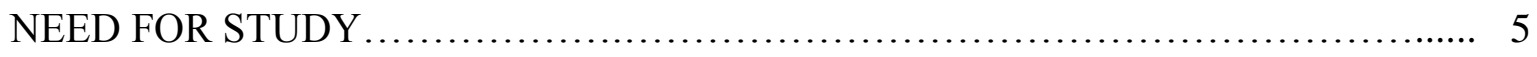

Persistence with Mammography Screening and Stage at Breast Cancer Diagnosis.............................................................. 5

Timeliness of Care Among Elderly Women Diagnosed with Breast Cancer....... 6

Total Healthcare Costs of Breast Cancer in the Initial Phase (12-Months)

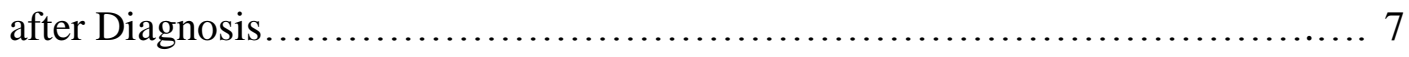

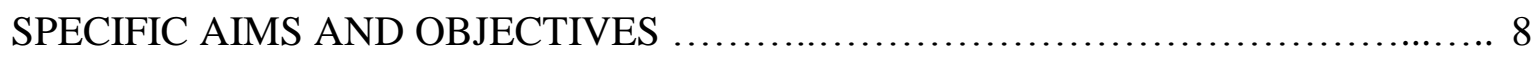

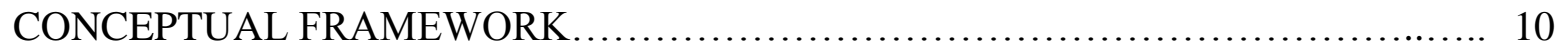

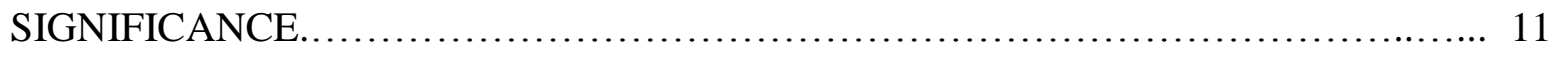

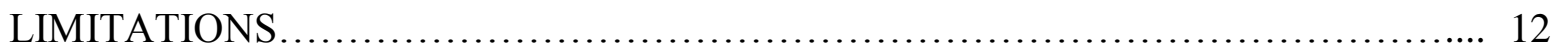


REFERENCES............................................................ 14

CHAPTER 2: MANUSCRIPT 1 "Persistence with Mammography Screening"..... 20

INTRODUCTION ........................................................... 21

Breast Cancer.............................................................. 21

Mammography Screening ............................................... 22

Breast Cancer and Mammography Screening in West Virginia.................... 22

Persistence with Mammography Screening and Stage at Breast Cancer

Diagnosis................................................................... 23

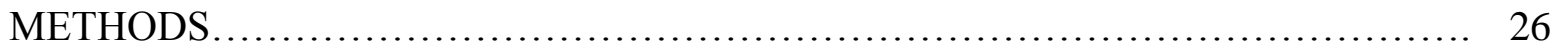

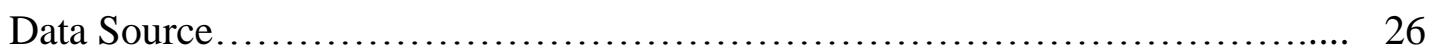

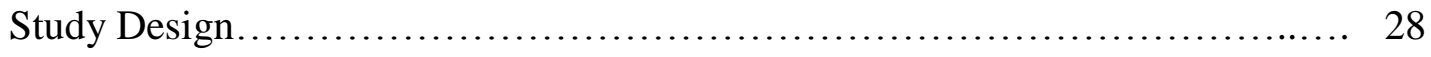

Study Cohorts..................................................... 29

Measures.......................................................... 30

Statistical Analyses.................................................. 33

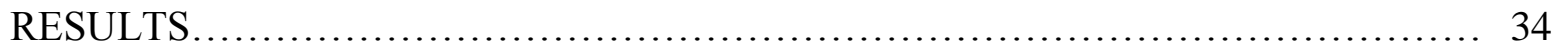

Description of the Study Cohorts by Persistence with Mammography

Screening............................................................... 34

Stage at Breast Cancer Diagnosis by Persistence with Mammography

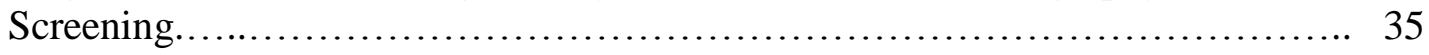

Association between Persistence with Mammography Screening and Stage at Breast Cancer Diagnosis............................................. 35

Description of non-Hispanic White Study Cohorts.......................... 36

Differences in Stage at Breast Cancer Diagnosis between Study Cohorts in a Multivariate Framework........................................................................ 36

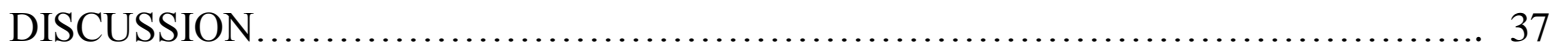

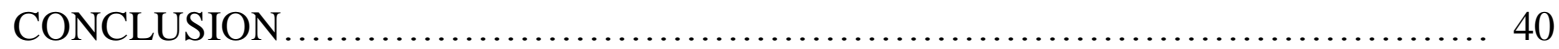


CHAPTER 3: MANUSCRIPT 2 "Timely Diagnosis and Treatment"................ 53

INTRODUCTION ...................................................................... 54

Breast Cancer...................................................... 54

Timely Diagnosis and Treatment of Breast Cancer in Elderly Women........... 54

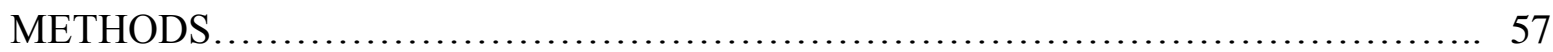

Data Source..................................................... 57

Study Design................................................... 59

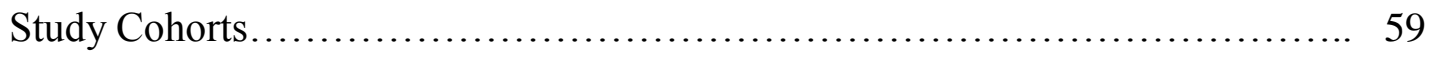

Measures........................................................... 61

Statistical Analyses................................................. 64

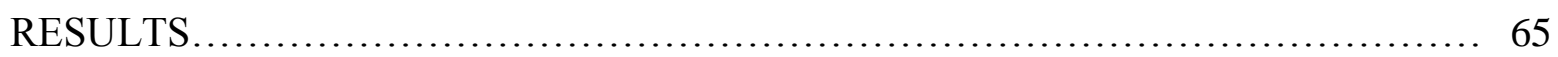

Description of the Study Cohorts .................................... 65

Median Days for Diagnosis and Treatment for the Study Cohorts.............. 65

Median Days for Type of Initial Treatment by Stage at Breast Cancer

Diagnosis for the Study Cohorts ...................................... 66

Median Days for Diagnosis and Treatment within Independent Variables........ 67

Proportion of Study Cohorts Receiving Timely Diagnosis and Treatment As Per the Published Recommendations.................................. 67

Factors Associated with Timely Diagnosis and Timely Treatment............. 68

Differences in Timely Diagnosis and Treatment between Study Cohorts In a Multivariate Framework............................................ 68

Differences in Survival between Study Cohorts with Receipt of Timely Diagnosis and Timely Treatment in a Multivariate Framework................ 69

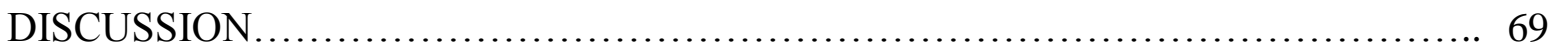


CONCLUSION

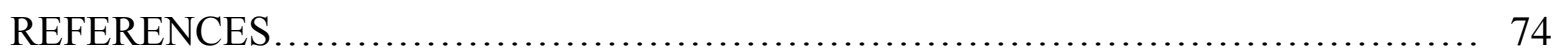

CHAPTER 4: MANUSCRIPT 3 "Total Healthcare Costs in the Initial Phase"....... 95

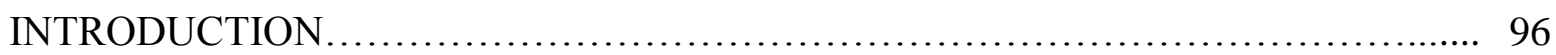

Breast Cancer.......................................................... 96

Total Healthcare Costs in the Initial Phase of One Year after Breast Cancer Diagnosis................................................................ 97

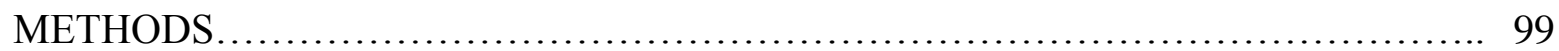

Data Source........................................................ 99

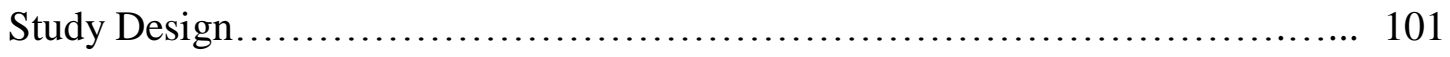

Study Cohorts..................................................... 101

Measures.................................................................. 103

Statistical Analyses.................................................. 106

RESULTS.................................................................. 108

Description of the Study Cohorts..................................... 108

Average Total Costs and Averages Costs by Types of Services................ 109

Average Total Costs for Clinically Important Variables..................... 110

Factors Associated with Average Total Costs............................... 110

Differences in Average Total Costs and Average Costs by Types of Services....... 111

Factors Explaining Lower Average Total Costs in the WV-Medicare Cohort Using Blinder-Oaxaca Linear Decomposition Analyses...................... 112

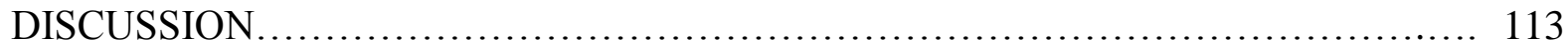

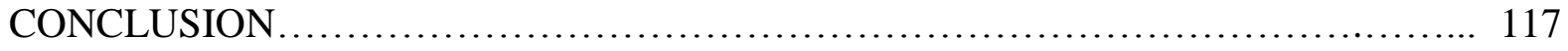

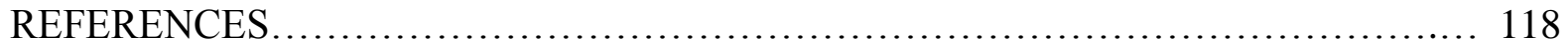


CHAPTER 5: SUMMARY AND CONCLUSIONS............................... 131

RATIONALE AND OBJECTIVES................................................ 132

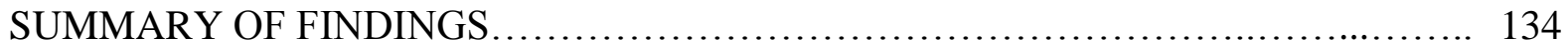

Persistence with Mammography Screening and Stage at Breast Cancer

Diagnosis Among Elderly Women ........................................ 135

Timeliness of Care Among Elderly Women Diagnosed with Breast Cancer........ 136

Total Healthcare Costs in the Initial Phase (12-Months) after Breast Cancer

Diagnosis.................................................................... 137

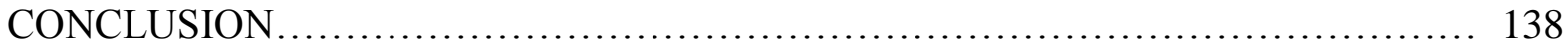

FUTURE RESEARCH............................................................. 139

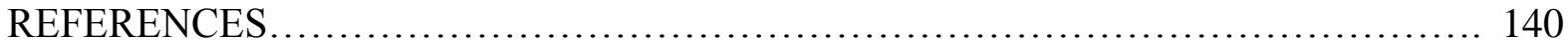




\section{LIST OF FIGURES}

Figure 1.1: The Andersen Behavioral Model for Healthcare Utilization................ 19

Figure 2.1: The Andersen Behavioral Model for Healthcare Utilization (For Aim 1)..... 46

Figure 2.2: WV-Medicare Cohort by Persistence with Mammography Screening....... 47

Figure 2.3: SEER-Medicare Cohort by Persistence with Mammography Screening..... 47

Figure 2.4: Stage at Breast Cancer Diagnosis by Persistence with Mammography Screening for the WV-Medicare Cohort............................. 48

Figure 2.5: Stage at Breast Cancer Diagnosis by Persistence with Mammography Screening for the SEER-Medicare Cohort............................. 48

Figure 3.1: The Andersen Behavioral Model for Healthcare Utilization (For Aim 2)..... 80

Figure 3.2: Proportion of Study Cohorts Receiving Timely Breast Cancer Diagnosis As Per the Published Recommendations............................. 81

Figure 3.3: Proportion of Study Cohorts Receiving Timely Breast Cancer Treatment As Per the Published Recommendations.............................. 81

Figure 4.1: The Andersen Behavioral Model for Healthcare Utilization (For Aim 3)..... 122 


\section{LIST OF TABLES}

Table 2.1: Description of the Study Cohorts by Persistence with Mammography Screening

Table 2.2: Association between Persistence with Mammography Screening and Stage At Breast Cancer Diagnosis, Separately for the Study Cohorts............... 50

Table 2.3: Description of the Study Cohorts (only non-Hispanic White Women)........ 51

Table 2.4: Differences in Stage at Breast Cancer Diagnosis between Study Cohorts In a Multivariate Framework........................................... 52

Table 3.1: Description of the Study Cohorts ....................................... 82

Table 3.2: Median Days in Diagnosis and Treatment for the Study Cohorts.............. 83

Table 3.3: Median Days (IQR) for Type of Initial Treatment by Stage at Breast Cancer Diagnosis for the Study Cohorts................................. 84

Table 3.4: Median Days in Diagnosis and Treatment within Independent Variables For the Study Cohorts................................................. 85

Table 3.5: Factors Associated with Timely Diagnosis and Timely Treatment........... 87

Table 3.6: Differences in Timely Diagnosis and Treatment between Study Cohorts In a Multivariate Framework.............................................. 90

Table 3.6: Differences in Survival between Study Cohorts with Receipt of Timely Diagnosis and Timely Treatment In a Multivariate Framework

Table 4.1: Description of the Study Cohorts

Table 4.2: Description of the Study Cohorts for Differences in the Healthcare Utilization.

Table 4.3: Average Total Healthcare Costs in the Initial Phase for the Study Cohorts.... 125

Table 4.4: Average Total Healthcare Costs for Clinically Important Variables for the Study Cohorts

Table 4.5: Factors Associated with Average Total Healthcare Costs

Table 4.6: Differences in Average Total Costs between Study Cohorts in a Multivariate Framework 
Table 4.7: Factors Explaining Lower Average Total Costs in WV-Medicare Cohort Using Blinder-Oaxaca Linear Decomposition Analysis................... 130 
CHAPTER 1 


\section{CHAPTER 1 \\ INTRODUCTION}

\section{BACKGROUND}

\section{Breast Cancer Overview}

Breast cancer $(\mathrm{BC})$ is a malignant tumor that starts in the cells of the breast. A malignant tumor is a group of cancer cells that invade surrounding tissues of the breast or metastasize to distant areas of the body. BC is the most common cancer in women and is the second leading cause of cancer death in women in the United States (US). About 1 in 8 (12\%) women in the US will develop invasive BC during their lifetime. According to the 2014 statistics by American Cancer Society, it is estimated that about 232,670 new cases of invasive BC, and about 62,570 new cases of carcinoma in situ (CIS) will be diagnosed, and 40,000 women will die from BC in the US ${ }^{1}$.

\section{Risk factors for Breast Cancer ${ }^{2}$}

There are various modifiable and non-modifiable factors which affect a woman's chance of developing BC. Some of the non-modifiable risk factors increasing a woman's risk of developing BC are gender (female), advanced age, family history of BC, personal history of BC, early menarche and late menopause, inherited genetic mutations (BRCA1/BRCA2 or others), having dense breast tissue, some benign breast conditions, previous chest radiation for other malignancies, and diethylstilbestrol exposure. Modifiable risk factors associated with the development of BC in women include nulliparity, delayed child bearing, no full-term pregnancies, never breastfed, oral contraceptive use, post-menopausal hormone therapy, obesity, decreased physical activity, and alcohol consumption. 


\section{Breast Cancer Epidemiology}

BC incidence and mortality rates vary significantly by age. Based on 2005-2009 Surveillance, Epidemiology and End Results (SEER) statistics, the median age at diagnosis and mortality due to BC is 61 and 68 years, respectively ${ }^{3}$. Also, $41 \%$ of the new BC cases and $57.4 \%$ of the BC deaths occur in women age 65 and above ${ }^{3}$. The overall incidence of BC in women below 65 years of age is 82.97 per 100,000 and is 421.30 per 100,000 women in those above age $65^{3}$. The overall mortality from BC is 11.15 per 100,000 women for those less than 65 years of age and is 98.64 per 100,000 women in those above age $65^{3}$. Furthermore, older women age 65 and above have a greater burden of $\mathrm{BC}$ as they are diagnosed at advanced stages and with larger tumors impacting their survival ${ }^{4}$.

\section{Mammography Screening}

Screening tests can find cancers in early stages before they start to cause symptoms and hence help in reducing cancer-related mortality. Mammography screening is considered to be the 'gold standard' for women at average risk and it enables BC detection at an early stage, when the treatment is most effective and tends to require less intense systemic and local therapies ${ }^{5,6}$. Several clinical trials have shown that mammography screening reduces BC-related mortality by $20-35 \%$ in women age $40-69$ years of age ${ }^{6-10}$. Also, a recent Cochrane review reported that mammography screening reduces relative risk in $\mathrm{BC}$ mortality by $15 \%$ with $0.05 \%$ reduction in absolute risk ${ }^{11}$.

Women diagnosed with $\mathrm{BC}$ who have had a screening mammogram within the previous two years are significantly less likely to have late-stage disease ${ }^{12}$. However, in 2010 , only $64 \%$ of women age 65 and above had a mammography screening within the previous two years as 
compared to $73 \%$ of women age $50-64$ years ${ }^{2}$ even though annual screening mammograms are recommended and covered by both Medicare and Medicaid.

\section{Breast Cancer and Mammography Screening in West Virginia}

West Virginia (WV) is the only state that lies entirely in Appalachia, a region which is predominantly rural and medically underserved, characterized by high poverty rates, low levels of education, an aging population, high rates of chronic disease, and poor health behaviors ${ }^{13-16}$. For 2009, WV was reported to have a lower incidence of BC (112.6 vs. 122.9 nationally) but a higher BC-related mortality (23.3 vs. 22.2 nationally) ${ }^{17,18}$. Also, WV is reported to have higher rates of advanced and unstaged $\mathrm{BC}{ }^{19-23}$, which has been attributed to lower mammography screening rates of women in WV ${ }^{20-24}$. In 2010, WV was ranked $48^{\text {th }}$ among US states for women having mammography screening within the past two years ${ }^{25}$. In 2008 , WV was ranked sixth nationally in BC deaths ${ }^{26,27}$.

In WV women age 65 years and above, $\mathrm{BC}$ accounted for $12 \%$ of all the incident cancer cases $^{28}$ and $5.3 \%$ of all cancer deaths ${ }^{29}$. For 2009 among women age 65 and older, WV had lower incidence of BC (372.8 per 100,000 vs. 411.7 per 100,000) but higher BC-related mortality (110.4 per 100,000 vs. 98.6 per 100,000$){ }^{17,18}$ as compared to the national estimates. This may be attributed to numerous factors such as lower mammography screening rates in these elderly women $^{21-23,30}$, limited physical access to services, shortage of healthcare professionals and services ${ }^{31}$, and untimely BC care. These disparities also indicate that elderly women diagnosed with BC in WV may have higher healthcare costs after cancer diagnosis. 


\section{NEED FOR STUDY}

\section{Persistence with Mammography Screening and Stage at Breast Cancer Diagnosis}

Though mammography screening has been shown to reduce BC mortality by $20-35 \%$ in the average-risk women age $40-69$ years ${ }^{6-10}$, it is not clearly evident whether or not mammography screening is beneficial in older women. This is because very few screening trials assessing the benefits of mammography screening have included women aged 70 and above ${ }^{32}$. Moreover, there is a deficit of evidence-based guidelines for mammography screening in elderly women. Current US-based guidelines about screening mammography ${ }^{33-35}$ have no upper age limit set for the procedure and suggest woman should have mammography screening as long as she is in good health. Elderly women age 65 and above have a greater burden of $\mathrm{BC}$ as cancer tends to be found at advanced stages with larger tumor sizes, and thereby leading to poorer survival ${ }^{4}$. Additionally, the literature has also reported that these women are less likely to utilize mammography screening as compared to their younger counterparts ${ }^{33,36,37}$. In $2010,64 \%$ of women age 65 and above had a mammography screening within the previous two years as compared to $73 \%$ among women age $50-64$ years ${ }^{33}$. Various studies have demonstrated the benefits of mammography screening utilization in women age 65 and above on stage at BC diagnosis, an important predictor of survival ${ }^{38-41}$. Yet, these studies have limitations in terms of only including younger women, utilizing data from fewer cancer registries or utilizing data from limited time period before $\mathrm{BC}$ diagnosis, and not effectively distinguishing screening and diagnostic mammography claims, an inherent problem with Medicare claims data.

Very limited information is available about the effect of mammography screening and stage at $\mathrm{BC}$ diagnosis among elderly Medicare beneficiaries diagnosed with $\mathrm{BC}$ from rural settings and non-SEER Medicare states. With lower incidence of BC but higher BC-related 
mortality in elderly WV women and lower mammography screening rates in these women, there is a vital need to determine the association between persistence with mammography screening and stage at $\mathrm{BC}$ diagnosis.

\section{Timeliness of Care among Elderly Women Diagnosed with Breast Cancer}

Though BC is a major health issue and the second cause of cancer-related deaths in women in the US, measuring quality of care delivered to women diagnosed with BC is extremely challenging. Timeliness of care i.e. prompt diagnosis after detecting an abnormality in the breast and prompt initiation of the treatment after BC diagnosis is an important component of highquality $\mathrm{BC}$ treatment. Providing timely care to BC patients is significant to both patients and primary providers in order to reduce BC-related mortality ${ }^{42,43}$. Despite the widely accepted benefit of timely care in BC patients, the US-based guidelines have yet to define an appropriate time frame from presentation of abnormality in a breast to confirmed $\mathrm{BC}$ diagnosis and from $\mathrm{BC}$ diagnosis to the initiation of the treatment. However, other international oncology organizations such as European Society of Breast Cancer Specialists (EUSOMA) and National Health Service of United Kingdom have published professional opinion-based recommendations. Each group provides recommendations on time intervals between events such as presentation of abnormality to diagnosis of $\mathrm{BC}^{44}$ and between $\mathrm{BC}$ diagnosis to the initiation of the treatment ${ }^{45}$, respectively.

Various studies regarding timeliness of BC care have been conducted in the last decade in the US ${ }^{46-54}$, but no consensus exists regarding an appropriate time from diagnosis and to treatment. Also, none of these studies have followed any published opinion-based recommendations to appropriately define timely diagnosis and treatment.

As elderly women age 65 years and above have higher BC incidence and mortality and are more likely to have advanced stage disease at diagnosis ${ }^{3,4}$, it is highly likely that delayed 
diagnosis and/or delayed treatment may negatively affect the prognosis of the disease, and hence their survival. Previous literature has also reported that delay in diagnosis is a major factor contributing to the poor survival in elderly women diagnosed with $\mathrm{BC}^{4}$. Hence, it is exceedingly important to determine timeliness of $\mathrm{BC}$ care based on the published opinion-based recommendations among elderly women with BC in the US. In addition, as WV had a lower incidence of BC among women age 65 and above but higher BC-related mortality ${ }^{17,18}$ as compared to the national estimates, it is possible that the timeliness of care may be one of the important contributors to these disparities. Therefore, a study comparing the timeliness of BC care among elderly $\mathrm{WV}$ women diagnosed with $\mathrm{BC}$ to the national estimates may help begin to understand these disparities.

\section{Total Healthcare Costs of Breast Cancer in the Initial Phase (12-months) After Diagnosis}

The lifetime per-patient direct medical care cost estimates of $\mathrm{BC}$ ranged from $\$ 20,000$ to $\$ 100,000$ for the base cost year from 1984 to $2003^{55}$. The direct medical costs of initial and terminal care for women with $\mathrm{BC}$ are reported to be significantly higher than that of the continuing care on a per unit time basis ${ }^{55}$. This is because the costs of BC care are substantial during the initial care (12-months) period encompassing the time from diagnosis to surgery, radiation and adjuvant systemic therapy which constitute the major cost components in cancer therapy ${ }^{56-59}$.

To date, a majority of the studies estimating total healthcare costs during the initial period after BC diagnosis in elderly women are either outdated or have utilized SEER-Medicare data from fewer cancer registries and states/regions or have not stratified the results by stage at diagnosis, comorbidity and type of initial treatment. Besides, very limited information is available about the healthcare costs in elderly women diagnosed with $\mathrm{BC}$ from rural settings and 
from non-SEER states, such as WV. As WV has a lower incidence of BC but a higher BCrelated mortality among women age 65 and older ${ }^{17,18}$ as compared to the national estimates and with the increasing median age of the population and higher BC cases at advanced stages, it may be likely that healthcare costs during the initial period among elderly WV women diagnosed with $\mathrm{BC}$ may be higher as compared to the national estimates. Thus, a study comparing the healthcare costs during the initial period of 12-months among elderly WV women diagnosed with $\mathrm{BC}$ with that of the national estimates is essential to understand any such disparities. This data may aid in planning for healthcare costs and may facilitate resource allocation in the future.

\section{SPECIFIC AIMS AND OBJECTIVES}

The specific aims and objectives of the project are:

Specific Aim 1: To determine the association between persistence with mammography screening and stage at BC diagnosis among Medicare fee-for-service (FFS) beneficiaries in WV and compare it with national estimates from the SEER-Medicare data

Objective 1: To determine the proportion of Medicare FFS women beneficiaries with incident $\mathrm{BC}$ persistent with mammography screening in $\mathrm{WV}$ and compare it with national estimates from the SEER-Medicare data

Objective 2: To determine the stage at BC diagnosis among women Medicare FFS beneficiaries in WV by mammography screening persistence and compare it with the national estimates from the SEER-Medicare data

Objective 3: To determine the association between persistence with mammography screening and stage at $\mathrm{BC}$ diagnosis among women Medicare FFS beneficiaries in $\mathrm{WV}$, after controlling for predisposing factors (age), enabling factors (median household income, education level), need factors (co-occurring chronic conditions), healthcare use (number of primary care physicians 
(PCP) visits in five years before BC diagnosis) and external healthcare environmental factors (location of residence and number of hospitals offering BC screening/mammography services in the area of residence), and compare it with the national estimates from the SEER-Medicare data Specific Aim 2: To determine the timeliness of BC care based on published recommendations among Medicare FFS beneficiaries in WV and compare it with the national estimates from the SEER-Medicare data

Objective 1: To determine time to diagnosis and treatment among WV women Medicare FFS beneficiaries and compare them with the national estimates from the SEER-Medicare data Objective 2: To determine the proportion of WV women Medicare FFS beneficiaries receiving timely $\mathrm{BC}$ care based on published recommendations and compare it with the national estimates from the SEER-Medicare data

Objective 3: To identify the factors associated with receipt of timely BC care based on published recommendations among WV women Medicare FFS beneficiaries and compare them with the national estimates from the SEER-Medicare data

Objective 4: To determine the association between receipt of timely BC care based on published recommendations and survival among WV women Medicare FFS beneficiaries, and compare it with the national estimates from SEER-Medicare data

Specific Aim 3: To determine average total healthcare costs and costs by type of specific services during the initial phase of 12 months following an incident diagnosis of $\mathrm{BC}$ among Medicare FFS beneficiaries in WV and compare it with the national estimates from SEERMedicare data

Objective 1: To determine average total healthcare costs in initial phase among Medicare FFS beneficiaries in WV, and compare it with the national estimates from the SEER-Medicare data 
Objective 2: To determine average total healthcare costs by types of specific services in the initial phase among Medicare FFS beneficiaries in WV, and compare them with the national estimates from the SEER-Medicare data

Objective 3: To determine the predictors of average total healthcare costs in the initial phase among Medicare FFS beneficiaries in WV and compare them with the estimates from SEERMedicare data

Objective 4: To determine the magnitude of differences in the average total healthcare costs in the initial phase between Medicare FFS beneficiaries in WV and those from the SEER-Medicare using decomposition analysis

\section{CONCEPTUAL FRAMEWORK}

The Andersen Behavioral Model for Health Services Utilization (Andersen model) was utilized as the conceptual model in these studies ${ }^{60,61}$. This model that has been used for decades in predicting health services utilization in population-based studies postulates that healthcare services utilization is the function of the predisposition of individuals to use services, factors which enable or impede use, the need for care, healthcare use, and external environmental. This model is one of the most frequently used conceptual frameworks for analyzing individual's utilization of health care services (Figure 1.1).

Predisposing factors such as age, race, and enabling factors such as census tract annual household income and census tract education level were included in the model. Need-related factors included in the model were comorbidities, mental conditions, stage at diagnosis, grade of tumor, estrogen-receptor status, and size of tumor. The later four variables were included only in Aims 2 and 3. Healthcare use consisted of persistence with mammography screening, primary care physicians visits, type of initial treatment, and inpatient use. The later two variables were 
included only in Aims 2 and 3. External health care environment factors included in the model were location of residence and number of hospitals offering BC screening and oncology related services. Using this Andersen Behavioral model of healthcare services utilization provides a strong theoretical framework to identify the factors which influence stage at BC diagnosis (Aim 1), timeliness of BC care (Aim 2), and total healthcare costs in the initial period of one year (Aim $3)$.

\section{SIGNIFICANCE}

Aim 1 results from this study will help understand the disparities in stage at the time of BC diagnosis by persistence with mammography screening among Medicare FFS beneficiaries from rural setting, such as $\mathrm{WV}$, and how this association varies from national estimates. Aim 2 results will help to identify disparities in the timeliness of $\mathrm{BC}$ care and the factors contributing to timely diagnosis and treatment and how timely care affect survival among elderly Medicare FFS beneficiaries diagnosed with $\mathrm{BC}$ from a rural setting such as $\mathrm{WV}$, and compare them with the national sample estimates. Aim 3 results will help to understand average total healthcare costs in the initial phase, and to what extent age, race, location of residence, type of treatment, comorbidity burden and clinical variables affect these costs in elderly Medicare FFS beneficiaries in $\mathrm{WV}$ diagnosed with $\mathrm{BC}$ and variation from the national estimates will also be obtained. In addition, comparing average total healthcare costs among elderly Medicare beneficiaries in $\mathrm{WV}$ with incident $\mathrm{BC}$ to the national sample will help to determine whether or not these costs were higher in a rural setting such as WV with higher median age and where the majority of the elderly women are diagnosed at advanced stages of BC. Overall, this project laid the foundation for larger studies aimed at decreasing $\mathrm{BC}$ disparities in a rural and geographically 
challenged state such as WV, through the development of strategies and interventions to foster early detection and timely treatment of BC among elderly women.

\section{LIMITATIONS}

Since the study utilized administrative claims data, the limitations of these studies include selection bias, misclassification and coding errors. Data on beneficiaries from the Medicare managed care program, and uninsured population was not be used, thus the study results may be generalizable only to FFS beneficiaries. Since information on each patient's socio-economic status is not available with SEER-Medicare, the county level census tract median household income and education level were utilized ${ }^{62}$. Medicaid claims for dual-eligible Medicare beneficiaries in the SEER-Medicare data are not available; therefore, we limited our comparisons of costs to those incurred only by Medicare for beneficiaries diagnosed with cancer in WV and in SEER-Medicare. Any screening mammograms obtained outside the Medicare program such as from free mammography screening programs are not captured by Medicare and hence may affect the precision of the estimates. This may not be a significant limitation as Medicare is the primary health insurer for the older adult population. Any genetic factors, family history of BC, and psychosocial factors such as perceived risk and knowledge about mammography screening and $\mathrm{BC}$, affecting the screening behavior and incidence of $\mathrm{BC}$ are not captured by this database and hence may affect the precision of the estimates. As per the literature, the FFS beneficiaries tend to be sicker than those in managed care, thus the costs may be skewed for the beneficiaries. The costs reported do not include out-of-pocket costs, and hence do not represent total cost of care during initial one year period. Moreover, costs associated with lost productivity and other non-medical costs which constitutes important economic burden are not captured by Medicare and hence are not included. As Medicare data on prescription drugs is not available before 2007, 
the costs associated with adjuvant therapies with prescription drugs such as Tamoxifen were not be captured and hence not included in the studies. 


\section{REFERENCES}

1. American Cancer Society. Cancer Facts and Figures 2014, Atlanta: American Cancer Society; 2014. http://www.cancer.org/acs/groups/cid/documents/webcontent/003090-pdf.pdf. Updated 2014. Accessed 02/19, 2014.

2. American Cancer Society. Breast Cancer Facts and Figures 2012, Atlanta, Georgia. http://www.cancer.org/acs/groups/cid/documents/webcontent/003090-pdf.pdf. Updated 2012. Accessed 02/19, 2014.

3. Howlader N, Noone A, Krapcho M, et al. SEER cancer statistics review, 1975-2009 (vintage 2009 populations), National Cancer Institute. Bethesda, MD. Based on November 2011 SEER data submission. http://seer.cancer.gov/csr/1975_2009_pops09/. Updated April 2012. Accessed 02/19, 2014.

4. Hillner BE, Penberthy L, Desch CE, McDonald MK, Smith TJ, Retchin SM. Variation in staging and treatment of local and regional breast cancer in the elderly. Breast Cancer Res Treat. 1996;40(1):75-86.

5. Nelson HD, Tyne K, Naik A, et al. Screening for breast cancer: an update for the U.S. Preventive Services Task Force. Ann Intern Med. 2009;151(10):727-737.

6. Tabar L, Dean PB. Mammography and breast cancer: The new era. Int J Gynaecol Obstet. 2003;82(3):319-326.

7. Fletcher SW, Elmore JG. Clinical practice. Mammographic screening for breast cancer. $N$ Engl J Med. 2003;348(17):1672-1680.

8. Nystrom L, Andersson I, Bjurstam N, Frisell J, Nordenskjold B, Rutqvist LE. Long-term effects of mammography screening: Updated overview of the swedish randomised trials. Lancet. 2002;359(9310):909-919.

9. Smith-Bindman R, Kerlikowske K, Gebretsadik T, Newman J. Is screening mammography effective in elderly women? Am J Med. 2000;108(2):112-119.

10. Hellquist BN, Duffy SW, Abdsaleh S, et al. Effectiveness of population-based service screening with mammography for women ages 40 to 49 years: Evaluation of the swedish mammography screening in young women (SCRY) cohort. Cancer. 2011;117(4):714-722.

11. Gotzsche PC, Nielsen M. Screening for breast cancer with mammography. Cochrane Database Syst Rev. 2009;(4):CD001877.

12. Norman SA, Localio AR, Zhou L, et al. Benefit of screening mammography in reducing the rate of late-stage breast cancer diagnoses (united states). Cancer Causes Control. 2006;17(7):921-929. 
13. Kaiser State Health facts. Percent of adults who smoke by sex, 2008. Menlo Park, CA:

Kaiser Family Foundation. http://www.statehealthfacts.org. Updated 2008. Accessed 02/24, 2014.

14. Kaiser State Health Facts. Overweight and obesity rates for adults by sex, 2009. Menlo Park, CA: Kaiser Family Foundation. http://www.statehealthfacts.org. Updated 2009. Accessed 02/24, 2014.

15. U.S. Census Bureau. Persons 25 years old and over with a bachelor's degree or more, 2008. Washington, DC: U.S. Census Bureau. http://www.census.gov/compendia/statab/2010/ranks/rank19.html. Updated 2010. Accessed 02/24, 2014.

16. U.S. Census Bureau. Persons below the poverty level, 2008. Washington, DC: U.S. Census Bureau. http://www.census.gov/compendia/statab/2010/ranks/rank34.html. Updated 2010. Accessed 02/24, 2014.

17. SEER State Cancer Profiles 2009. http://statecancerprofiles.cancer.gov/map/map.withimage.php?00\&157\&055\&00\&2\&01\&1\&1\& 6\&0\#map. Updated 2009. Accessed 02/19, 2014.

18. SEER State Cancer Profiles 2009. http://statecancerprofiles.cancer.gov/map/map.withimage.php?00\&157\&055\&00\&2\&02\&1\&1\& 6\&0\#map. Updated 2009. Accessed 02/19, 2014.

19. Wingo PA, Tucker TC, Jamison PM, et al. Cancer in Appalachia, 2001-2003. Cancer. 2008;112(1):181-192.

20. Lengerich EJ, Chase GA,Beiler J, Darnell M. Increased risk of unknown stage cancer from residence in a rural area: Health disparities with poverty and minority status. Hershey, PA: Pennsylvania State University and the Penn State Cancer Institute, Department of Health Evaluation Sciences. 2006.

21. State Cancer Profiles. Incidence and mortality rate reports for West Virginia by county, 2010. Bethesda, MD: National Cancer Institute. http://statecancerprofiles.cancer.gov/. Updated 2010. Accessed 02/24, 2014.

22. United States Cancer Statistics. Rankings by state: 2006, male and female, all cancer sites combined. Atlanta, GA: Centers for Disease Control and Prevention (CDC). http://apps.nccd.cdc.gov/uscs/. Updated 2010. Accessed 02/24, 2014.

23. United States Cancer Statistics. State vs. National Rates: 2006, female, West Virginia. Atlanta, GA: Centers for Disease Control and Prevention (CDC). http://apps.nccd.cdc.gov/uscs/. Updated 2010. Accessed 02/24, 2014. 
24. Khanna R, Bhanegaonkar A, Colsher P, Madhavan SS, Halverson J. Breast cancer screening, incidence, and mortality in West Virginia. WV Med J. 2009;105 Spec No:24-32.

25. Kaiser State Health Facts. Percent of women age 40 and older who report having had a mammogram within the last two years, 2008. Menlo Park, CA: Kaiser Family Foundation. http://statehealthfacts.org. Updated 2010. Accessed 02/24, 2014.

26. United Health Foundation. American's health rankings-2008 edition.

http://www.americashealthrankings.org/2008/results.html. Updated 2008. Accessed 02/24, 2014.

27. Centers for Disease Control and Prevention (CDC). State Cancer Profiles, 2008. http://statecancerprofiles.cancer.gov/. Updated 2008. Accessed 02/24, 2014.

28. United States Cancer Statistics: 1999-2004 Incidence WONDER on-line database. United States Department of Health and Human Services, Centers for Disease Control and Prevention and National Cancer Institute. http://wonder.cdc.gov/cancer-v2004.html. Updated 2010. Accessed 02/24, 2014.

29. Centers for Disease Control and Prevention, National Center for Health Statistics. Compressed Mortality File 1999-2005. CDC WONDER. http://wonder.cdc.gov/cmf-icd10.html. Updated 2010. Accessed 02/24, 2014.

30. Hall HI, Uhler RJ, Coughlin SS, Miller DS. Breast and cervical cancer screening among Appalachian women. Cancer Epidemiol Biomarkers Prev. 2002;11(1):137-142.

31. Wingo PA, Howe HL, Thun MJ, et al. A national framework for cancer surveillance in the United States. Cancer Causes Control. 2005;16(2):151-170.

32. Walter LC, Covinsky KE. Cancer screening in elderly patients: A framework for individualized decision making. JAMA. 2001;285(21):2750-2756.

33. American Cancer Society. Breast Cancer Facts and Figures 2013-2014. Atlanta, GA. http://www.cancer.org/acs/groups/content/@ research/documents/document/acspc-040951.pdf. Updated 2013. Accessed 02/19, 2014.

34. National Comprehensive Cancer Network practical guidelines in oncology 2010 (NCCN guidelines) breast cancer screening and diagnosis. http://www.nccn.org/professionals/physician_gls/pdf/breast-screening.pdf. Updated 2013. Accessed 02/19, 2014.

35. American College of Obstetricians-Gynecologists. Practice bulletin no. 122: Breast cancer screening. Obstet Gynecol. 2011;118(2 Pt 1):372-382.

36. Caplan LS, Haynes SG. Breast cancer screening in older women. Public Health Rev. 1996;24(2):193-204. 
37. MMWR Morb Mortal Wkly Report. Use of mammography services by women aged $>$ or $=$ 65 years enrolled in Medicare-United States, 1991-1993. 1995;44;777-781.

38. McCarthy EP, Burns RB, Freund KM, et al. Mammography use, breast cancer stage at diagnosis, and survival among older women. J Am Geriatr Soc. 2000;48(10):1226-1233.

39. Randolph WM, Mahnken JD, Goodwin JS, Freeman JL. Using Medicare data to estimate the prevalence of breast cancer screening in older women: Comparison of different methods to identify screening mammograms. Health Serv Res. 2002;37(6):1643-1657.

40. Badgwell BD, Giordano SH, Duan ZZ, et al. Mammography before diagnosis among women age 80 years and older with breast cancer. J Clin Oncol. 2008;26(15):2482-2488.

41. Galit W, Green MS, Lital KB. Routine screening mammography in women older than 74 years: A review of the available data. Maturitas. 2007;57(2):109-119.

42. Stone MD, Norton S, Mendez JE, Hirsch E. Positive impact of a breast-health triaging system on breast-care access and physician satisfaction. Am J Surg. 2007;194(4):482-487.

43. Toomey DP, Cahill RA, Birido N, et al. Rapid assessment breast clinics--evolution through audit. Eur J Cancer. 2006;42(17):2961-2967.

44. Perry NM, EUSOMA Working Party. Quality assurance in the diagnosis of breast disease. EUSOMA working party. Eur J Cancer. 2001;37(2):159-172.

45. Improving outcomes in breast cancer-manual update. National Institute for Clinical Excellence, UK. 2002;1-84257-188-5(02/19).

46. Gorin SS, Heck JE, Cheng B, Smith SJ. Delays in breast cancer diagnosis and treatment by racial/ethnic group. Arch Intern Med. 2006;166(20):2244-2252.

47. Gwyn K, Bondy ML, Cohen DS, et al. Racial differences in diagnosis, treatment, and clinical delays in a population-based study of patients with newly diagnosed breast carcinoma. Cancer. 2004;100(8):1595-1604.

48. Elmore JG, Nakano CY, Linden HM, Reisch LM, Ayanian JZ, Larson EB. Racial inequities in the timing of breast cancer detection, diagnosis, and initiation of treatment. Med Care. 2005;43(2):141-148.

49. Lobb R, Allen JD, Emmons KM, Ayanian JZ. Timely care after an abnormal mammogram among low-income women in a public breast cancer screening program. Arch Intern Med. 2010;170(6):521-528.

50. Bilimoria KY, Ko CY, Tomlinson JS, et al. Wait times for cancer surgery in the United States: Trends and predictors of delays. Ann Surg. 2011;253(4):779-785. 
51. Richardson LC, Royalty J, Howe W, Helsel W, Kammerer W, Benard VB. Timeliness of breast cancer diagnosis and initiation of treatment in the national breast and cervical cancer early detection program, 1996-2005. Am J Public Health. 2010;100(9):1769-1776.

52. McLaughlin JM, Anderson RT, Ferketich AK, Seiber EE, Balkrishnan R, Paskett ED. Effect on survival of longer intervals between confirmed diagnosis and treatment initiation among lowincome women with breast cancer. J Clin Oncol. 2012;30(36):4493-4500.

53. Halpern MT, Holden DJ. Disparities in timeliness of care for U.S. Medicare patients diagnosed with cancer. Curr Oncol. 2012;19(6):e404-13.

54. Bleicher RJ, Ruth K, Sigurdson ER, et al. Preoperative delays in the US Medicare population with breast cancer. J Clin Oncol. 2012;30(36):4485-4492.

55. Campbell JD, Ramsey SD. The costs of treating breast cancer in the US: A synthesis of published evidence. Pharmacoeconomics. 2009;27(3):199-209.

56. Brown ML, Riley GF, Schussler N, Etzioni R. Estimating health care costs related to cancer treatment from SEER-Medicare data. Med Care. 2002;40(8 Suppl):IV-104-17.

57. Yabroff KR, Lamont EB, Mariotto A, et al. Cost of care for elderly cancer patients in the United States. J Natl Cancer Inst. 2008;100(9):630-641.

58. Warren JL, Brown ML, Fay MP, Schussler N, Potosky AL, Riley GF. Costs of treatment for elderly women with early-stage breast cancer in fee-for-service settings. J Clin Oncol. 2002;20(1):307-316.

59. Riley GF, Potosky AL, Lubitz JD, Kessler LG. Medicare payments from diagnosis to death for elderly cancer patients by stage at diagnosis. Med Care. 1995;33(8):828-841.

60. Andersen RM. Revisiting the behavioral model and access to medical care: Does it matter? $J$ Health Soc Behav. 1995;36(1):1-10.

61. Andersen R, Newman JF. Societal and individual determinants of medical care utilization in the United States. Milbank Mem Fund Q Health Soc. 1973;51(1):95-124.

62. Krieger N. Overcoming the absence of socioeconomic data in medical records: Validation and application of a census-based methodology. Am J Public Health. 1992;82(5):703-710. 


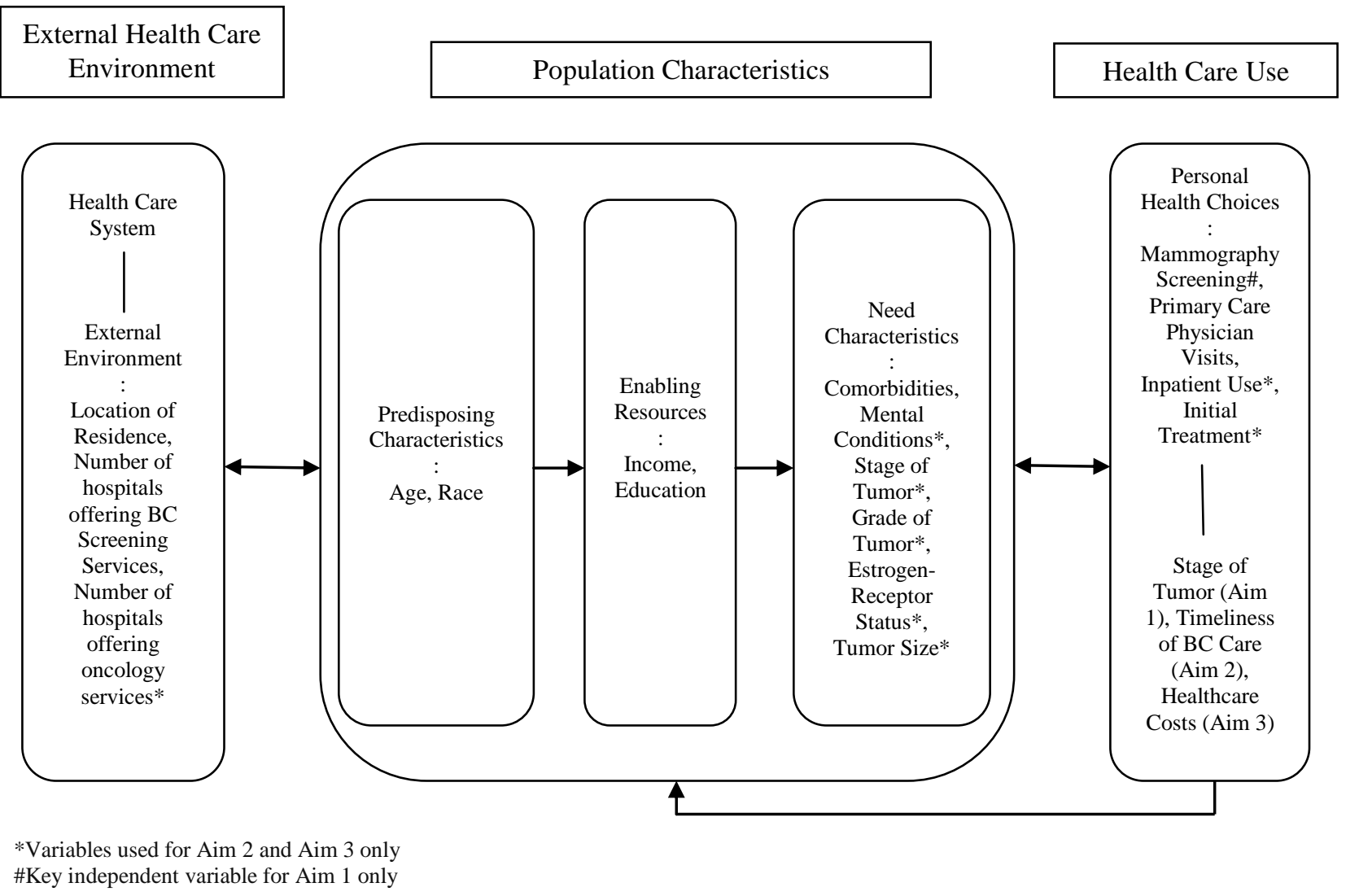

Figure 1.1: The Andersen Behavioral Model for Health Care Utilization 
CHAPTER 2 


\section{CHAPTER 2}

\section{ASSOCIATION BETWEEN PERSISTENCE WITH MAMMOGRAPHY SCREENING AND STAGE AT DIAGNOSIS AMONG ELDERLY WOMEN DIAGNOSED WITH BREAST CANCER}

\section{INTRODUCTION}

\section{Breast Cancer}

Breast cancer $(\mathrm{BC})$ is the most common cancer and the second leading cause of cancer death in women in the United States (US). For year 2014, about 232,670 new cases of invasive BC, and about 62,570 new cases of carcinoma in situ (CIS) will be diagnosed, and 40,000 women will die from $\mathrm{BC}$ in the US ${ }^{1}$.

BC incidence and mortality rates vary significantly by age. Based on Surveillance, Epidemiology and End Results (SEER) statistics for 2005-2009, the median age at diagnosis and mortality due to BC was 61 and 68 years, respectively ${ }^{2}$. Also $41 \%$ of the new cases of BC were diagnosed, and $57.4 \%$ of the BC deaths occurred in women age 65 and above ${ }^{2}$. More than half of incident $\mathrm{BC}$ diagnoses occur in women age 65 and above ${ }^{3}$. The overall incidence of BC for 2005-2009 was 82.97 per 100,000 in women age below 65 years and was 421.30 per 100,000 in women age 65 and above. The overall mortality from BC for 2005-2009 was 11.15 per 100,000 in women below 65 years of age and was 98.64 per 100,000 in women age 65 and above ${ }^{2}$. Moreover, elderly women age 65 and above have a greater burden of $\mathrm{BC}$ as tumor in these women may be found at more advanced stages and with larger sizes thereby leading to poorer survival $^{4}$. 


\section{Mammography Screening}

Mammography screening is considered the 'gold standard' for women at an average risk to detect BC at an early stage, when the treatment is less aggressive and most effective ${ }^{5,6}$. Mammography screening has demonstrated a reduction in BC-related mortality by $20-35 \%$ in average-risk women age 40-69 years of age ${ }^{6-10}$. Also, women diagnosed with BC who have had a mammography screening within the previous two years are significantly less likely to have late-stage disease ${ }^{11}$. However, in 2010 only $64 \%$ of women age 65 and above have had mammography screening within the past two years as compared to $73 \%$ among women age 5064 years ${ }^{12}$ even though annual screening mammograms are covered by both Medicare and Medicaid. This lower percentage may be partly due to the uncertainty regarding the frequency and upper age limit to avail mammography screening as reflected in the BC screening guidelines. The US Preventive Service Task Force recommends biennial mammography screening for women in age group 69 to 74 years, but reported insufficient evidence for mammography screening for women age above 74 years ${ }^{13}$. In contrast, the American Cancer Society recommends annual mammography screening with no set upper age limit for women till her life expectancy is at least five years ${ }^{14}$. In absence of no direct evidence of beneficial effects of mammography screening and with suggested potential and immediate harms of mammography screening in elderly women age 75 and older, this group encounters contrasting recommendations and guidelines for mammography screening which may affect their screening behavior thereby leading to poorer breast cancer outcomes.

\section{Breast Cancer and Mammography Screening in West Virginia}

West Virginia (WV), the only state that lies completely in Appalachia is a largely rural and medically underserved region in the US characterized by high poverty rates, low levels of 
education, aging population, high rates of chronic diseases, and poor health behaviors ${ }^{15-18}$. WV is reported to have higher rates of advanced and unstaged $\mathrm{BC}{ }^{19-23}$, which has been attributed to lower mammography screening rates in women in $\mathrm{WV}^{20,21,24,25}$. Additionally, $\mathrm{WV}$ was ranked sixth nationally in $\mathrm{BC}$ deaths in $2008^{26,27}$.

In $\mathrm{WV}$ women age 65 years and above, $\mathrm{BC}$ accounted for $12 \%$ of all the incident cancer cases ${ }^{25}$ and $5.3 \%$ of all cancer deaths ${ }^{28}$. For 2009 among women age 65 and older, WV had lower incidence of BC (372.8 per 100,000 vs. 411.7 per 100,000 nationally) but higher mortality (110.4 per 100,000 vs. 98.6 per 100,000 nationally) $)^{29,30}$ as compared to the national estimates. The authors of various studies have argued that low mammography screening rates in WV women may be one of the significant factors responsible for this disparity ${ }^{21,25,31}$.

\section{Persistence with Mammography Screening and Stage at Breast Cancer Diagnosis}

Although mammography screening has been reported to reduce BC mortality by $20-35 \%$ in women age 40-69 years ${ }^{6-10}$, it is not yet clear whether or not mammography screening is beneficial in older women. This is because very few screening trials evaluating the benefits of mammography screening in women have included women aged 70 and above ${ }^{32}$. Elderly women age 65 and above have a greater burden of $\mathrm{BC}$ since it is found at more advanced stages and with larger tumor sizes thereby leading to poorer survival ${ }^{4}$. Also, though these women are more vulnerable to BC, they are less likely to utilize mammography screening ${ }^{33,34}$. In $2010,64 \%$ of women age 65 and above have had mammography screening within the previous 2 years as compared to $73 \%$ among women age 50-64 years ${ }^{12}$. Without clear scientific evidence of benefits of mammography screening in older women, physicians are left with the decision whether or not to recommend mammography screening to these elderly women. Physicians have 
several mammography screening guidelines from which to choose for this expanding aging population, when most of the current US-based guidelines have no upper age limit set up.

Even though reducing BC-related mortality is the ultimate goal of mammography screening, intermediate measures such as stage at diagnosis are useful to evaluate the utility of screening ${ }^{35,36}$. In elderly women age 65 and above, various studies have demonstrated the benefits of mammography screening utilization on an important predictor of survival, stage at BC diagnosis. Two studies which used Surveillance Epidemiology and End Results (SEER)Medicare database reported that mammography use decreased with advancing age at diagnosis, and older women who undergo regular mammography were diagnosed with an earlier stage of disease ${ }^{37,38}$. However, these studies utilized the mammography screening data from only two years before $\mathrm{BC}$ diagnosis, which may have failed to capture the effect of persistence with mammography screening on the stage at BC diagnosis. Also, a study by McCarthy et al. utilized SEER data from only three registries which may limit the generalizability of the study findings 37. A study which utilized 5-years mammography utilization data from all the SEER registries reported that regular mammography screening was associated with earlier stage at BC diagnosis, though it focused only on women age 80 and above ${ }^{39}$. A systematic review of routine mammography screening demonstrated that regular mammography screening was associated with earlier-stage disease and lower BC mortality, but it focused only on women over 74 years of age $^{40}$.

Thus, most of the studies evaluating the association between mammography screening utilization and stage at BC diagnosis have been conducted using data from either a few SEERMedicare registries, or data for limited time period of two years before BC diagnosis, or among women age 80 and above. Moreover, the major limitation with all these previous studies is that 
the authors did not use any model or technique to distinguish screening from diagnostic mammograms which is one of the key concerns with Medicare or any administrative claims data. A study by Freeman et al. ${ }^{41}$ reported that challenges persist in distinguishing screening mammograms from the diagnostic ones with the Medicare claims data as many screening procedures may be billed as diagnostic procedures as the later are reimbursed at higher level. The authors of a recently published study have developed and suggested a 3-step algorithm with higher sensitivity (99.7\%) and higher positive predictive value (97.4\%) to distinguish between screening and diagnostic mammograms using Medicare data linked to a cancer registry ${ }^{42}$. In the absence of strong evidence supporting beneficial effects of mammography screening and hence no current guidelines supporting mammography screening in older women and in absence of proper studies focusing on this crucial issue, overall there is a vital need to determine the association between mammography screening and stage at BC diagnosis among elderly women age 65 and above, that clearly distinguishes between screening and diagnostic mammograms, from a large number of SEER-Medicare registries, with a longer follow-up time period of at least five years before $\mathrm{BC}$ diagnosis to capture persistence to mammography screening.

In addition, SEER-Medicare data represents only 17 cancer registries and states/regions and reflects a population more likely to be residing in urban setting ${ }^{43}$. Very limited information is available about the use of mammography screening and stage at BC diagnosis among elderly Medicare beneficiaries diagnosed with BC from rural settings and from non-SEER Medicare states. In contrast to population characteristics prevalent in SEER-Medicare areas, a large majority of the population in WV is white and a significant proportion resides in rural areas. For 2009, WV had a lower incidence of BC among women age 65 and older (372.8 per 100,000 vs. 410.6 per 100,000$)$ but higher mortality (110.4 per 100,000 vs. 98.6 per 100,000$)^{29,30}$ as 
compared to the national estimates. The proportion of WV women who have had a mammogram in the past two years increased with increase in age until 64 years, but the trend reversed for those who were age 65 and above ${ }^{24}$. Moreover, the overall mammography screening rates in WV women was also lower than the national estimates ${ }^{24}$. Due to higher BC mortality in women age 65 years and above in WV as compared to national estimates, there is a need to determine the association between persistence with mammography screening and stage at $\mathrm{BC}$ diagnosis in elderly WV women and compare this with the national estimates.

Hence, the purpose of the study is to determine the persistence with mammography screening in WV Medicare fee-for-service (FFS) women beneficiaries diagnosed with first incident BC and compare it with national estimates using SEER-Medicare data and to determine the association between persistence with mammography screening and stage at $\mathrm{BC}$ diagnosis in these WV women and compare it with the national estimates, after controlling for predisposing factors (age), enabling factors (median household income, education level), need factors (cooccurring chronic conditions), healthcare use (number of primary care physicians (PCP) visits in five years before $\mathrm{BC}$ diagnosis) and external healthcare environmental factors (location of residence and number of hospitals offering $\mathrm{BC}$ screening/mammography services in the area of residence).

\section{METHODS}

\section{Data Source}

\section{West Virginia Cancer Registry-Medicare-Area Resource File linked dataset}

Established by the West Virginia Department of Health and Human Resources in 1993, the West Virginia Cancer Registry (WVCR) is a state-level cancer registry which provides information on cancer incidence and mortality in West Virginia (WV) ${ }^{44}$. The registry collects 
and provides data on the primary site of cancer, tumor grade, date and stage of diagnosis, date and cause of mortality, and demographics such as age, gender, race, and also zip code information (for location of residence). The de-identified linked WVCR-Medicare dataset was established at West Virginia University (WVU) in full compliance with the WVU Institutional Review Board and HIPPA requirements ${ }^{45}$. The WVCR file served as the case source file, and individuals who were aged $\geq 65$ years and diagnosed with cancer between the January 1, 2002 and December 31, 2007 were extracted from this file. The Social security numbers (SSN) for these individuals was then provided to the CMS by the WVCR, using which the CMS identified the corresponding Health Insurance Claim (HIC) number. To extract information on the individuals as Medicare beneficiaries, a "crosswalk" file is created using the HIC which allows for linkage across the WVCR and the Medicare. Individuals with a missing SSN were excluded from the linkage. The Area Resource File (ARF) was linked to the WVCR-Medicare dataset using the state and county FIPS codes for each beneficiary to extract the county level information on the availability of healthcare facilities, healthcare providers, and socioeconomic characteristics of the region's population.

\section{SEER-Medicare-Area Resource File linked dataset}

The SEER-Medicare linked dataset provides population-based information on cancerrelated epidemiologic and health services research. The SEER-Medicare program collects information on newly diagnosed cases of cancer from 17 population-based tumor registries which in turn collect information from several sources including hospitals, outpatient clinics, laboratories, private practitioners, laboratories, hospices, autopsy reports and death certificates. The SEER-Medicare data represents approximately $26 \%$ of the US population. The SEER part of the SEER-Medicare data is in the form of a tailored file known as the Patient Entitlement and 
Diagnosis Summary File (PEDSF). PEDSF contains one record per person for individuals in the SEER database who have been matched with Medicare enrollment records. These files provide diagnostic information for up to 10 diagnosed cancer cases (including date of cancer diagnosis, cancer sub-site, cancer stage at diagnosis, tumor size, histology, grade), and information on the first course of cancer related treatment (surgery and radiation provided in the first 4 months after diagnosis) for each individual. The PEDSF additionally includes information on the median household income and education level for each individual based on their census tract and zip code data.

The Medicare files that are a part of the SEER-Medicare linked dataset provide information about any health care utilized by individuals age 65 and above who are enrolled in and are covered under the Medicare program. These files have claims from the inpatient, outpatient, physician, home health, and hospice care utilized by individuals enrolled in the program. The linkage of the SEER data with the Medicare data, and formation of the SEER case number involves matching individuals across the two files using an algorithm based on a match of SSN, name, sex, and date of birth. The linkage process is described elsewhere ${ }^{43}$. The Area Resource File (ARF) was linked to the SEER-Medicare dataset using the state and county Federal Information Processing Standards (FIPS) code for each beneficiary to extract the county level information on the availability of healthcare facilities and healthcare providers.

\section{Study Design}

This study utilized a retrospective observational cohort design to assess the association between persistence with mammography screening and stage at diagnosis among Medicare FFS beneficiaries diagnosed with $\mathrm{BC}$. 


\section{Study Cohorts}

The two study cohorts consisted of all women from WVCR-Medicare-ARF linked dataset and SEER-Medicare-ARF linked dataset, age 70 and above at the first primary diagnosis of incident BC between January 1, 2007 and December 31, 2007. Since mammography screening persistence during the period of five years before $\mathrm{BC}$ diagnosis was to be determined, women age 70 and above who were continuously enrolled in Medicare parts A and B for at least 60 months before $\mathrm{BC}$ diagnosis and till the month of $\mathrm{BC}$ diagnosis, and who were not enrolled in health maintenance organizations (HMOs) at any time during the study period were included in the study. Women with a previous cancer diagnosis, unknown or missing BC stage information, and who were diagnosed via death certificate or autopsy were excluded from the study. BC diagnosis codes were based on the primary site and International Classification of Diseases, $9^{\text {th }}$ edition Clinical Modification (ICD-9-CM) codes 174.xx, 233.0x, 238.3x, and 239.3x.

According to the WVCR-Medicare-ARF linked dataset, 661 women were diagnosed with BC from January 1, 2007 to December 31, 2007. The following women were excluded from the final study population: 168 women who were younger than 70 years at diagnosis, 99 women with any previous cancer diagnosis, 7 women who were diagnosed with BC during death or autopsy, 56 women for whom BC stage information was unknown or missing, 32 women who were not continuously enrolled in Medicare parts A and B for 5 years before diagnosis, and 72 women who were members of HMO any time during the study follow-up period. From the remaining 227 women, only 6 women (2.6\%) belonged to 'other' race which resulted in very small cell-size for stage at diagnosis categories, and hence were removed from the analyses. Hence, the cohort of $221 \mathrm{WV}$ women was included in the final analyses. 
According to the SEER-Medicare-ARF linked dataset, 27,781 women were diagnosed with BC from January 1, 2007 and December 31, 2007. The following women were excluded from the final study population: 14,175 women who were younger than 70 years at diagnosis, 721 women with any previous cancer diagnosis, 171 women who were diagnosed with BC during death or autopsy, 383 women for whom BC stage information was unknown or missing, 770 women who were not continuously enrolled in Medicare parts A and B for 5 years before diagnosis, and 3,616 women who were members of HMO any time during the study follow-up period. The remaining 7,945 SEER-Medicare women were eligible to be included in all further analyses to derive national estimates.

\section{Measures}

Dependent Variable: Stage at diagnosis: $\mathrm{BC}$ stage at diagnosis was determined according to the SEER summary staging system which is a combination of the most accurate clinical and pathological documentation of the extent of disease ${ }^{46}$ and which uses all the data in the medical record. The variable was categorized as an 'early stage' consisting of carcinoma insitu and localized cancers, and the 'late stage' consisting of regional and distant cancers as defined in a previous study ${ }^{47}$.

Key Independent Variable: Persistence with mammography screening: There is ambiguity regarding the ability of Medicare claims data to distinguish screening from diagnostic mammograms. Appropriately distinguishing screening mammograms from diagnostic mammograms is very crucial when assessing screening utilization using claims-based database 48. No clear distinction between screening and diagnostic mammograms may affect measurement of the effect of mammography screening on BC-related outcomes using Medicare claims. A recently published 3-step algorithm with high sensitivity (99.7\%) and high positive 
predictive value (97.4\%) of a screening designation was utilized to classify screening mammograms from diagnostic mammograms ${ }^{\mathbf{4 2}}$.

After capturing the claims for all the mammograms, this 3-step algorithm was applied ${ }^{\mathbf{4 2}}$. It had the following sequential steps:

Step 1: To identify if women had a mammogram in the previous 9 months ( $<=270$ days): If a woman had a mammogram within 9 months then those mammograms were removed. If a woman did not a mammogram within 9 months then those mammograms led to step 2 .

Step 2: To identify if the Healthcare Common Procedure Coding System (HCPCS) code for a mammogram was for 'screening' or 'diagnostic' purpose: If the HCPCS code for a mammogram was for 'screening' purpose then those mammograms were considered to be screening mammograms and were utilized to determine persistence with mammography screening. If the HCPCS code for a mammogram was for 'diagnostic' purpose then those mammograms led to step 3 .

Step 3: If identify if a woman had any BC-related symptom 349 days prior to 'diagnostic' mammogram: If a woman had a BC-related symptom within 349 days prior to diagnostic mammogram then those mammograms were removed. While, if a women had a BC-related symptom beyond 349 days prior to diagnostic mammogram were utilized to determine persistence with mammography screening.

All the mammograms which had HCPCS codes for 'screening' in step 2 and those for which prior BC-related symptom was beyond 349 days in step 3 were considered to be actual screening mammograms and were utilized to determine persistence with mammography screening for each woman in the study cohorts. Using this algorithm improved the precision of estimates for this study. 
The key independent variable for this study was persistence with mammography screening defined in the literature as having had at least three consecutive mammograms as per the screening guidelines ${ }^{49}$. Based on the number of screening mammograms a woman had during the five years period before $\mathrm{BC}$ diagnosis, women were categorized as Non-persistent users (with 0-2 screening mammograms), and Persistent users (with three or more screening mammograms). As per the recently published study, older women above 65 years of age have similar risk of advanced stage of BC with biennial screening mammography as compared to annual screening mammography ${ }^{\mathbf{5 0}}$. Hence, persistent users represented a population who have had annual to biennial screening mammography before $\mathrm{BC}$ diagnosis.

Other Independent Variables: To identify the factors that contributed to an early stage at BC diagnosis associated with persistence with mammography screening, the Andersen behavioral healthcare services utilization model was used ${ }^{51,52}$. Based on this model, the independent variables were grouped into predisposing factors, enabling factors, need-related factors, factors associated with healthcare use, and external healthcare environmental factors (Figure 2.1).

Predisposing factors consisted of age at BC diagnosis (70-74, 75-79, 80 and older), race (white, other), while enabling factors included census tract median household income of their zip code of residence $(=<\$ 35,000 ;>\$ 35,000)$, and census tract percentage of people age $>=25$ years with at least 4 years of college education $(<15 \%\rangle=,15 \%)$. As individual level information on household income and education level were not available with both SEER-Medicare and WVCancer Registry, census tract information for these two variables were utilized in this study. Need-related factor comprised of co-occurring chronic conditions during the twelve months before $\mathrm{BC}$ diagnosis which were identified from the Medicare files using the ICD-9 diagnosis codes. Comorbidity scores were calculated using Charlson comorbidity index with macros 
provided by the National Cancer Institute ${ }^{53-55}$ and were categorized as 0 (no comorbidity), 1 , and 2+. Healthcare use factors comprised of number of primary care physicians (PCP) visits in the five years before BC diagnosis. Similar to previous research, PCP visits were derived from National Claims History $(\mathrm{NCH})$ files using the Medicare provider specialty field found in $\mathrm{NCH}$ claims and the PCP included those in general practice (01), family practice (08), internal medicine (11), geriatric medicine (38), and multi-specialty group practice (70) ${ }^{56}$. The PCP visits were categorized into two groups (high, low) based on the median value. External healthcare environmental factors included location of residence based on US Department of Agriculture rural-urban continuum codes (metro, urban, rural) and the number of hospitals with BC screening/mammography services in the area of residence for each woman derived from ARF file.

\section{Statistical Analyses}

Chi-square statistics for categorical variables and t-test test for continuous variables were used to determine significant differences in persistence to mammography screening categories across all the independent variables, for both the study cohorts. The percentage of women with each stage of disease according to persistence with mammography screening was also calculated for both the study cohorts. For each cohort, logistic regression was performed to determine the association between screening mammography persistence and an early stage of disease, after controlling for predisposing, enabling, need, healthcare use and external healthcare environmental factors. In both the regressions, "late stage" was used as the reference group for the dependent variable. As the sample size for the WV-Medicare cohort was very small as compared to the SEER-Medicare cohort and consisted of only white women, $10 \%$ of nonHispanic white women from each SEER-Medicare registry were randomly selected to make the 
national cohort comparable to WV cohort. This randomly selected sample had similar distribution of characteristics as the entire SEER-Medicare non-Hispanic white population (data not shown). Hence, 708 women comprised of the SEER-Medicare cohort who were included for further analyses to determine the relationship between type of cohort (WV-Medicare and SEERMedicare) and an early stage of disease, after controlling for all the independent variables. Logistic regression was performed using "late stage" as the reference group for the dependent variable. The fit of the regression models were tested by Pearson chi-square and likelihood ratio chi-square (deviance statistics) and Hosmer-Lemeshow goodness-of-fit statistic ${ }^{57}$. From the logistic regressions, the parameter estimates were transformed to odds ratios and their corresponding $95 \%$ confidence intervals were examined and the findings that were significant with p-values less than 0.05 levels are discussed. All analyses were conducted within statistical analysis systems software SAS 9.3 (SAS ${ }^{\circledR}$ version 9.3, SAS Institute Inc., Cary, NC, USA).

\section{RESULTS}

\section{Description of the Study Cohorts by Persistence with Mammography Screening}

Table 2.1 characterizes WV-Medicare and SEER-Medicare cohorts by persistence with mammography screening in women age 70 and above, diagnosed with first primary incident $\mathrm{BC}$ in 2007. For the WV-Medicare cohort, younger age at diagnosis was associated with screening mammography persistence. However for SEER-Medicare cohort, younger age at diagnosis, being white, higher household income, residence in an area with higher proportion of the population with higher education, no or one co-occurring condition, and low PCP visits were associated with screening mammography persistence. 


\section{Stage at Breast Cancer Diagnosis by Persistence with Mammography Screening}

Approximately, 51\% of women in WV-Medicare cohort were persistent with mammography screening (Figure 2.2) as compared to $45.4 \%$ in the SEER-Medicare cohort (Figure 2.3). Figure 2.4 describes disease stage according to persistence with mammography screening during five years before diagnosis for WV-Medicare cohort. Among women who were not persistent with mammography screening, $31 \%$ were diagnosed with the late stage disease. Among women who were persistent with mammography screening, only $12 \%$ were diagnosed with late stage disease. Figure 2.5 describes disease stage by persistence with mammography screening during five years before diagnosis for the SEER-Medicare cohort. Among women who were not persistent with mammography screening, 39\% were diagnosed with late stage disease. Among women who were persistent with mammography screening, 17\% were diagnosed with late stage disease. This indicates that the WV-Medicare cohort had a larger proportion of women diagnosed at an early stage $\mathrm{BC}$ if they were persistent with mammography screening as compared to the SEER-Medicare cohort.

\section{Association between Persistence with Mammography Screening and Stage at Breast Cancer Diagnosis}

Table 2.2 describes the results of separate multivariate logistic regressions for the probability of an early stage disease for both the study cohorts. For the WV-Medicare cohort, women who were persistent with mammography screening were four times more likely of being diagnosed at an early stage $\mathrm{BC}$ (Adjusted odds ratio $(\mathrm{AOR})=4.18,95 \%$ confidence interval $(\mathrm{CI})$ $=1.94-8.98)$ as compared to those who were not persistent with mammography screening. No other factors significantly affected the probability of being diagnosed at an early stage in this sample. For the SEER-Medicare cohort, women who were persistent with mammography 
screening were significantly more likely to be diagnosed at an early stage BC (AOR $=1.44,95 \%$ $\mathrm{CI}=1.31-1.58)$ as compared to those who were not persistent with screening mammography. Among enabling factors, higher household income was significantly associated with more likelihood of women being diagnosed at an early stage disease $(\mathrm{AOR}=1.19,95 \% \mathrm{CI}=1.04$ 1.35) as compared to those with lower household income. Women who had higher PCP visits during five years before $\mathrm{BC}$ diagnosis were significantly more likely to be diagnosed at an early stage $\mathrm{BC}(\mathrm{AOR}=1.17,95 \% \mathrm{CI}=1.06-1.28)$ as compared to those who had lower PCP visits.

\section{Description of the Study Cohorts}

Table 2.3 characterizes the significant differences in WV-Medicare and SEER-Medicare cohorts. The two cohorts were significantly different from each other in terms of enabling factors such as census tract household income and census tract education level, and external healthcare environmental factors such as location of residence and number of hospitals with BC screening services in the area of residence. Elderly women in WV diagnosed with $\mathrm{BC}$ were more likely to reside in rural areas, had lower census tract annual household income, had lower education levels, and had less access to BC screening centers as compared to those from the SEER-Medicare cohort.

\section{Differences in Stage at Breast Cancer Diagnosis between Study Cohorts in a Multivariate}

\section{Framework}

Table 2.4 lists the results of the multivariate logistic regression for the probability of an early stage disease after combining both WV-Medicare and SEER-Medicare cohorts and controlling for the type of setting (WV-Medicare vs. SEER-Medicare) and other independent variables. Women in WV-Medicare cohort were more likely to be diagnosed at an early stage 
disease as compared to women in the SEER-Medicare cohort, however the association was not significant $(\mathrm{AOR}=1.57,95 \% \mathrm{CI}=0.97-2.55)$.

\section{DISCUSSION}

As per the literature to date, this is the first study which after appropriately identifying screening mammograms from the Medicare claims using a recently published algorithm, evaluated the association between persistence with mammography screening and stage at BC diagnosis in a rural state such as WV and compared it with the national estimates derived from the SEER-Medicare data. In the absence of data on persistence with mammography screening from a rural setting and from non-SEER-Medicare states, this study has filled a significant literature gap by addressing these issues and improving the precision of the estimates by appropriately identifying screening mammograms from the Medicare claims. The findings of this study are consistent to the previous studies which reported that regular mammography screening or having had a mammography screening in one to two years before BC diagnosis was associated with earlier disease stage ${ }^{37,39,40,48}$.

Approximately $51 \%$ of elderly WV women diagnosed with BC were persistent with mammography screening as compared to $45 \%$ from those in the SEER-Medicare cohort. Also in WV-Medicare cohort, approximately $89 \%$ of women with BC were diagnosed with an early disease if they were persistent with mammography screening as compared to $83 \%$ from the SEER-Medicare cohort. Thus, the arguments made by the authors of the previous studies about lower mammography screening utilization in WV women as one of the contributing factors to late stage BC diagnosis ${ }^{20,24,31}$ are conflicting with the findings of this study. There may be other factors such as poor health status, family history of BC, BRCA gene mutation, untimely 
and inappropriate care, that may be responsible for higher rates of late stage $\mathrm{BC}$ in elderly women in WV.

Even though WV women were more likely to reside in rural regions, had lower income and education levels, and had lower access to BC screening centers as compared to women from the SEER-Medicare regions, the likelihood of being diagnosed with an earlier stage BC was higher for WV women who were persistent with mammography screening (AOR=4.18) as compared to women belonging to the SEER-Medicare cohort $(\mathrm{AOR}=1.44)$. This indicates that enabling factors and external healthcare environmental factors had no negative impact on persistence with mammography screening in WV women diagnosed with BC, and they were diagnosed at earlier stages when the treatments are usually less aggressive, and survival is significantly better. Among all the independent variables controlled in the model, only persistence with mammography screening was significantly associated with an earlier stage of disease in elderly WV women which indicates that persistence with mammography screening is extremely beneficial in these women to get diagnosed at an earlier stage of BC. However, for the SEER-Medicare cohort, along with persistence with mammography screening, enabling factor such as higher census tract household income and healthcare use in terms of higher PCP visits significantly increased the likelihood of earlier representation of BC. This indicates that women who have higher PCP visits are more likely to be consulted for healthy preventive behaviors such as mammography screening, and are more likely to get screening at regular intervals thereby being able to get diagnosed at an earlier stage of BC.

When controlled for the type of setting (WV-Medicare vs SEER-Medicare) along with persistence with mammography screening and other independent variables, WV-Medicare cohort was more likely to be diagnosed at an earlier stage BC as compared to the SEER-Medicare 
sample, but the association was not significant. This indicates that elderly women in WV are equally likely to be diagnosed at an early stage BC as women in the SEER-Medicare sample.

A major strength of this study is it helps in understanding the benefits of persistence with mammography screening for elderly women age 70 and above in a rural setting such as WV and how it differs from the national estimates obtained from the SEER-Medicare regions. Utilization of the recently published algorithm with very high sensitivity (99.7\%) and high predictive value (97.4\%) to identify the screening mammograms from the Medicare claims files ${ }^{42}$ may have improved the precision of the estimates and hence must also be considered a major strength of the study. Though it is very crucial in appropriately distinguishing screening from diagnostic mammograms when evaluating screening utilization from claims-based data ${ }^{48}$, difficulty in this distinction has been reported as a major limitation by several previous studies which have evaluated the association between utilization of mammography screening and stage at BC diagnosis $37,39,40,48$.

There are several limitations worth noting when interpreting the results of this study. Some of the study women may have been recipients of free screening mammograms which will not be captured in the Medicare data and hence may underestimate persistence with mammography screening. However, this may not be considered a major limitation as Medicare is the primary health insurer for all of the older adult population. Since the study utilized cancer registries-Medicare linked databases, certain patient characteristics such as annual household income, education level, access to total of BC screening centers at patient level are not available and hence census tract information for these variables has been utilized ${ }^{58}$. The findings of the study are generalizable only to elderly women age 70 and above, and to other rural areas having same characteristics as that of WV. 


\section{CONCLUSION}

The findings of the study indicate that persistence with mammography screening is significantly associated with earlier stage at BC diagnosis in elderly women in WV, and the likelihood of earlier representation of disease was similar in WV as compared to the national cohort derived from the SEER-Medicare registries. 


\section{REFERENCES}

1. American Cancer Society. Breast Cancer Facts and Figures 2013-2014. Atlanta, GA. http://www.cancer.org/acs/groups/content/@ research/documents/document/acspc-040951.pdf. Updated 2014. Accessed 02/19, 2014.

2. Howlader N, Noone A, Krapcho M, et al. SEER Cancer Statistics Review, 1975-2009 (Vintage 2009 populations), National Cancer Institute. Bethesda, MD. Based on November 2011 SEER data submission. http://seer.cancer.gov/csr/1975_2009_pops09/. Updated April 2012. Accessed 02/19, 2014.

3. Ries LAG, Melbert D, Krapcho M, et al. SEER Cancer Statistics Review, 1975-2005. US National Institutes of Health, National Cancer Institute, Bethesda, MD 2008.

4. Hillner BE, Penberthy L, Desch CE, McDonald MK, Smith TJ, Retchin SM. Variation in staging and treatment of local and regional breast cancer in the elderly. Breast Cancer Res Treat. 1996;40(1):75-86.

5. Nelson HD, Tyne K, Naik A, et al. Screening for breast cancer: An update for the U.S. preventive services task force. Ann Intern Med. 2009;151(10):727-737.

6. Tabar L, Dean PB. Mammography and breast cancer: The new era. Int J Gynaecol Obstet. 2003;82(3):319-326.

7. Fletcher SW, Elmore JG. Clinical practice. Mammographic screening for breast cancer. $N$ Engl J Med. 2003;348(17):1672-1680.

8. Smith-Bindman R, Kerlikowske K, Gebretsadik T, Newman J. Is screening mammography effective in elderly women? Am J Med. 2000;108(2):112-119.

9. Nystrom L, Andersson I, Bjurstam N, Frisell J, Nordenskjold B, Rutqvist LE. Long-term effects of mammography screening: Updated overview of the Swedish randomised trials. Lancet. 2002;359(9310):909-919.

10. Hellquist BN, Duffy SW, Abdsaleh S, et al. Effectiveness of population-based service screening with mammography for women ages 40 to 49 years: Evaluation of the Swedish mammography screening in young women (SCRY) cohort. Cancer. 2011;117(4):714-722.

11. Norman SA, Localio AR, Zhou L, et al. Benefit of screening mammography in reducing the rate of late-stage breast cancer diagnoses (United States). Cancer Causes Control. 2006;17(7):921-929.

12. American Cancer Society. Breast Cancer Facts and Figures 2012, Atlanta, Georgia. http://www.cancer.org/acs/groups/cid/documents/webcontent/003090-pdf.pdf. Updated 2012. Accessed 02/19, 2014. 
13. US Preventive Services Task Force. Screening for breast cancer: U.S. preventive services task force recommendation statement. Ann Intern Med. 2009;151(10):716-726, W-236.

14. Smith RA, Manassaram-Baptiste D, Brooks D, et al. Cancer screening in the United States, 2014: A review of current American Cancer Society guidelines and current issues in cancer screening. CA Cancer J Clin. 2014;64(1):30-51.

15. U.S. Census Bureau. Persons 25 years old and over with a bachelor's degree or more, 2008. Washington, DC: U.S. Census Bureau. http://www.census.gov/compendia/statab/2010/ranks/rank19.html. Updated 2010. Accessed 02/24, 2014.

16. U.S. Census Bureau. Persons below the poverty level, 2008. Washington, DC: U.S. Census Bureau. http://www.census.gov/compendia/statab/2010/ranks/rank34.html. Updated 2010. Accessed 02/24, 2014.

17. Kaiser State Health Facts. Percent of adults who smoke by sex, 2008. Menlo park, CA: Kaiser Family Foundation. http://www.statehealthfacts.org. Updated 2008. Accessed 02/24, 2014.

18. Kaiser State Health Facts. Overweight and obesity rates for adults by sex, 2009. Menlo Park, CA: Kaiser Family Foundation. http://www.statehealthfacts.org. Updated 2009. Accessed 02/24, 2014.

19. Wingo PA, Tucker TC, Jamison PM, et al. Cancer in Appalachia, 2001-2003. Cancer. 2008;112(1):181-192.

20. Lengerich EJ, Chase GA, Beiler J, Darnell M. Increased risk of unknown stage cancer from residence in a rural area: Health disparities with poverty and minority status. Hershey, PA: Pennsylvania State University and the Penn State Cancer Institute, Department of Health Evaluation Sciences. 2006.

21. State Cancer Profiles. Incidence and Mortality rate reports for West Virginia by county, 2010. Bethesda, MD: National Cancer Institute. http://statecancerprofiles.cancer.gov/. Updated 2010. Accessed 02/24, 2014.

22. United States Cancer Statistics. Rankings by State: 2006, male and female, all cancer sites combined. Atlanta, GA: Centers for Disease Control and Prevention (CDC). http://apps.nccd.cdc.gov/uscs/. Updated 2010. Accessed 02/24, 2014.

23. United States Cancer Statistics. State vs. National rates: 2006, female, West Virginia. Atlanta, GA: Centers for Disease Control and Prevention (CDC). http://apps.nccd.cdc.gov/uscs/. Updated 2010. Accessed 02/24, 2014.

24. Khanna R, Bhanegaonkar A, Colsher P, Madhavan SS, Halverson J. Breast cancer screening, incidence, and mortality in West Virginia. WV Med J. 2009;105 Spec No:24-32. 
25. United States Cancer Statistics: 1999-2004 Incidence WONDER on-line database. United States Department of Health and Human Services, Centers for Disease Control and Prevention and National Cancer Institute. http://wonder.cdc.gov/cancer-v2004.html. Updated 2010. Accessed 02/24, 2014.

26. United Health Foundation. American's health rankings-2008 edition. http://www.americashealthrankings.org/2008/results.html. Updated 2008. Accessed 02/24, 2014.

27. Centers for Disease Control and Prevention (CDC). State Cancer Profiles, 2008. http://statecancerprofiles.cancer.gov/. Updated 2008. Accessed 02/24, 2014.

28. Centers for Disease Control and Prevention, National Center for Health Statistics. Compressed mortality file 1999-2005. CDC WONDER. http://wonder.cdc.gov/cmf-icd10.html. Updated 2010. Accessed 02/24, 2014.

29. SEER State Cancer Profiles 2009. http://statecancerprofiles.cancer.gov/map/map.withimage.php?00\&157\&055\&00\&2\&01\&1\&1\& 6\&0\#map. Updated 2009. Accessed 02/19, 2014.

30. SEER State Cancer Profiles 2009. http://statecancerprofiles.cancer.gov/map/map.withimage.php?00\&157\&055\&00\&2\&02\&1\&1\& 6\&0\#map. Updated 2009. Accessed 02/19, 2014.

31. Hall HI, Uhler RJ, Coughlin SS, Miller DS. Breast and cervical cancer screening among Appalachian women. Cancer Epidemiol Biomarkers Prev. 2002;11(1):137-142.

32. Walter LC, Covinsky KE. Cancer screening in elderly patients: A framework for individualized decision making. JAMA. 2001;285(21):2750-2756.

33. Caplan LS, Haynes SG. Breast cancer screening in older women. Public Health Rev. 1996;24(2):193-204.

34. MMWR Morb Mortal Wkly Report. Use of mammography services by women aged $>$ or $=$ 65 years enrolled in Medicare-United States, 1991-1993. 1995;44;777-781.

35. Day NE. Quantitative approaches to the evaluation of screening programs. World J Surg. 1989;13(1):3-8.

36. Sant M, Allemani C, Capocaccia R, et al. Stage at diagnosis is a key explanation of differences in breast cancer survival across Europe. Int J Cancer. 2003;106(3):416-422.

37. McCarthy EP, Burns RB, Freund KM, et al. Mammography use, breast cancer stage at diagnosis, and survival among older women. J Am Geriatr Soc. 2000;48(10):1226-1233. 
38. Randolph WM, Goodwin JS, Mahnken JD, Freeman JL. Regular mammography use is associated with elimination of age-related disparities in size and stage of breast cancer at diagnosis. Ann Intern Med. 2002;137(10):783-790.

39. Badgwell BD, Giordano SH, Duan ZZ, et al. Mammography before diagnosis among women age 80 years and older with breast cancer. J Clin Oncol. 2008;26(15):2482-2488.

40. Galit W, Green MS, Lital KB. Routine screening mammography in women older than 74 years: A review of the available data. Maturitas. 2007;57(2):109-119.

41. Freeman JL, Klabunde CN, Schussler N, Warren JL, Virnig BA, Cooper GS. Measuring breast, colorectal, and prostate cancer screening with Medicare claims data. Med Care. 2002;40(8 Suppl):IV-36-42.

42. Fenton JJ, Zhu W, Balch S, Smith-Bindman R, Fishman P, Hubbard RA. Distinguishing screening from diagnostic mammograms using Medicare claims data. Med Care. 2014 July;52(7):e44-e51.

43. Warren JL, Klabunde CN, Schrag D, Bach PB, Riley GF. Overview of the SEER-Medicare data: Content, research applications, and generalizability to the United States elderly population. Med Care. 2002;40(8 Suppl):IV-3-18.

44. Cancer Incidence in West Virginia, 1993-2009, West Virginia Cancer Registry, Charleston WV, 2012.

45. Nadpara PA, Madhavan SS. Linking Medicare, Medicaid, and cancer registry data to study the burden of cancers in West Virginia. Medicare and Medicaid Research Review.

2012;2(4):02/25/2014.

46. Young JL Jr, Roffers SD, Ries LAG, Fritz AG, Hurlbut AA. (eds). SEER summary staging manual-2000: Codes and coding instructions, National Cancer Institute, NIH pub. no. 01-4969. . 2001.

47. Bleyer A, Welch HG. Effect of three decades of screening mammography on breast-cancer incidence. N Engl J Med. 2012;367(21):1998-2005.

48. Randolph WM, Mahnken JD, Goodwin JS, Freeman JL. Using Medicare data to estimate the prevalence of breast cancer screening in older women: Comparison of different methods to identify screening mammograms. Health Serv Res. 2002;37(6):1643-1657.

49. Gierisch JM, Reiter PL, Rimer BK, Brewer NT. Standard definitions of adherence for infrequent yet repeated health behaviors. Am J Health Behav. 2010;34(6):669-679.

50. Braithwaite D, Zhu W, Hubbard RA, et al. Screening outcomes in older US women undergoing multiple mammograms in community practice: Does interval, age, or comorbidity 
score affect tumor characteristics or false positive rates? J Natl Cancer Inst. 2013;105(5):334341.

51. Andersen RM. Revisiting the behavioral model and access to medical care: Does it matter? $J$ Health Soc Behav. 1995;36(1):1-10.

52. Andersen R, Newman JF. Societal and individual determinants of medical care utilization in the United States. Milbank Mem Fund Q Health Soc. 1973;51(1):95-124.

53. Klabunde CN, Potosky AL, Legler JM, Warren JL. Development of a comorbidity index using physician claims data. J Clin Epidemiol. 2000;53(12):1258-1267.

54. Charlson ME, Pompei P, Ales KL, MacKenzie CR. A new method of classifying prognostic comorbidity in longitudinal studies: Development and validation. J Chronic Dis. 1987;40(5):373-383.

55. National Cancer Institute: SEER-Medicare: Calculation of comorbidity weights. . http://healthservices.cancer.gov/seermedicare/program/comorbidity.html. Updated 2013. Accessed 02/25, 2014.

56. Yu X, McBean AM, Virnig BA. Physician visits, patient comorbidities, and mammography use among elderly colorectal cancer survivors. J Cancer Surviv. 2007;1(4):275-282.

57. Hosmer DW, Lemeshow S. Applied logistic regression. 2nd ed. John Wiley \& Sons, Inc.; 2000 .

58. Krieger N. Overcoming the absence of socioeconomic data in medical records: Validation and application of a census-based methodology. Am J Public Health. 1992;82(5):703-710. 


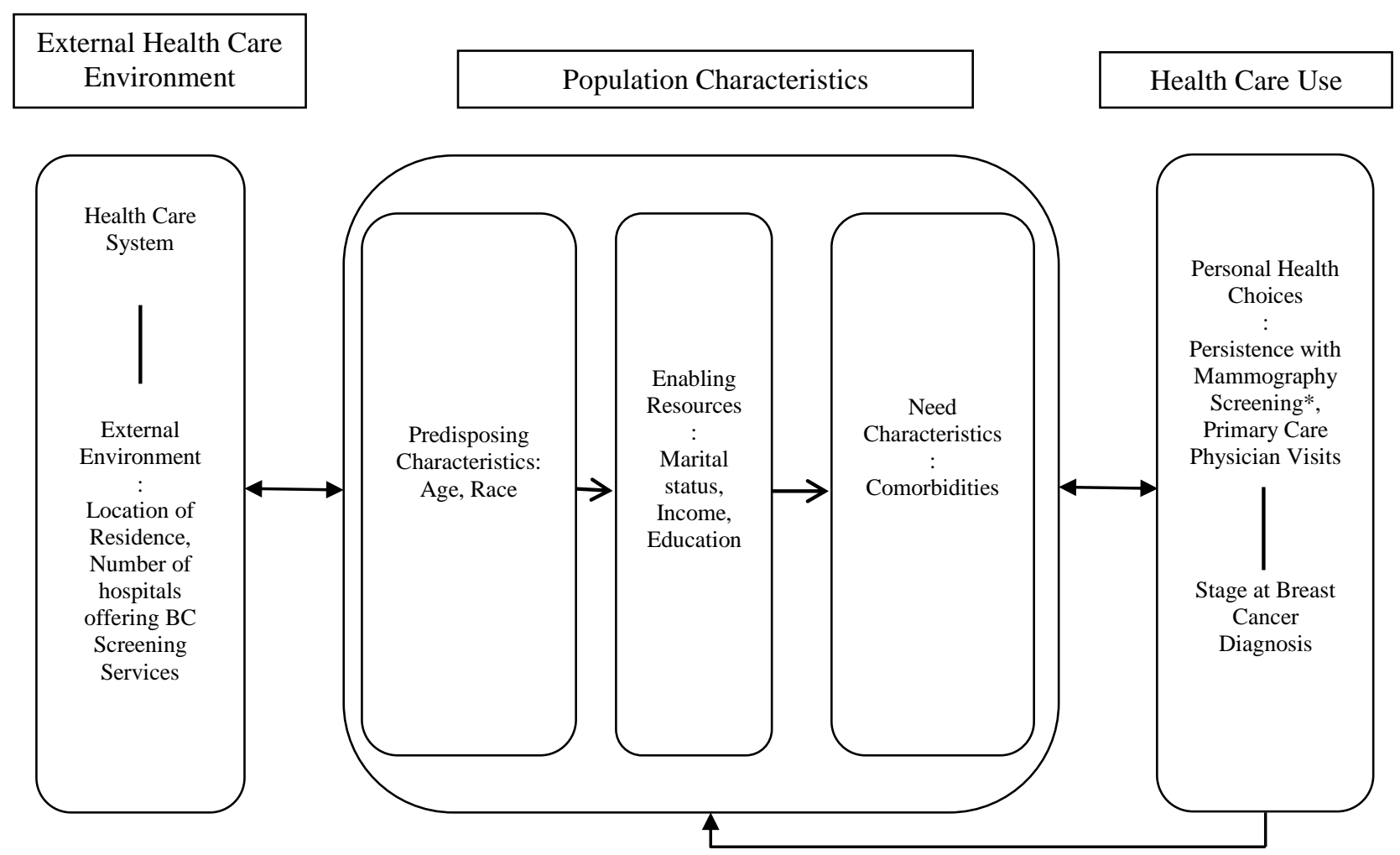

*Key Independent Variable

Figure 2.1: The Andersen Behavioral Model for Health Care Utilization (For Aim 1) 


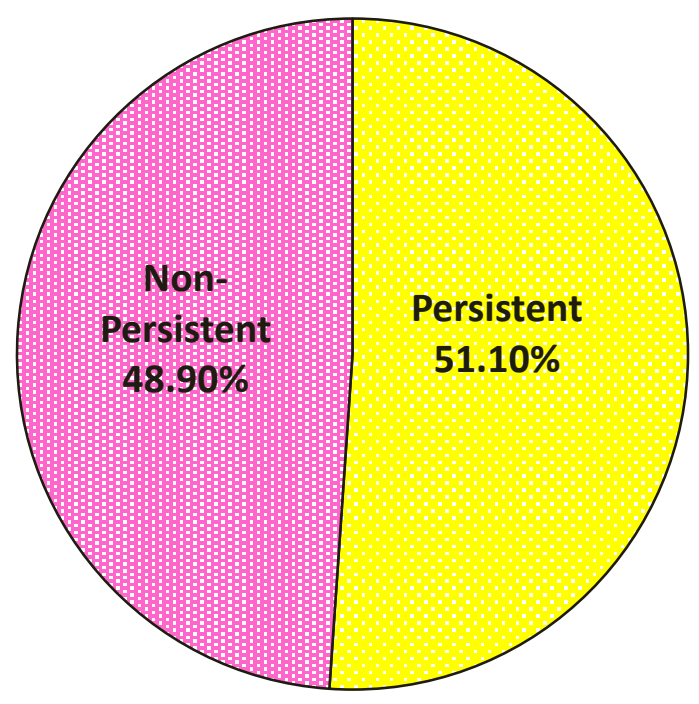

Figure 2.2: WV-Medicare Cohort by Persistence with Mammography Screening

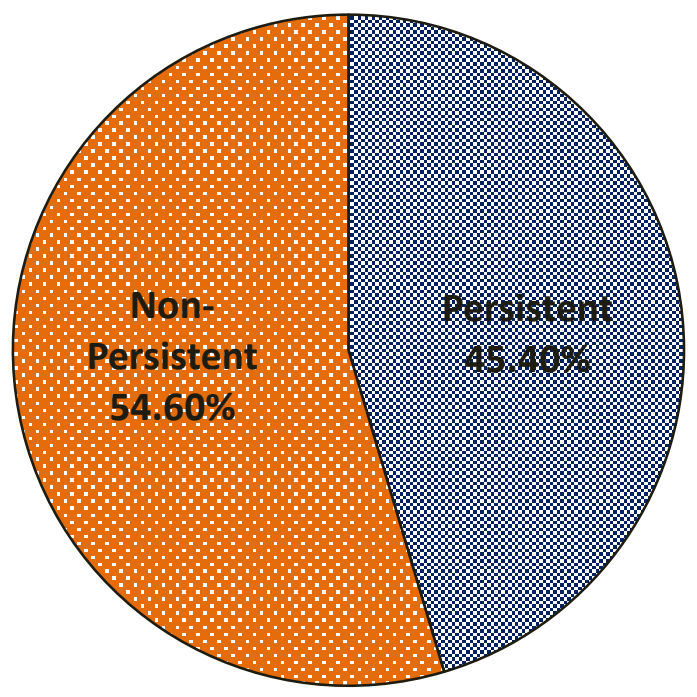

Figure 2.3: SEER-Medicare Cohort by Persistence with Mammography Screening 


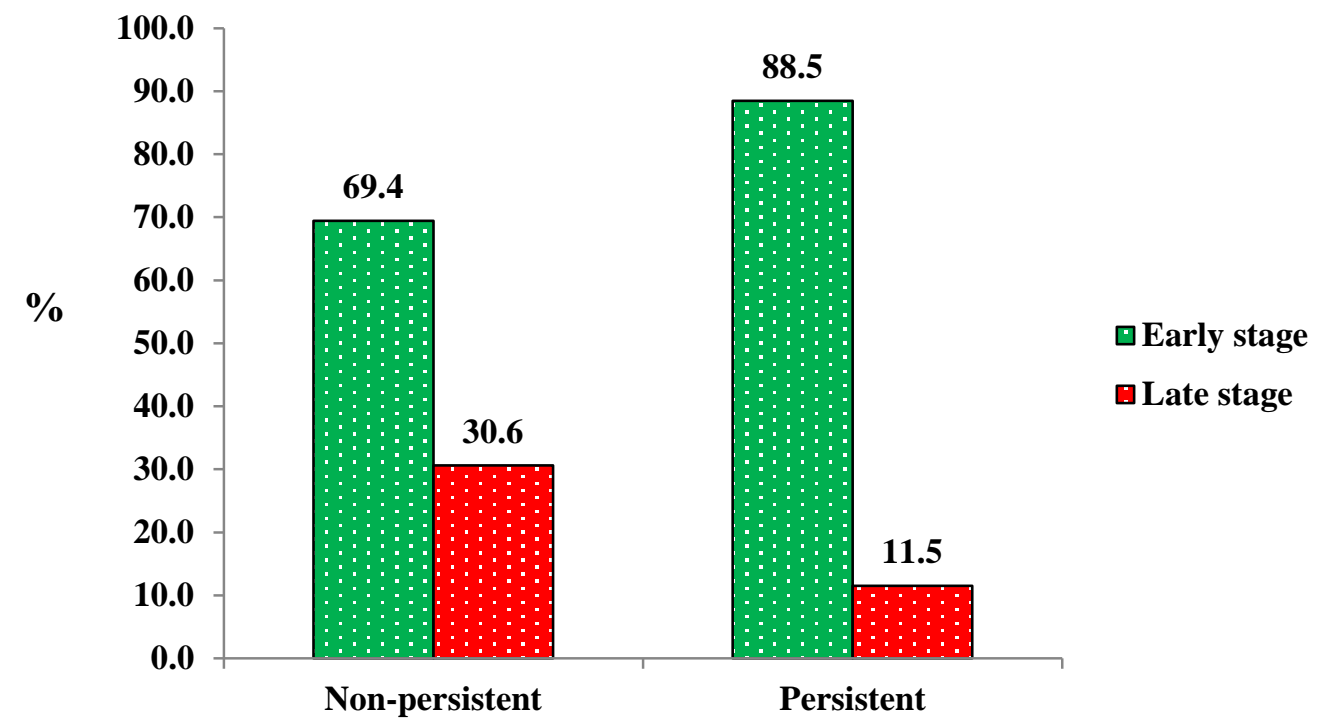

Figure 2.4: Stage at Breast Cancer Diagnosis by Persistence with Mammography Screening for the WV-Medicare Cohort

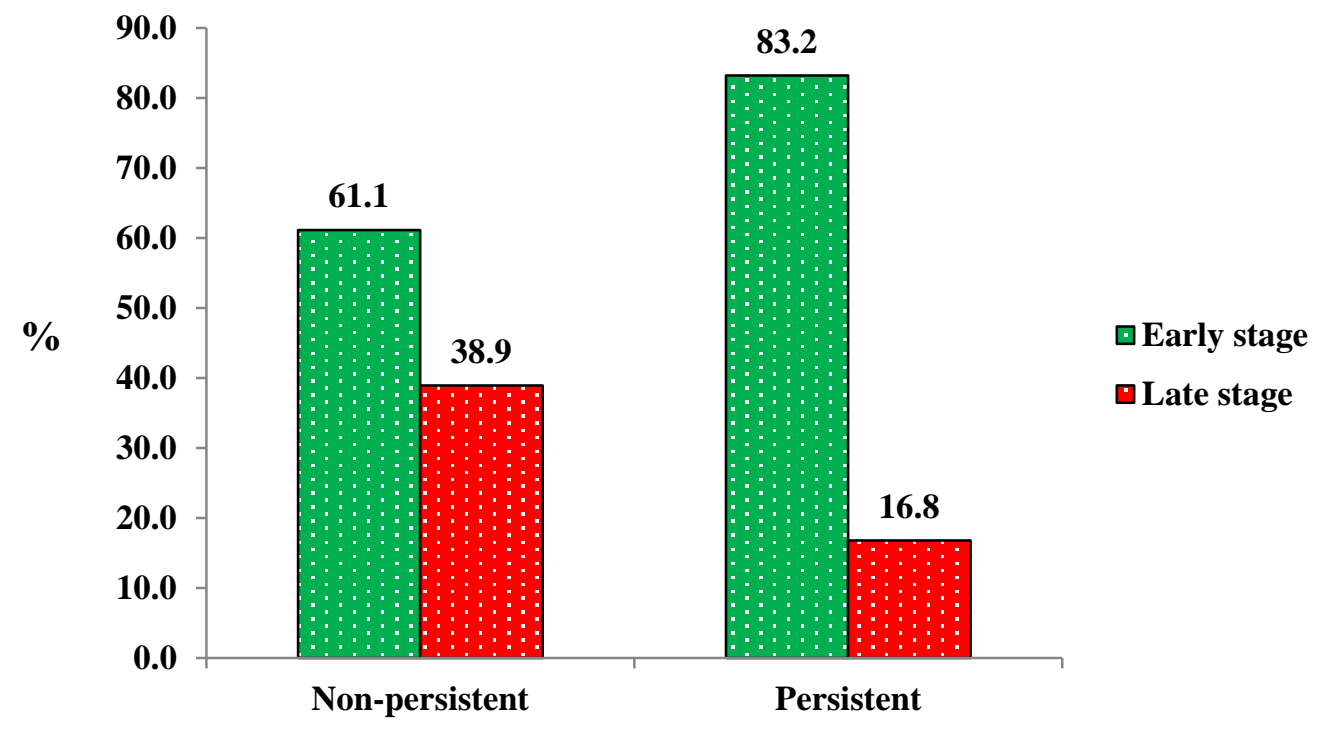

Figure 2.5: Stage at Breast Cancer Diagnosis by Persistence with Mammography Screening for the SEER-Medicare Cohort 
Table 2.1

Description of the Study Cohorts by Persistence with Mammography Screening 2007

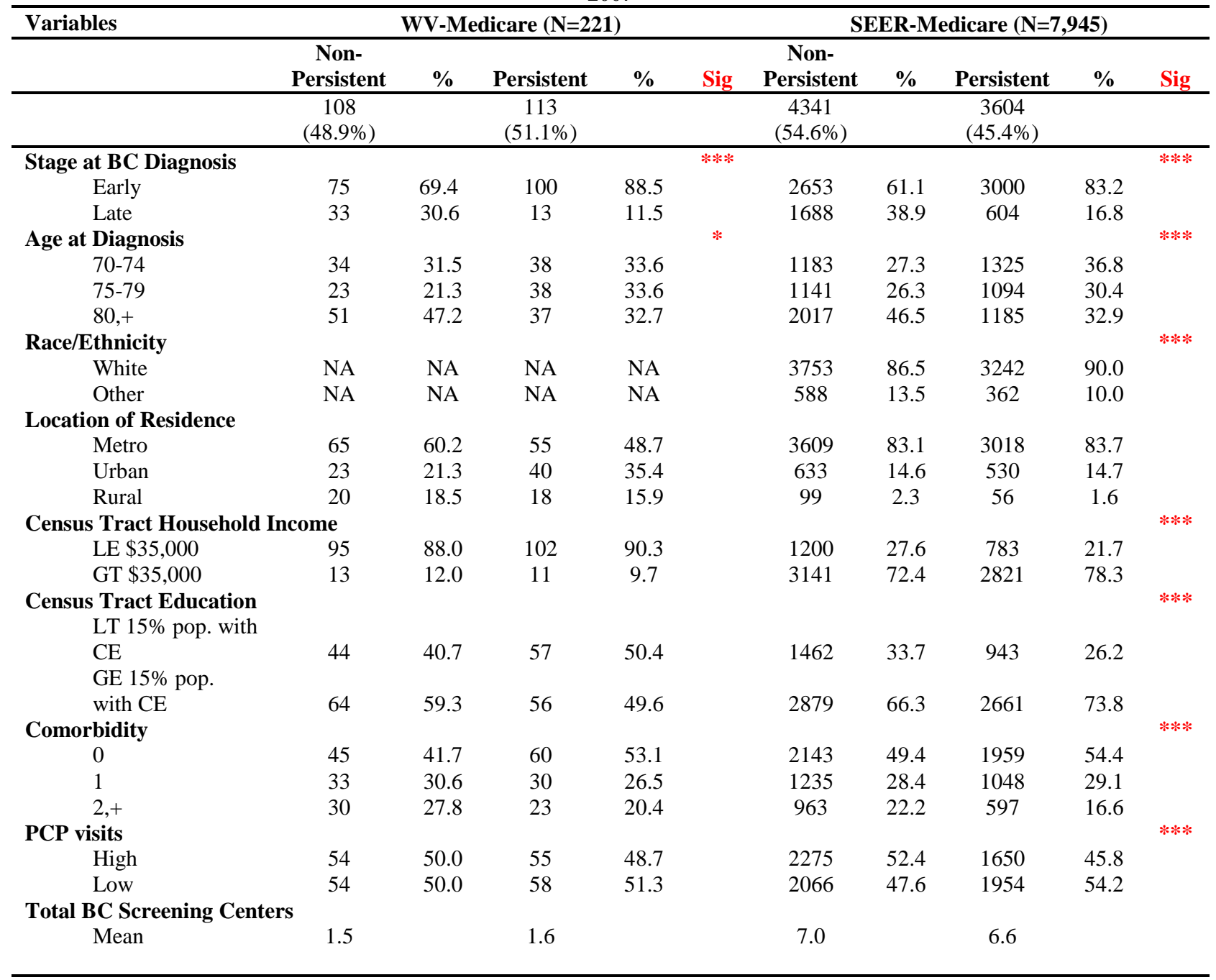

Note: Based on 221 elderly WV-Medicare women and 7,945 elderly SEER-Medicare women, age 70 and above diagnosed with primary incident breast cancer in 2007. WV, West Virginia; SEER, Surveillance, Epidemiology, and End Results; PCP, Primary Care Physicians, BC, Breast Cancer; pop., population; LE, Less than or equal to; GT, Greater than; LT, Less than; GE, Greater than or equal to; CE, College education; Sig, Significance; NA, Not Applicable. For WV-Medicare cohort, $\chi 2$ test for race/ethnicity variable was not performed due to 0 sample size in one of the persistent groups. Asterisks represent statistically significant group differences based on $\chi 2$ tests and t-tests separately for two study cohorts: $* * * \mathrm{P}<0.001 ; * * 001<=\mathrm{P}<.01$; $* .01<=\mathrm{P}<.05$. 
Table 2.2

Association between Persistence with Mammography Screening and Stage at Breast Cancer Diagnosis, Separately for WV-Medicare and SEER-Medicare

Adjusted Odds Ratios and 95\% Confidence Intervals from Logistic Regressions 2007

\begin{tabular}{|c|c|c|c|c|c|c|}
\hline \multirow[t]{2}{*}{ Variables } & \multicolumn{3}{|c|}{ WV-Medicare $(\mathrm{N}=221)$} & \multicolumn{3}{|c|}{ SEER-Medicare $(\mathrm{N}=7,945)$} \\
\hline & AOR & $95 \% \mathrm{CI}$ & Sig & AOR & $95 \% \mathrm{CI}$ & Sig \\
\hline \multicolumn{7}{|c|}{ Persistence with Mammography Screening } \\
\hline Persistent & 4.18 & {$[1.94,8.98]$} & $* * *$ & 1.44 & {$[1.31,1.58]$} & $* * *$ \\
\hline Non-Persistent & 1 & & & 1 & & \\
\hline \multicolumn{7}{|l|}{ Age at Diagnosis } \\
\hline $70-74$ & 1 & & & 1 & & \\
\hline $75-79$ & 0.75 & {$[0.31,1.79]$} & & 1.04 & {$[0.92,1.16]$} & \\
\hline $80,+$ & 1.72 & {$[0.73,4.07]$} & & 1.11 & {$[1.00,1.23]$} & \\
\hline \multicolumn{7}{|l|}{ Race/Ethnicity } \\
\hline White & NA & NA & & 1.1 & {$[0.95,1.26]$} & \\
\hline Other & NA & NA & & 1 & & \\
\hline \multicolumn{7}{|l|}{ Location of Residence } \\
\hline Metro & 1 & & & 1 & & \\
\hline Urban & 1.13 & {$[0.44,2.87]$} & & 1.07 & {$[0.93,1.23]$} & \\
\hline Rural & 1.00 & {$[0.31,3.15]$} & & 1 & {$[0.72,1.39]$} & \\
\hline \multicolumn{7}{|l|}{ Census Tract Household Income } \\
\hline LE $\$ 35,000$ & 1 & & & 1 & & \\
\hline GT $\$ 35,000$ & 0.77 & {$[0.21,2.85]$} & & 1.19 & {$[1.04,1.35]$} & $* *$ \\
\hline \multicolumn{7}{|l|}{ Census Tract Education } \\
\hline LT $15 \%$ pop. with & & & & & & \\
\hline $\mathrm{CE}$ & 1 & & & 1 & & \\
\hline GE $15 \%$ pop. with & & & & & & \\
\hline $\mathrm{CE}$ & 2.3 & {$[0.90,5.86]$} & & 1.1 & {$[0.98,1.24]$} & \\
\hline \multicolumn{7}{|l|}{ Comorbidity } \\
\hline - & 1 & & & 1 & & \\
\hline 1 & 0.72 & {$[0.31,1.65]$} & & 0.97 & {$[0.87,1.08]$} & \\
\hline $2,+$ & 0.89 & {$[0.36,2.24]$} & & 1.04 & {$[0.92,1.18]$} & \\
\hline \multicolumn{7}{|l|}{ PCP visits } \\
\hline High & 1.24 & {$[0.60,2.56]$} & & 1.17 & {$[1.06,1.28]$} & $* *$ \\
\hline Low & 1 & & & 1 & & \\
\hline Total BC Screening Centers & 0.85 & {$[0.52,1.38]$} & & 1.00 & {$[1.00,1.01]$} & \\
\hline
\end{tabular}

Note: Based on 221 elderly WV-Medicare women and 7,945 elderly SEER-Medicare women, age 70 and above diagnosed with primary incident breast cancer in 2007. WV, West Virginia; SEER, Surveillance, Epidemiology, and End Results; PCP, Primary Care Physicians, BC, Breast Cancer; CE, College Education; pop., population; LE, Less than or equal to; GT, Greater than; LT, Less than; GE, Greater than or equal to; AOR, Adjusted odds ratio; CI, Confidence Interval; Sig, Significance; NA, Not Applicable. The regressions also include intercept terms and parameter estimates for other variable controlled are not presented. "Late Stage at Breast Cancer Diagnosis" is the reference group for the dependent variable for both the study cohorts. For WV-Medicare cohort, logistic regression did not include race/ethnicity as one of the controlled variables due to 0 sample size in one of the persistent groups. Asterisks represent statistically significant group differences compared with the reference group: $* * * \mathrm{P}<0.001 ; * * 001<=\mathrm{P}<.01 ; * .01<=\mathrm{P}<.05$. 
Table 2.3

Description of WV-Medicare and SEER-Medicare (randomly selected non-Hispanic white SEERMedicare) cohorts

2007

\begin{tabular}{|c|c|c|c|c|c|}
\hline \multirow[t]{2}{*}{ Variables } & \multicolumn{2}{|c|}{$\begin{array}{c}\text { WV-Medicare } \\
(\mathbf{N}=221)\end{array}$} & \multicolumn{2}{|c|}{$\begin{array}{c}\text { SEER-Medicare } \\
(\mathrm{N}=708)\end{array}$} & \multirow[b]{2}{*}{ Sig } \\
\hline & $\mathbf{N}$ & $\%$ & $\mathbf{N}$ & $\%$ & \\
\hline \multicolumn{6}{|l|}{ Stage at BC Diagnosis } \\
\hline Early & 175 & 79.2 & 514 & 72.6 & \\
\hline Late & 46 & 20.8 & 194 & 27.4 & \\
\hline \multicolumn{6}{|l|}{ Persistence with Mammography Screening } \\
\hline Persistent & 113 & 51.1 & 339 & 47.9 & \\
\hline Non-Persistent & 108 & 48.9 & 369 & 52.1 & \\
\hline \multicolumn{6}{|l|}{ Age at Diagnosis } \\
\hline $70-74$ & 72 & 32.6 & 242 & 34.2 & \\
\hline $75-79$ & 61 & 27.6 & 179 & 25.3 & \\
\hline $80,+$ & 88 & 39.8 & 287 & 40.5 & \\
\hline Location of Residence & & & & & $* * *$ \\
\hline Metro & 120 & 54.3 & 580 & 81.9 & \\
\hline Urban & 63 & 28.5 & 120 & 16.9 & \\
\hline Rural & 38 & 17.2 & 8 & 1.1 & \\
\hline Census Tract Household Income & & & & & $* * *$ \\
\hline LE $\$ 35,000$ & 197 & 89.1 & 147 & 20.8 & \\
\hline GT $\$ 35,000$ & 24 & 10.9 & 561 & 79.2 & \\
\hline Census Tract Education & & & & & $* * *$ \\
\hline LT $15 \%$ pop. with CE & 101 & 45.7 & 192 & 27.1 & \\
\hline GE $15 \%$ pop. with CE & 120 & 54.3 & 516 & 72.9 & \\
\hline \multicolumn{6}{|l|}{ Comorbidity } \\
\hline 0 & 105 & 47.5 & 374 & 52.8 & \\
\hline 1 & 63 & 28.5 & 193 & 27.3 & \\
\hline $2,+$ & 53 & 24.0 & 141 & 19.9 & \\
\hline \multicolumn{6}{|l|}{ PCP visits } \\
\hline High & 112 & 50.7 & 325 & 45.9 & \\
\hline Low & 109 & 49.3 & 383 & 54.1 & \\
\hline \multicolumn{6}{|l|}{ Total BC Screening Centers } \\
\hline Mean & 1.5 & & 6.5 & & $* * *$ \\
\hline
\end{tabular}

Note: Based on 221 elderly WV-Medicare women and randomly selected non-Hispanic white 708 elderly SEER-Medicare women, age 70 and above diagnosed with primary incident breast cancer in 2007. WV, West Virginia; SEER, Surveillance, Epidemiology, and End Results; PCP, Primary Care Physicians, BC, Breast Cancer; pop., population; CE, College Education; LE, Less than or equal to; GT, Greater than; LT, Less than; GE, Greater than or equal to; Sig, Significance. Asterisks represent statistically significant group differences based on $\chi 2$ tests and t-tests: $* * * \mathrm{P}<0.001 ; * * 001<=\mathrm{P}<.01$; $* .01<=\mathrm{P}<.05$. 
Table 2.4

Differences in Stage at Breast Cancer Diagnosis between Study Cohorts In a Multivariate Framework

Adjusted Odds Ratio and 95\% Confidence Intervals from Logistic Regression 2007

\begin{tabular}{|c|c|c|c|}
\hline \multirow[t]{2}{*}{ Variables } & \multicolumn{3}{|c|}{ Early Stage at Diagnosis } \\
\hline & AOR & $95 \% \mathrm{CI}$ & Sig \\
\hline \multicolumn{4}{|l|}{ Type of Setting } \\
\hline WV-Medicare & 1.57 & {$[0.97,2.55]$} & \\
\hline SEER-Medicare & 1 & & \\
\hline \multicolumn{4}{|l|}{ Persistence with Mammography Screening } \\
\hline Persistent & 2.87 & {$[2.08,3.97]$} & $* * *$ \\
\hline Non-Persistent & 1 & & \\
\hline \multicolumn{4}{|l|}{ Age at Diagnosis } \\
\hline $70-74$ & 1 & & \\
\hline $75-79$ & 0.63 & {$[0.42,0.93]$} & $*$ \\
\hline $80,+$ & 0.94 & {$[0.65,1.36]$} & \\
\hline \multicolumn{4}{|l|}{ Location of Residence } \\
\hline Metro & 1 & & \\
\hline Urban & 0.99 & {$[0.65,1.50]$} & \\
\hline Rural & 1.12 & {$[0.51,2.47]$} & \\
\hline \multicolumn{4}{|l|}{ Census Tract Household Income } \\
\hline LE $\$ 35,000$ & 1 & & \\
\hline GT $\$ 35,000$ & 1.05 & {$[0.66,1.67]$} & \\
\hline \multicolumn{4}{|l|}{ Census Tract Education } \\
\hline LT $15 \%$ pop. with CE & 1 & & \\
\hline GE $15 \%$ pop. with CE & 1.60 & {$[1.07,2.40]$} & $*$ \\
\hline \multicolumn{4}{|l|}{ Comorbidity } \\
\hline 0 & 1 & & \\
\hline 1 & 0.82 & {$[0.57,1.18]$} & \\
\hline $2,+$ & 1.06 & {$[0.70,1.61]$} & \\
\hline \multicolumn{4}{|l|}{ PCP visits } \\
\hline High & 1.24 & {$[0.89,1.71]$} & \\
\hline Low & 1 & & \\
\hline Total BC Screening Centers & 1.00 & {$[0.98,1.02]$} & \\
\hline
\end{tabular}

Note: Based on 221 elderly WV women and 708 randomly selected non-Hispanic elderly women from SEER-Medicare, age 70 and above diagnosed with primary incident breast cancer in 2007 . WV, West Virginia; SEER, Surveillance, Epidemiology, and End Results; PCP, Primary Care Physicians, BC, Breast Cancer; CE, College Education; pop., population; LE, Less than or equal to; GT, Greater than; LT, Less than; GE, Greater than or equal to; AOR, Adjusted odds ratio; CI, Confidence Interval; Sig, Significance. The regressions also include intercept terms and parameter estimates for other variable controlled are not presented. "Late Stage at Breast Cancer Diagnosis" is the reference group for the dependent variable. Asterisks represent statistically significant group differences compared with the reference group: $* * * \mathrm{P}<0.001 ; * * 001<=\mathrm{P}<.01 ; * .01<=\mathrm{P}<.05$. 
CHAPTER 3 


\section{CHAPTER 3}

TIMELY DIAGNOSIS AND TREATMENT OF BREAST CANCER IN ELDERLY WOMEN

\section{INTRODUCTION}

\section{Breast Cancer}

Breast cancer $(\mathrm{BC})$ is the most common occurring cancer in women and is the second leading cause of cancer death in women in the United States (US). As per the Surveillance, Epidemiology and End Results (SEER) statistics for 2005-2009, the overall incidence of BC was 82.97 per 100,000 women in those below 65 years of age and was 421.30 per 100,000 women in those age 65 and above ${ }^{1}$ and the overall mortality from BC was 11.15 per 100,000 women in those below 65 years of age and was 98.64 per 100,000 women in those age 65 and above ${ }^{1}$. Moreover, older women age 65 and above have a greater burden of $\mathrm{BC}$ as cancer in these women may be found at more advanced stages and with larger tumor sizes thereby leading to poorer survival $^{2}$. However, BC has 5-years survival of $88.5 \%$ in elderly women age 65 and above which is only a little lower as compared to $89.7 \%$ for women below 65 years of age ${ }^{3}$.

\section{Timely Diagnosis and Treatment of Breast Cancer in Elderly Women}

$\mathrm{BC}$ is a major and complex health issue among women and the second cause of cancerrelated deaths among women in the US, as such, measuring quality of care delivered to BC patients is challenging. Timeliness of care, i.e., rapid diagnosis after noticing abnormality in the breast and rapid initiation of treatment after diagnosis, is one of the key components of highquality cancer treatment. Determining timeliness of care provided to BC patients is extremely important as both patients and referring care providers expect rapid access to care for breast problems ${ }^{4,5}$. Also, emotional distress may occur during the wait time for the patient's diagnostic 
evaluation and subsequent treatment ${ }^{6-8}$. Most research in this area has demonstrated a possible relationship between delay and survival because of a complex interaction of clinical and sociocultural factors ${ }^{9}$.

To our knowledge, despite the widely accepted benefit of timely care in BC patients, USbased agencies such as the National Initiative for Cancer Care Quality, National Comprehensive Cancer Network Quality, American Society of Clinical Oncology, National Quality Forum are yet to define guidelines for an appropriate time frame from presentation of abnormality to confirmed diagnosis and from diagnosis to the initiation of the treatment ${ }^{10}$. As per a quality review of the timeliness of $\mathrm{BC}$ diagnosis and treatment ${ }^{11}$, the European Society of Breast Cancer Specialists (EUSOMA) has published professional opinion-based guidelines on time intervals between various events from presentation of abnormality to diagnosis of $\mathrm{BC}^{12,13}$. Moreover, the National Health Service of United Kingdom has published professional opinion-based guidelines on appropriate time interval from BC diagnosis to the initiation of the treatment ${ }^{14}$. The USbased National Initiative of Cancer Care Quality (NICCQ) has suggested time intervals for few events which occur between presentation of abnormality to initiation of treatment, however it does not define the appropriate time from presentation of abnormality to confirmed diagnosis and from diagnosis to the initiation of the treatment ${ }^{15}$.

Despite numerous studies about timeliness of $\mathrm{BC}$ care have been conducted in the last decade in the US ${ }^{16-24}$, no consensus exists regarding the time intervals for diagnosis and treatment delays. Among the studies about delay in diagnosis, only three studies included women age 65 and above in their analyses ${ }^{16,19,20}$. One study did not assess the effect of important clinical covariates such as tumor size, grade of tumor, ER- and PR-status, socioeconomic variables such as income and education, and access factors, which affect timely 
diagnosis and care ${ }^{20}$. While other two studies were conducted in a smaller geographic location which may affect the generalizability of the findings to other populations ${ }^{16,19}$. Among studies about delay of treatment, only four studies included women age 65 years and above in their analyses ${ }^{21-24}$. One study restricted women till 72 years of age and did not adjust for any clinical covariates which affect treatment delays ${ }^{21}$. Another study was limited to North CarolinaMedicaid population only which may affect the generalizability of the findings to the other populations ${ }^{22}$. Only two studies were conducted using SEER-Medicare dataset of which one study did not include patients with distant or stage IV disease and did not adjust for clinical covariates and access factors in the analyses ${ }^{24}$, and the other study reported treatment delay in terms of months (whole numbers), which was not consistent with any of the studies estimating delay in care ${ }^{23}$. Finally, none of the above studies followed the published opinion-based EUSOMA, National Health Service of United Kingdom or any guidelines to define timeliness of diagnosis and treatment in women with BC.

As older women age 65 years and above have higher BC incidence and mortality and are more likely to have advanced stage disease with larger tumors ${ }^{1,2}$, it is highly likely that diagnosis delay and/or treatment delay may negatively affect the prognosis of the disease and hence the survival. Hence, it is extremely important to determine timeliness of care based on the published opinion-based guidelines among elderly BC patients in the US.

WV is the only state that lies entirely in Appalachia, a region which is a predominantly rural and medically underserved in the United States characterized by high poverty rates, low levels of education, aging population, high rates of chronic disease, and poor health behaviors ${ }^{25-}$ 28. With lower incidence of BC among WV women age 65 and older (372.8 per 100,000 vs. 410.6 per 100,000$)$ but higher mortality $(110.4 \text { per } 100,000 \text { vs. } 98.6 \text { per } 100,000)^{29,30}$ as 
compared to the national estimates, and with higher rates of advanced and unstaged $\mathrm{BC}$ in these women ${ }^{31-35}$, it is likely that timeliness of care may be one of the significant contributors to these disparities. Therefore, a study comparing the timeliness of care among elderly $\mathrm{BC}$ patients from WV to the national estimates may help understand these disparities.

Hence, the purpose of the study is to determine timeliness of BC care based on published recommendations and its effect on survival in elderly women with BC among WV Medicare feefor-service (FFS) women beneficiaries and compare it with the national estimates derived from SEER-Medicare data, and to determine the factors associated with timeliness of BC care in WV women and compare it with the national estimates, after controlling for predisposing factors (age, race), enabling factors (median household income, education level), need-related factors (stage at diagnosis, grade of tumor, estrogen-receptor (ER) status, co-occurring chronic conditions), factors associated with healthcare use (number of primary care physicians (PCP) visits in year prior to $\mathrm{BC}$ diagnosis, type of initial cancer-related treatment) and external healthcare environmental factors (location of residence and number of hospitals offering oncology services in the area of residence).

\section{METHODS}

\section{Data Source}

\section{West Virginia Cancer Registry-Medicare-Area Resource File linked dataset}

Established in 1993 by the West Virginia Department of Health and Human Resources, the West Virginia Cancer Registry (WVCR) provides information on cancer incidence and mortality in the state ${ }^{36}$. The registry provides information on clinical characteristics of cancer such as primary cancer site, tumor grade, date and stage of diagnosis, date and cause of mortality, and demographic data on age, gender, race, and zip code. In the full compliance with 
the WVU Institutional Review Board and HIPPA requirements, the de-identified linked WVCRMedicare dataset was established at West Virginia University which provided information about WV individuals who are age $\geq 65$ years and diagnosed with cancer between the January 1, 2002 and December 31, $2007^{37}$. The Social security numbers (SSN) for individuals in WVCR were then provided to the CMS by the WVCR, using which the CMS identified the corresponding Health Insurance Claim (HIC) number. A "crosswalk" file created using the HIC allowed for linkage across the WVCR and the Medicare for extracting information on these individuals as Medicare beneficiaries. Individuals with a missing SSN were excluded from the linkage. To extract the county level information on the availability of healthcare facilities, and socioeconomic characteristics of the region's population, the Area Resource File (ARF) was linked to the WVCR-Medicare dataset using the state and county FIPS codes for each beneficiary.

\section{SEER-Medicare-Area Resource File linked dataset}

The SEER-Medicare linked dataset provides important data useful for population-level cancer-related epidemiologic and health outcomes studies. The SEER-Medicare program collects information on newly diagnosed cases of cancer from 17 population-based tumor registries which ultimately collect information from hospitals, outpatient clinics, laboratories, private practitioners, laboratories, hospices, autopsy reports and death certificates and it represents $26 \%$ of the US population. Patient Entitlement and Diagnosis Summary File (PEDSF) is a customized file which contains one record per person for individuals in the SEER part of the SEER-Medicare database who have been matched with Medicare enrollment records. PEDSF provides diagnostic information for up to 10 diagnosed cancer cases (including date of cancer diagnosis, cancer sub-site, cancer stage at diagnosis), and information on the first course of 
cancer related treatment (surgery and radiation provided in the first 4 months after diagnosis) for each individual. Additionally it includes information on the median household income and education level for each individual based on their census tract and zip code data.

The Medicare files of the SEER-Medicare linked dataset provide data about health care utilization inpatient, outpatient, physician, home health, and hospice care by individuals age 65 and above who are enrolled in the Medicare program. These files have information about dates of healthcare service and codes for specific diagnosis and procedures using the International Classification of Disease, Ninth Edition (ICD-9) codes or Common Procedure Terminology codes. The linkage process of the SEER data with the Medicare data is described elsewhere ${ }^{38}$. The Area Resource File (ARF) was linked to the SEER-Medicare dataset using the state and county Federal Information Processing Standards (FIPS) code for each beneficiary to extract the county level information on the availability of healthcare facilities and healthcare providers.

\section{Study Design}

This study utilized a retrospective observational cohort design to assess time to diagnosis and time to treatment and its effect on chances of being alive among Medicare FFS beneficiaries diagnosed with BC.

\section{Study Cohorts}

The two cohorts for this study consisted of women from WVCR-Medicare-ARF linked dataset and SEER-Medicare-ARF linked dataset, age 66 and older at the first primary pathologically confirmed diagnosis of incident BC from January 1, 2003 to December 31, 2006. These women were required to be continuously enrolled in Medicare parts A and B at least 12 months prior to the $\mathrm{BC}$ diagnosis to identify comorbidities and timeliness of care from the initial consultation to $\mathrm{BC}$ diagnosis, and till the follow-up period of 12 months after $\mathrm{BC}$ diagnosis to 
determine timeliness of care from diagnosis to treatment. Women who died during the study period and who were enrolled in health maintenance organizations (HMOs) at any time during the study period were excluded from the study. Also, women with any previous cancer diagnosis, with unknown or missing stage of $\mathrm{BC}$, and who were diagnosed through death certificate or autopsy were excluded from the study. To determine the effect of timeliness of care on the probability of being alive, women diagnosed with first primary pathologically confirmed incident BC from January 1, 2003 to December 31, 2004 and who followed all the inclusion and exclusion criteria as described above were identified from both the datasets and were followed for three years. BC diagnosis codes were based on the primary site and International Classification of Diseases, 9th edition Clinical Modification (ICD-9-CM) codes 174.xx, 233.0x, 238.3x, and 239.3x.

The WVCR-Medicare-ARF linked dataset identified 2,814 women diagnosed with BC from January 1, 2003 to December 31, 2006. The following women were excluded from the final study population: 152 women who were below 66 years at diagnosis, 527 women with any previous cancer diagnosis, 24 women who were diagnosed with BC during death or autopsy, 246 women with unknown or missing BC stage, 245 women who were not continuously enrolled in Medicare parts A and B in the 12 months before and 12 months after diagnosis, and 232 women who were members of a HMO any time during the study period. Thus, a final sample of 1,388 women who had claims for breast biopsy was included in the final analyses.

The SEER-Medicare-ARF linked dataset had 112,719 women diagnosed with BC from January 1, 2003 to December 31, 2006. The following women were excluded from the final study population: 45,198 women who were below 66 years at diagnosis, 3,385 women with any previous cancer diagnosis, 815 women who were diagnosed with BC during death or autopsy, 
1,947 women with unknown or missing BC stage, 5,714 women who were not continuously enrolled in Medicare parts A and B in 12 months before and 12 months after diagnosis, 14,671 women who were members of a HMO any time during the study period, and 7 women from all the remaining women who died during the 12 months after $\mathrm{BC}$ diagnosis. From the remaining 40,982 women, 4,706 women did not have claims for breast biopsy which were used to ascertain biopsy-proved diagnosis and hence were removed from the analyses. Thus, a final sample of 36,276 women was included in the final analyses.

\section{Measures}

\section{Timely Care Intervals}

Based on previous studies ${ }^{16,17}$, two intervals were created for both the study cohorts: timely diagnosis, timely treatment and timely clinical care.

Timely Diagnosis: Timely diagnosis was defined as the period (in days) between the initial consultation for abnormality and biopsy-proved BC diagnosis as per the published opinion-based guidelines. Breast biopsies (fine-needle aspiration, core biopsy, incision, or excision) were identified using Current Procedural Terminology (CPT) and International Classification of Diseases, Ninth Revision, Clinical Modification (ICD-9-CM) procedure codes. The initial consultation date for abnormality was defined as the date of a consultation for breast symptoms or date of diagnostic mammography or diagnostic magnetic resonance imaging (MRI) or diagnostic ultrasonography. Breast symptoms were identified using International Classification of Diseases, Ninth Revision, Clinical Modification diagnostic codes 611.7x and 611.9 occurring within one year before the breast biopsy proved diagnosis date. Diagnostic mammograms were identified using CPT codes 76090, 76091, 77055, 77056, G0204, G0206. Diagnostic MRI was identified using CPT codes 76093, 76094, 77058, 77059, C8903-C8908 and diagnostic 
ultrasonography was identified using CPT code 76645. According to the published guidelines of the EUSOMA on quality assurance in the diagnosis of breast disease ${ }^{12,13}$, the number of days from abnormality in the form of breast symptom or diagnostic procedure to the confirmed BC diagnosis range from 21 days ( 3 weeks) to 35 days (5 weeks). This range is calculated based on the guideline recommended time interval for each event and the typical sequence of events leading to diagnosis of $\mathrm{BC}$ depending on the type of abnormality. Hence, diagnosis delay was categorized into two groups based on the number of days from initial consultation for abnormality to biopsy-proved BC diagnosis (timely diagnosis - 35 days or less, and delayed diagnosis - greater than 35 days).

Timely Treatment: Timely treatment was defined as the period (in days) between biopsy-proven $\mathrm{BC}$ diagnosis and the initiation of treatment as per the published opinion-based guidelines. Treatment was defined as definitive surgery, neoadjuvant chemotherapy or radiation, whichever came first. The use of prescription drug was not included in the analysis as data pertaining to prescription drugs was not available for these study cohorts. According to the only published BC care guidelines by National Health Service of United Kingdom on timeliness to BC treatment, the initiation of treatment should occur within less than or equal to 4 weeks (28 days) after BC diagnosis ${ }^{14}$. Based on this guideline, timely treatment was categorized into two groups based on number of days from biopsy-proved BC diagnosis to initiation of the treatment (timely treatment - 28 days or less, and delayed treatment - greater than 28 days).

Independent Variables: To identify the factors associated with timely BC care in elderly Medicare FFS with first primary incident BC, the Andersen behavioral healthcare services utilization model was utilized ${ }^{39,40}$. Based on this model, the independent variables were grouped 
into predisposing factors, enabling factors, need-related factors, healthcare use factors and external healthcare environmental factors (Figure 3.1).

Predisposing factors included age at diagnosis (66-69, 70-74, 75-79, 80 and older), and race (white, other), and enabling factors included census tract median household income $(=\langle \$ 35,000 ;>\$ 35,000)$, and census tract percentage of people age $>=25$ years with at least 4 years of college education $(<15 \%,>=15 \%)$. As individual level information on household income and education level are not available with both SEER-Medicare and WVCR-Medicare datasets, census tract information for these two variables was used. Need-related factors consisted of clinical covariates such as stage at diagnosis (insitu, local, regional, distant), grade of tumor (well-differentiated, moderately differentiated, poorly differentiated, undifferentiated/unknown), estrogen-receptor status (positive, negative, borderline/unknown), tumor size $(<1 \mathrm{~cm}, 1-2 \mathrm{~cm}, 2-3 \mathrm{~cm},>3 \mathrm{~cm})$, and comorbidity scores obtained from co-occurring chronic conditions during the 12 months prior to $\mathrm{BC}$ diagnosis identified from the Medicare files using the ICD-9-CM diagnosis codes. As stage at BC diagnosis is considered as a predictor or outcome of delay and as chemotherapy treatment choices are determined by stage, and tumor size, grade of tumor, estrogen receptor status ${ }^{41}$, these variables were included in the analyses. $\mathrm{BC}$ stage at diagnosis was determined according to the SEER Summary staging system that uses all information available in the medical record. It is a combination of the most precise clinical and pathological documentation of the extent of disease ${ }^{42}$. Comorbidity scores were calculated using Charlson comorbidity index to account for possible misclassification using codes from physician claims with macros provided by the National Cancer Institute ${ }^{43-45}$. The comorbidity scores were categorized as 0 (no comorbidity), 1,2+. The number of primary care physicians (PCP) visits 12 months prior to $\mathrm{BC}$ diagnosis was included as a healthcare use factor in the 
model and its median value was utilized to categorize as low or high. External healthcare environmental factors included location of residence (metro, non-metro) and ARF-derived number of hospitals offering oncology-related services and number of hospitals offering BC screening and mammography services in the area of residence, both categorized as low or high based on their respective median values.

\section{Statistical Analyses}

Descriptive statistics and chi-square statistics were used to describe the characteristics and the significant differences in characteristics between the two study cohorts. Unadjusted median time to diagnosis (in days) in women who had any initial consultation and median time to treatment (in days) in women who had any $\mathrm{BC}$ treatment, with their respective $25 \%$ and $75 \%$ inter quartile range (IQR) were estimated for both the study cohorts. These time periods (median days with IQR) were also estimated for all the groups within each independent variable. In addition, a non-parametric test, Kruskal-Wallis test, was performed to assess statistical significant differences in time period for diagnosis and treatment within each group. Bar charts were used to exhibit timely diagnosis and timely treatment based on published opinion-based recommendations for both the Medicare study cohorts. Separate logistic regression models were used to characterize timely diagnosis and timely treatment based on published opinion-based recommendations for both the study populations to identify the predictors of timely care, after controlling for all the independent variables. Logistic regressions were also conducted on timely diagnosis and timely treatment to determine significant differences in timely care between WVMedicare and SEER-Medicare cohorts. In all models, "delayed care” for diagnosis and treatment were used as the reference group for the dependent variables. Another set of logistic regressions to model the association between timely diagnosis and timely treatment and survival, 
were performed to determine significant differences in survival between WV-Medicare and SEER-Medicare cohorts. In these regressions, "death" was used as the reference group for the dependent variable. From all the logistic regressions, the parameter estimates were transformed to odds ratios, and their corresponding $95 \%$ confidence intervals were examined. The findings that were significant with p-values less than 0.05 levels are discussed. All analyses were conducted within statistical analysis system software SAS 9.3 (SAS ${ }^{\circledR}$ version 9.3, SAS Institute Inc., Cary, NC, USA).

\section{RESULTS}

\section{Description of the Study Cohorts}

Table 3.1 describes the WV-Medicare and SEER-Medicare women age 66 and above, diagnosed with first primary incident BC in 2003-2006. Twenty-five percent of women in WV cohort were age 80 and above as compared to $29 \%$ in SEER-Medicare. Approximately $98 \%$ of the WV-Medicare women were white as compared to $89 \%$ in the SEER-Medicare cohort. A higher proportion of WV-Medicare cohort had household income below $\$ 35,000$ (91\%), resided in areas with less than $15 \%$ population with some college education $(51 \%)$, and resided in areas with lower number of hospitals with oncology services (60\%) and BC screening centers (58\%). However, a majority of SEER-Medicare women resided in metro areas (84\%), had household income above $\$ 35,000(75 \%)$, resided in areas with greater than $15 \%$ of population with some college education (70\%), and resided in areas with lower number of hospitals with oncology services $(56 \%)$ and BC screening centers $(51 \%)$.

\section{Median Days for Diagnosis and Treatment for the Study Cohorts}

Table 3.2 describes median time period in days with IQR for diagnosis and treatment in the WV-Medicare and SEER-Medicare cohorts. The median days from initial consultation for 
abnormality to $\mathrm{BC}$ diagnosis was 26 (IQR=12-50 days) for the WV-Medicare cohort as compared to 20 (IQR=8 to 41 days) for the SEER-Medicare cohort. The overall median days from $\mathrm{BC}$ diagnosis to any $\mathrm{BC}$ treatment was 8 (IQR=0-28 days) for the WV-Medicare cohort as compared to 15 (IQR=0-29 days) for the SEER-Medicare cohort. Among women who had their first $\mathrm{BC}$ treatment as surgery, the median days from $\mathrm{BC}$ diagnosis to surgery was 0 (IQR=0-25 days) for the WV-Medicare cohort as compared to 14 (IQR=0-29 days) for the SEER-Medicare cohort. Women who had their first BC treatment as chemotherapy, the median days from BC diagnosis to chemotherapy was 20 (IQR=15-29 days) for the WV-Medicare cohort as compared to 25 (IQR=14-45 days) for the SEER-Medicare cohort. However, women who had their first $\mathrm{BC}$ treatment as radiation therapy, the median days from $\mathrm{BC}$ diagnosis to radiation therapy was 27 (IQR=16-48 days) for the WV-Medicare cohort as compared to 28 (IQR=15-49 days) for the SEER-Medicare cohort.

\section{Median Days for Type of Initial Treatment by Stage at Diagnosis for the Study Cohorts}

Table 3.3 describes median time period in days with IQR for type of initial treatment by stage at $\mathrm{BC}$ diagnosis in the WV-Medicare and SEER-Medicare cohorts. The median days from $\mathrm{BC}$ diagnosis to surgery as the first treatment increased with advancing stage of tumor for the WV-Medicare cohort. It was 0 days for insitu tumor and 10 days for distant tumor. However, the median days from $\mathrm{BC}$ diagnosis to surgery as the first treatment did not vary much by stage at diagnosis for the SEER-Medicare cohort. It was 11 days for insitu tumor and 14 days for distant tumor. The median days from $\mathrm{BC}$ diagnosis to first treatment with chemotherapy ranged from 17 (distant tumor) to 178 (insitu tumor) for the WV-Medicare cohort. While the median days from $\mathrm{BC}$ diagnosis to first treatment with chemotherapy were 21 for insitu, 29 for local, 25 for regional and 24 for distant tumors for women in the SEER-Medicare cohort. The median 
days from BC diagnosis to radiation therapy as the first treatment were 31 for insitu, 27 for local, 17 for regional and 25 for distant tumors for women in the WV-Medicare cohort. However, the median days from $\mathrm{BC}$ diagnosis to radiation therapy as the first treatment were 28 for insitu, 30 for local, 29 for regional and 13 for distant tumors for women in the SEER-Medicare cohort. Median Days for Diagnosis and Treatment within Independent Variables for the Study

\section{Cohorts}

Table 3.4 describes the significant differences in time period in median days with respective IQR for diagnosis and treatment within each independent variable for both the study cohorts. For the WV-Medicare cohort, median time period for diagnosis was significantly different for stage at diagnosis, grade of tumor and tumor size. While for the SEER-Medicare cohort, median time period for diagnosis was significantly different for all the independent variables except census tract income and education. For the WV-Medicare cohort, median time

period for treatment was significantly different for age at diagnosis, census tract income, stage at diagnosis, ER status, and the number of hospitals with oncology services in the area of residence. However, for the SEER-Medicare cohort, median time period for treatment was significantly different for all the variables except mental health condition and number of hospitals with oncology services in the area of residence.

\section{Proportion of Study Cohorts Receiving Timely Diagnosis and Treatment as Per the Published Recommendations}

Figure 3.2 summarizes the proportion of the study cohorts who received timely BC diagnosis of $\mathrm{BC}$ as per the published opinion-based recommendations. Approximately only $63 \%$ of women in the WV-Medicare cohort received timely diagnosis of BC as compared to $71 \%$ of the SEER-Medicare cohort. Figure 3.3 summarizes the proportion of the study cohorts who 
received timely treatment of $\mathrm{BC}$ as per the published opinion-based recommendations. Seventysix percent of the WV-Medicare cohort received timely BC treatment as compared to $73 \%$ of the SEER-Medicare cohort.

\section{Factors Associated with Timely Diagnosis and Timely Treatment}

Table 3.5 describes the factors associated with timely diagnosis and timely treatment as per the published opinion-based recommendations for both the study cohorts. For the WVMedicare cohort, higher census tract household income above $\$ 35,000$ (AOR=3.33, 95\% $\mathrm{CI}=1.41-7.83$ ) and tumor size $>3 \mathrm{~cm}$ was significantly associated with timely diagnosis of BC. While for the SEER-Medicare cohort, age 80 and above, white race (AOR=1.21, 95\% CI=1.121.30), non-metro residence ( $\mathrm{AOR}=1.30,95 \% \mathrm{CI}=1.20-1.40)$, higher census tract education $(\mathrm{AOR}=1.07,95 \% \mathrm{CI}=1.01-1.14)$, distant stage of $\mathrm{BC}$, moderately $(\mathrm{AOR}=1.09,95 \% \mathrm{CI}=1.02-$ 1.16 ) and poorly ( $\mathrm{AOR}=1.26,95 \% \mathrm{CI}=1.17-1.36)$ differentiated grade of tumor, tumor size $>3$ $\mathrm{cm}$, no comorbidity and low PCP visits were significantly associated with timely diagnosis of BC. Surprisingly, no factors were significantly associated with timely treatment of BC for the WV-Medicare cohort. However, for the SEER-Medicare cohort, age 66 to 74 years, white race $(\mathrm{AOR}=1.36,95 \% \mathrm{CI}=1.26-1.47)$, non-metro residence $(\mathrm{AOR}=1.28,95 \% \mathrm{CI}=1.18-1.39)$, earlier stages of $\mathrm{BC}$, tumor size $<3 \mathrm{~cm}$, no comorbidity, high PCP visits $(\mathrm{AOR}=1.06,95 \% \mathrm{CI}=1.01$ 1.12), and low hospitals with oncology services in the area of residence were significantly associated with timely treatment of $\mathrm{BC}$.

Differences in Timely Diagnosis and Treatment between Study Cohorts in a Multivariate Framework

Table 3.6 summarizes the results for timely diagnosis and timely treatment, to identify any significant differences in timeliness between WV-Medicare and SEER-Medicare study 
cohorts. As compared to the SEER-Medicare cohort, the WV-Medicare cohort was significantly less likely to receive timely diagnosis of $\mathrm{BC}(\mathrm{AOR}=0.76,95 \% \mathrm{CI}=0.64-0.90)$, but it was equally likely as the SEER-Medicare cohort to receive timely treatment of $\mathrm{BC}(\mathrm{AOR}=1.00,95 \%$ $\mathrm{CI}=0.83-1.23)$.

\section{Differences in Survival between Study Cohorts with Receipt of Timely Diagnosis and}

\section{Timely Treatment in a Multivariate Framework}

Table 3.7 summarizes the results on probabilities of survival with receipt of timely clinical BC care, to identify any significant differences between WV-Medicare and SEERMedicare study cohorts. As compared to the SEER-Medicare cohort, the WV-Medicare cohort was significantly more likely to be alive at the follow-up period of three years.

\section{DISCUSSION}

In the Institute of Medicine's report Crossing the Quality Chasm, six constructs of healthcare quality are defined ${ }^{46,47}$, out of which timeliness of care is one of the most important aspects of measuring quality of cancer care ${ }^{48}$. Delays in diagnosis and treatment in BC patients lead to high emotional distress in patients ${ }^{6-8,49}$, and also poor health outcomes in terms of compromised survival ${ }^{9}$. Previous studies which evaluated timeliness of BC care in elderly BC patients using nationally representative populations did not use any published recommendations to define timely BC care ${ }^{16-24}$. This is the first study to identify differences in timeliness of BC care (diagnosis, treatment) as per the published opinion-based recommendations from EUSOMA and NICE in elderly women with BC in a rural state such as WV and a nationally representative population from the SEER-Medicare data, and to determine the factors associated with timely $\mathrm{BC}$ care in these study cohorts. The study findings indicate that the two study cohorts were statistically different in terms of most of their characteristics. The median number of days for 
BC diagnosis was higher in WV-Medicare cohort as compared to that from the SEER-Medicare cohort. In addition, WV-Medicare cohort was significantly less likely to receive timely diagnosis of BC as compared to the SEER-Medicare cohort after controlling for all the factors. This difference of timely BC diagnosis between the WV-Medicare and SEER-Medicare cohorts may be a reflection of WV women's social and cultural barriers in form of psychosocial factors such as fear, sense of fatalism, knowledge and beliefs, perceived risk, social norms, physicians' characteristics, and health system factors such as cultural variations in BC detection and followup, or preferences in cancer detection ${ }^{19,50-56}$ which are not measured in this study. Future studies may assess the effects of these factors that may contribute to diagnosis delays in this rural state. Efforts to expedite diagnostic evaluations after any breast abnormality and abnormality in screenings may help reduce untimely BC diagnosis in elderly WV women.

Among the predictors of timely BC diagnosis, higher annual household income was significantly associated with timely diagnosis of BC in the WV-Medicare cohort. This finding was consistent with the previous studies which identified association between lower income and delayed BC diagnosis ${ }^{57-59}$. Again consistent with previous studies, WV women with tumor size less than $1 \mathrm{~cm}$ was associated with delayed $\mathrm{BC}$ diagnosis as compared to women with tumor size greater than $3 \mathrm{~cm}$, thereby emphasizing the prompt evaluation of women with large volume of tumors ${ }^{16,60-62}$.

The median days for initiation of BC treatment after diagnosis was lower in WV women as compared to those from the SEER-Medicare data. This finding is consistent with previous studies ${ }^{16,63}$ in which the authors argued that rural women who may have to travel longer distances for evaluations and treatments might well be referred for treatment on that same day to minimize travel ${ }^{63}$. Also, the median days from initiation of surgery, chemotherapy or radiation 
therapy did not vary much by stage at BC diagnosis for both the study cohorts. Within women who have had surgery as their first BC treatment, those with regional and local stage cancers had higher median days of treatment for the WV-Medicare cohort. Within those who had chemotherapy as their first $\mathrm{BC}$ treatment, women with distant cancer had lowest median days for the WV-Medicare cohort. Furthermore, there were no significant differences in timely treatment of BC between WV-Medicare and SEER-Medicare cohorts after controlling for all the factors. This indicates that rural and low income population in a state such as WV is equally likely to receive timely $\mathrm{BC}$ treatment as the SEER-Medicare population. This finding is remarkable since rural settings are less likely to have specialized equipment or trained healthcare professionals ${ }^{64}$. An interesting finding of this study is that there were no significant predictors of timely BC treatment in the WV-Medicare cohort thereby indicating that several unmeasured factors such as health status, body mass index (BMI), psychosocial factors such as fear, fatalism, knowledge and beliefs, and health system factors may be affecting timely BC treatment in these rural WV women.

Finally, it was found that WV-Medicare cohort had surprisingly higher probability of being alive at the end of the follow-up period of three years after controlling for timeliness of $\mathrm{BC}$ care. Given the prognosis of the disease and higher five-years survival in women with $\mathrm{BC}^{3}$, the follow-up period of three years to model probability of being alive in elderly women who receive timely BC care may not generate robust statistical estimates for this association to make any conclusions in this regards. Future studies to assess the effect of timely BC care in elderly women with $\mathrm{BC}$ on survival and how it varies between the rural setting and the national population, may require a longer follow-up period of at least five to ten years to generate robust conclusions. 
This study's interpretation is limited by the nature of the cancer registry-Medicare linked dataset. Since administrative claims were utilized for the analyses of timeliness of BC care, any healthcare services received outside of the Medicare settings may not be captured which may affect the precision of the estimates. Also, these data could only identify procedures and diagnoses that healthcare providers include on billings on the dates of services and hence could not determine types of $\mathrm{BC}$ symptoms or the sequence of procedures occurred on the same date. For instance, if the diagnostic mammography and MRI had the same claim date for a particular woman then it was not possible to identify which procedure occurred first. In addition, the typical sequence of events which leads to $\mathrm{BC}$ diagnosis depends on whether the abnormality in the breast was first detected by the patient, or the clinician, or through the screening mammogram ${ }^{19}$. Since this study utilized administrative claims data, whether diagnosis of BC was affected by patient-related factors (patient delay) or system-related factors (structural delay) was not identified and hence was not controlled in the analyses. Adjuvant therapy with prescription drugs was not captured in the analyses as these were not covered by Medicare prior to 2007. Several important variables such as annual household income, education level, access to $\mathrm{BC}$ screening centers and hospitals offering oncology services are not available in the cancer registries-Medicare linked databases and hence census tract information for these variables were utilized ${ }^{65}$. Data on some important variables which may affect timeliness of BC care such as health status, severity of comorbidities, and patient preferences were not available. This study included individuals who received BC treatment in the form of surgery, radiation, and chemotherapy within one year after diagnosis and hence the findings cannot be generalized to individuals who do not receive any treatment. As this study is based on observational data, the study findings cannot establish causality. In addition, the findings of this study are only 
generalizable to elderly BC patients covered only by Medicare. Also, the findings are not generalizable to other rural populations. Despite these limitations, this study provides important inputs on the timeliness of $\mathrm{BC}$ care and associated health outcomes in a $\mathrm{BC}$ population that is aged, belongs to a lower socio-economic status, and from a rural state such as WV.

\section{CONCLUSION}

Timely BC diagnosis is a critical concern in a rural state such as WV as women in this state are less likely to get timely $\mathrm{BC}$ diagnosis when compared to their national counterparts, however the chances of their survival are higher. Interventions that address patient, provider and health system factors which contribute to delay in BC diagnosis in WV are needed to be developed and implemented to achieve timely BC diagnosis. 


\section{REFERENCES}

1. Howlader N, Noone A, Krapcho M, et al. SEER Cancer Statistics Review, 1975-2009 (Vintage 2009 populations), National Cancer Institute. bethesda, MD. Based on November 2011 SEER data submission. http://seer.cancer.gov/csr/1975_2009_pops09/. Updated April 2012. Accessed 02/19, 2014.

2. Hillner BE, Penberthy L, Desch CE, McDonald MK, Smith TJ, Retchin SM. Variation in staging and treatment of local and regional breast cancer in the elderly. Breast Cancer Res Treat. 1996;40(1):75-86.

3. National Cancer Institute. Cancer query system: SEER survival statistics. http://seer.cancer.gov/canques/survival.html. Updated July 12, 2014. Accessed 02/19, 2014.

4. Stone MD, Norton S, Mendez JE, Hirsch E. Positive impact of a breast-health triaging system on breast-care access and physician satisfaction. Am J Surg. 2007;194(4):482-487.

5. Toomey DP, Cahill RA, Birido N, et al. Rapid assessment breast clinics--evolution through audit. Eur J Cancer. 2006;42(17):2961-2967.

6. Ganz PA. Quality of life across the continuum of breast cancer care. Breast J. 2000;6(5):324330.

7. Boudreau RM, McNally C, Rensing EM, Campbell MK. Improving the timeliness of written patient notification of mammography results by mammography centers. Breast J. 2004;10(1):1019.

8. Olivotto IA, Borugian MJ, Kan L, et al. Improving the time to diagnosis after an abnormal screening mammogram. Can J Public Health. 2001;92(5):366-371.

9. Richards MA, Westcombe AM, Love SB, Littlejohns P, Ramirez AJ. Influence of delay on survival in patients with breast cancer: A systematic review. Lancet. 1999;353(9159):1119-1126.

10. Kaufman CS, Landercasper J. Can we measure the quality of breast surgical care? Ann Surg Oncol. 2011;18(11):3053-3060.

11. Landercasper J, Linebarger JH, Ellis RL, et al. A quality review of the timeliness of breast cancer diagnosis and treatment in an integrated breast center. J Am Coll Surg. 2010;210(4):449455.

12. Perry NM, EUSOMA Working Party. Quality assurance in the diagnosis of breast disease. EUSOMA working party. Eur J Cancer. 2001;37(2):159-172. 
13. Perry N, Broeders M, de Wolf C, et al. European guidelines for quality assurance in breast cancer screening and diagnosis. Fourth edition--summary document. Ann Oncol.

2008;19(4):614-622.

14. Improving outcomes in breast cancer-manual update. National Institute for Clinical Excellence, UK. 2002;1-84257-188-5(02/19).

15. Malin JL, Schneider EC, Epstein AM, Adams J, Emanuel EJ, Kahn KL. Results of the national initiative for cancer care quality: How can we improve the quality of cancer care in the United States? J Clin Oncol. 2006;24(4):626-634.

16. Gorin SS, Heck JE, Cheng B, Smith SJ. Delays in breast cancer diagnosis and treatment by racial/ethnic group. Arch Intern Med. 2006;166(20):2244-2252.

17. Gwyn K, Bondy ML, Cohen DS, et al. Racial differences in diagnosis, treatment, and clinical delays in a population-based study of patients with newly diagnosed breast carcinoma. Cancer. 2004;100(8):1595-1604.

18. Lobb R, Allen JD, Emmons KM, Ayanian JZ. Timely care after an abnormal mammogram among low-income women in a public breast cancer screening program. Arch Intern Med. 2010;170(6):521-528.

19. Elmore JG, Nakano CY, Linden HM, Reisch LM, Ayanian JZ, Larson EB. Racial inequities in the timing of breast cancer detection, diagnosis, and initiation of treatment. Med Care. 2005;43(2):141-148.

20. Richardson LC, Royalty J, Howe W, Helsel W, Kammerer W, Benard VB. Timeliness of breast cancer diagnosis and initiation of treatment in the national breast and cervical cancer early detection program, 1996-2005. Am J Public Health. 2010;100(9):1769-1776.

21. Bilimoria KY, Ko CY, Tomlinson JS, et al. Wait times for cancer surgery in the United States: Trends and predictors of delays. Ann Surg. 2011;253(4):779-785.

22. McLaughlin JM, Anderson RT, Ferketich AK, Seiber EE, Balkrishnan R, Paskett ED. Effect on survival of longer intervals between confirmed diagnosis and treatment initiation among lowincome women with breast cancer. J Clin Oncol. 2012;30(36):4493-4500.

23. Halpern MT, Holden DJ. Disparities in timeliness of care for U.S. Medicare patients diagnosed with cancer. Curr Oncol. 2012;19(6):e404-413.

24. Bleicher RJ, Ruth K, Sigurdson ER, et al. Preoperative delays in the US Medicare population with breast cancer. J Clin Oncol. 2012;30(36):4485-4492. 
25. U.S. Census Bureau. Persons 25 years old and over with a bachelor's degree or more, 2008. Washington, DC: U.S. Census Bureau.

http://www.census.gov/compendia/statab/2010/ranks/rank19.html. Updated 2010. Accessed 02/24, 2014.

26. U.S. Census Bureau. Persons below the poverty level, 2008. Washington, DC: U.S. Census Bureau. http://www.census.gov/compendia/statab/2010/ranks/rank34.html. Updated 2010. Accessed 02/24, 2014.

27. Kaiser State Health Facts. Overweight and obesity rates for adults by sex, 2009. Menlo Park, CA: Kaiser Family Foundation. http://www.statehealthfacts.org. Updated 2009. Accessed 02/24, 2014.

28. Kaiser State Health Facts. Percent of adults who smoke by sex, 2008. Menlo Park, CA: Kaiser Family Foundation. http://www.statehealthfacts.org. Updated 2008. Accessed 02/24, 2014.

29. SEER State Cancer Profiles 2009.

http://statecancerprofiles.cancer.gov/map/map.withimage.php?00\&157\&055\&00\&2\&01\&1\&1\& 6\&0\#map. Updated 2009. Accessed 02/19, 2014.

30. SEER State Cancer Profiles 2009.

http://statecancerprofiles.cancer.gov/map/map.withimage.php?00\&157\&055\&00\&2\&02\&1\&1\& 6\&0\#map. Updated 2009. Accessed 02/19, 2014.

31. Wingo PA, Tucker TC, Jamison PM, et al. Cancer in Appalachia, 2001-2003. Cancer. 2008;112(1):181-192.

32. Lengerich EJ, Chase GA, Beiler J, Darnell M. Increased risk of unknown stage cancer from residence in a rural area: Health disparities with poverty and minority status. Hershey, PA: Pennsylvania State University and the Penn State Cancer Institute, Department of Health Evaluation Sciences. 2006.

33. State Cancer Profiles. Incidence and mortality rate reports for West Virginia by county, 2010. Bethesda, MD: National Cancer Institute. http://statecancerprofiles.cancer.gov/. Updated 2010. Accessed 02/24, 2014.

34. United States Cancer Statistics. State vs. National Rates: 2006, female, West Virginia. Atlanta, GA: Centers for Disease Control and Prevention (CDC). http://apps.nccd.cdc.gov/uscs/. Updated 2010. Accessed 02/24, 2014.

35. United States Cancer Statistics. Rankings by state: 2006, male and female, all cancer sites combined. Atlanta, GA: Centers for Disease Control and Prevention (CDC).

http://apps.nccd.cdc.gov/uscs/. Updated 2010. Accessed 02/24, 2014. 
36. Cancer Incidence in West Virginia, 1993-2009, West Virginia Cancer Registry, Charleston, WV, 2012.

37. Nadpara PA, Madhavan SS. Linking Medicare, Medicaid, and cancer registry data to study the burden of cancers in West Virginia. Medicare and Medicaid Research Review. 2012;2(4):02/25/2014.

38. Warren JL, Klabunde CN, Schrag D, Bach PB, Riley GF. Overview of the SEER-Medicare data: Content, research applications, and generalizability to the United States elderly population. Med Care. 2002;40(8 Suppl):IV-3-18.

39. Andersen RM. Revisiting the behavioral model and access to medical care: Does it matter? $J$ Health Soc Behav. 1995;36(1):1-10.

40. Andersen R, Newman JF. Societal and individual determinants of medical care utilization in the United Sates. Milbank Mem Fund Q Health Soc. 1973;51(1):95-124.

41. Harlan LC, Abrams J, Warren JL, Clegg L, Stevens J, Ballard-Barbash R. Adjuvant therapy for breast cancer: Practice patterns of community physicians. J Clin Oncol. 2002;20(7):18091817.

42. Young JL Jr, Roffers SD, Ries LAG, Fritz AG, Hurlbut AA. (eds). SEER summary staging manual-2000: Codes and coding instructions, National Cancer Institute, NIH pub. no. 01-4969. . 2001.

43. Klabunde CN, Potosky AL, Legler JM, Warren JL. Development of a comorbidity index using physician claims data. J Clin Epidemiol. 2000;53(12):1258-1267.

44. Charlson ME, Pompei P, Ales KL, MacKenzie CR. A new method of classifying prognostic comorbidity in longitudinal studies: Development and validation. J Chronic Dis. 1987;40(5):373-383.

45. National Cancer Institute: SEER-Medicare: Calculation of comorbidity weights. . http://healthservices.cancer.gov/seermedicare/program/comorbidity.html. Updated 2013. Accessed 02/25, 2014.

46. Institute of Medicine (US). Committee on Quality of Health Care in America. Crossing the quality chasm: A new health system for the 21st century. National Academies Press; 2001.

47. Agency for Healthcare Research and Quality, Rockville, MD, 2012 National Healthcare Quality Report. June 2013;13-0002.

48. Malin JL, Asch SM, Kerr EA, McGlynn EA. Evaluating the quality of cancer care: Development of cancer quality indicators for a global quality assessment tool. Cancer. 2000;88(3):701-707. 
49. Jones RV, Greenwood B. Breast cancer: Causes of patients' distress identified by qualitative analysis. Br J Gen Pract. 1994;44(385):370-371.

50. Facione NC, Miaskowski C, Dodd MJ, Paul SM. The self-reported likelihood of patient delay in breast cancer: New thoughts for early detection. Prev Med. 2002;34(4):397-407..

51. Facione NC. Delay versus help seeking for breast cancer symptoms: A critical review of the literature on patient and provider delay. Soc Sci Med. 1993;36(12):1521-1534.

52. Dennis CR, Gardner B, Lim B. Analysis of survival and recurrence vs. patient and doctor delay in treatment of breast cancer. Cancer. 1975;35(3):714-720.

53. Kerner JF, Yedidia M, Padgett D, et al. Realizing the promise of breast cancer screening: Clinical follow-up after abnormal screening among black women. Prev Med. 2003;37(2):92-101.

54. Lyttle NL, Stadelman K. Assessing awareness and knowledge of breast and cervical cancer among Appalachian women. Prev Chronic Dis. 2006;3(4):A125.

55. Leslie NS, Deiriggi P, Gross S, DuRant E, Smith C, Veshnesky JG. Knowledge, attitudes, and practices surrounding breast cancer screening in educated Appalachian women. Oncol Nurs Forum. 2003;30(4):659-667.

56. Schoenberg NE, Kruger TM, Bardach S, Howell BM. Appalachian women's perspectives on breast and cervical cancer screening. Rural Remote Health. 2013;13(3):2452.

57. Goldman LE, Walker R, Hubbard R, Kerlikowske K, Breast Cancer Surveillance Consortium. Timeliness of abnormal screening and diagnostic mammography follow-up at facilities serving vulnerable women. Med Care. 2013;51(4):307-314.

58. Kerlikowske K. Timeliness of follow-up after abnormal screening mammography. Breast Cancer Res Treat. 1996;40(1):53-64.

59. Kaplan CP, Crane LA, Stewart S, Juarez-Reyes M. Factors affecting follow-up among lowincome women with breast abnormalities. J Womens Health (Larchmt). 2004;13(2):195-206.

60. Bairati I, Jobin E, Fillion L, Larochelle M, Vincent L. Determinants of delay for breast cancer diagnosis. Cancer Detect Prev. 2007;31(4):323-331.

61. Ganry O, Peng J, Dubreuil A. Influence of abnormal screens on delays and prognostic indicators of screen-detected breast carcinoma. J Med Screen. 2004;11(1):28-31.

62. Olivotto IA, Gomi A, Bancej C, et al. Influence of delay to diagnosis on prognostic indicators of screen-detected breast carcinoma. Cancer. 2002;94(8):2143-2150. 
63. Caplan LS, May DS, Richardson LC. Time to diagnosis and treatment of breast cancer: Results from the National Breast and Cervical Cancer Early Detection Program, 1991-1995. Am J Public Health. 2000;90(1):130-134.

64. Vernon SW, Tilley BC, Neale AV, Steinfeldt L. Ethnicity, survival, and delay in seeking treatment for symptoms of breast cancer. Cancer. 1985;55(7):1563-1571.

65. Krieger N. Overcoming the absence of socioeconomic data in medical records: Validation and application of a census-based methodology. Am J Public Health. 1992;82(5):703-710. 


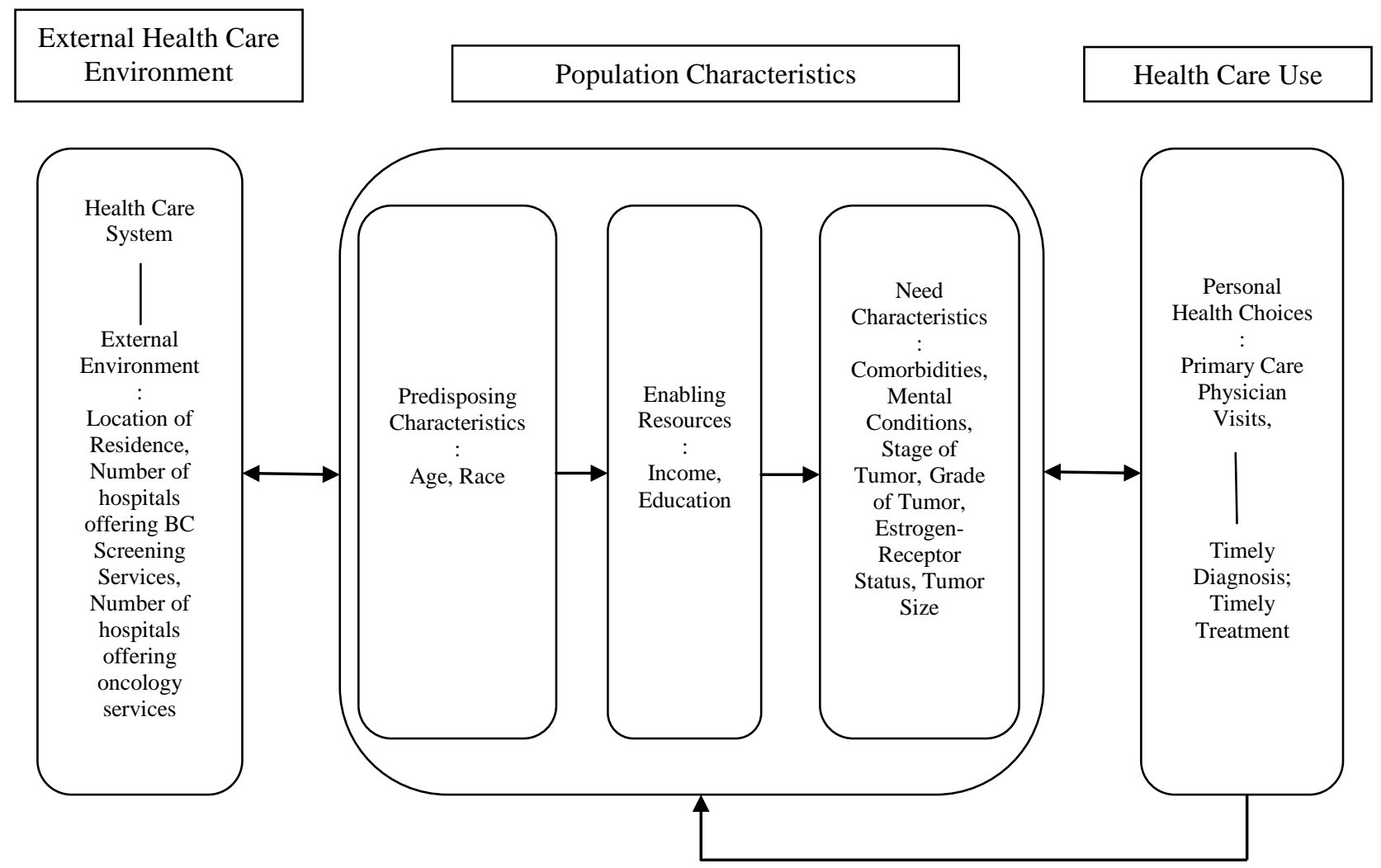

Figure 3.1: The Andersen Behavioral Model for Health Care Utilization (For Aim 2) 


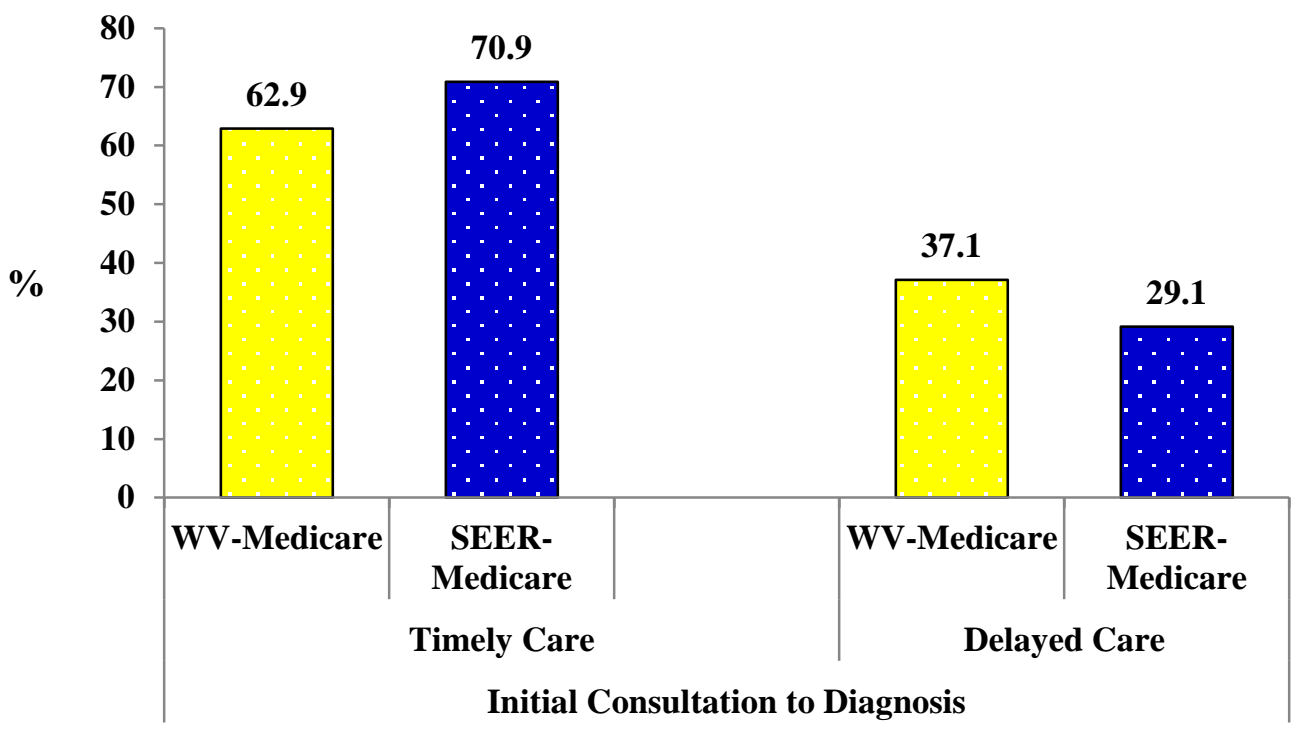

Figure 3.2: Proportion of Study Cohorts Receiving Timely Breast Cancer Diagnosis as Per the Published Recommendations

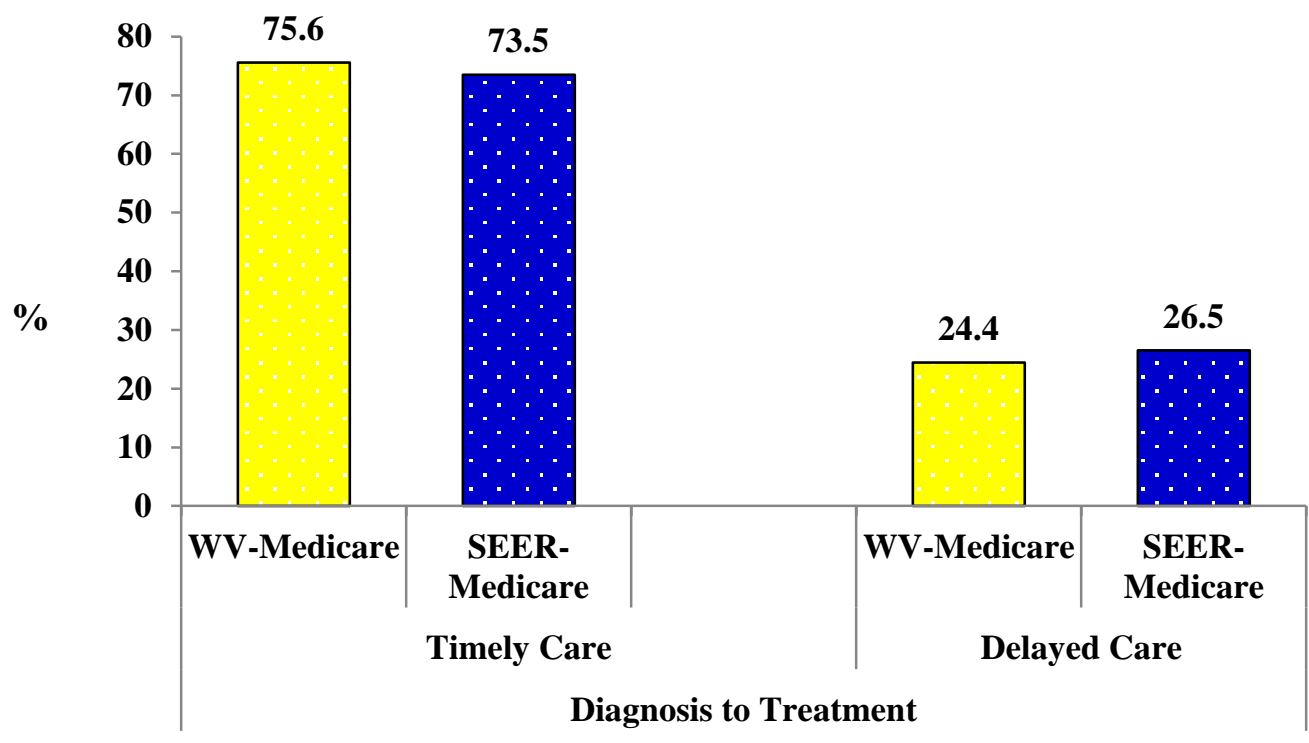

Figure 3.3: Proportion of Study Cohorts Receiving Timely Breast Cancer Treatment as Per the Published Recommendations 
Table 3.1

Description of the Study Cohorts

2003-2006

\begin{tabular}{|c|c|c|c|c|c|}
\hline \multirow[t]{2}{*}{ Variables } & \multicolumn{2}{|c|}{$\begin{array}{c}\text { WV-Medicare } \\
(\mathrm{N}=\mathbf{1 , 3 8 8})\end{array}$} & \multicolumn{2}{|c|}{$\begin{array}{c}\text { SEER-Medicare } \\
(\mathbf{N}=\mathbf{3 6 , 2 7 6 )}\end{array}$} & \multirow[b]{2}{*}{ Sig } \\
\hline & $\mathbf{N}$ & $\%$ & $\mathbf{N}$ & $\%$ & \\
\hline Age at Diagnosis & & & & & $* * * *$ \\
\hline $66-69$ & 275 & 19.8 & 7,975 & 22.0 & \\
\hline $70-74$ & 385 & 27.7 & 9,079 & 25.0 & \\
\hline $75-79$ & 379 & 27.3 & 8,624 & 23.8 & \\
\hline $80,+$ & 349 & 25.1 & 10,598 & 29.2 & \\
\hline Race & & & & & $* * *$ \\
\hline White & 1,355 & 97.6 & 32,124 & 88.6 & \\
\hline Other & 33 & 2.4 & 4,152 & 11.4 & \\
\hline Location of Residence & & & & & $* * *$ \\
\hline Metro & 762 & 54.9 & 30,349 & 83.7 & \\
\hline Non-metro & 626 & 45.1 & 5,927 & 16.3 & \\
\hline Census Tract Household Income & & & & & $* * *$ \\
\hline LE $\$ 35,000$ & 1,268 & 91.4 & 8,949 & 24.7 & \\
\hline GT $\$ 35,000$ & 120 & 8.6 & 27,327 & 75.3 & \\
\hline Census Tract Education & & & & & $* * *$ \\
\hline LT $15 \%$ pop. with CE & 704 & 50.7 & 11,005 & 30.3 & \\
\hline GE $15 \%$ pop. with CE & 684 & 49.3 & 25,271 & 69.7 & \\
\hline Stage at Diagnosis & & & & & * \\
\hline Insitu & 209 & 15.1 & 5,982 & 16.5 & \\
\hline Local & 866 & 62.4 & 20,982 & 57.8 & \\
\hline Regional & 274 & 19.8 & 8,166 & 22.5 & \\
\hline Distant & 38 & 2.7 & 1,146 & 3.2 & \\
\hline Grade of Tumor & & & & & $* * *$ \\
\hline Well Differentiated & 325 & 23.4 & 7,762 & 21.4 & \\
\hline Moderately Differentiated & 473 & 34.1 & 14,258 & 39.3 & \\
\hline Poorly Differentiated & 306 & 22.0 & 9,252 & 25.5 & \\
\hline Undifferentiated/Unknown & 284 & 20.5 & 5,004 & 13.8 & \\
\hline ER Status & & & & & **** \\
\hline Positive & 628 & 45.2 & 25,018 & 69.0 & \\
\hline Negative & 126 & 9.1 & 5,114 & 14.1 & \\
\hline Borderline/Unknown & 634 & 45.7 & 6,144 & 16.9 & \\
\hline Tumor Size & & & & & **** \\
\hline$<1 \mathrm{~cm}$ & 290 & 29.5 & 7,992 & 22.6 & \\
\hline $1-2 \mathrm{~cm}$ & 409 & 41.6 & 13,809 & 39.1 & \\
\hline $2-3 \mathrm{~cm}$ & 158 & 16.1 & 5,485 & 15.5 & \\
\hline$>3 \mathrm{~cm}$ & 126 & 12.8 & 7,999 & 22.7 & \\
\hline Comorbidity & & & & & **** \\
\hline 0 & 716 & 51.6 & 20,890 & 57.6 & \\
\hline 1 & 416 & 30.0 & 9,796 & 27.0 & \\
\hline $2,+$ & 256 & 18.4 & 5,590 & 15.4 & \\
\hline Mental Condition & & & & & **** \\
\hline Yes & 134 & 9.7 & 2,256 & 6.2 & \\
\hline No & 1,254 & 90.3 & 34,020 & 93.8 & \\
\hline \multicolumn{6}{|l|}{ PCP visits } \\
\hline High & 689 & 49.6 & 17,851 & 49.2 & \\
\hline Low & 699 & 50.4 & 18,425 & 50.8 & \\
\hline
\end{tabular}


Table 3.1

Description of the Study Cohorts

2003-2006

\begin{tabular}{|c|c|c|c|c|c|}
\hline \multirow[t]{2}{*}{ Variables } & \multicolumn{2}{|c|}{$\begin{array}{c}\text { WV-Medicare } \\
(\mathbf{N}=\mathbf{1 , 3 8 8})\end{array}$} & \multicolumn{2}{|c|}{$\begin{array}{c}\text { SEER-Medicare } \\
(\mathrm{N}=\mathbf{3 6 , 2 7 6 )}\end{array}$} & \multirow[b]{2}{*}{ Sig } \\
\hline & $\mathbf{N}$ & $\%$ & $\mathbf{N}$ & $\%$ & \\
\hline Total BC Screening Centers & & & & & $* * *$ \\
\hline High & 587 & 42.3 & 17,714 & 48.8 & \\
\hline Low & 801 & 57.7 & 18,562 & 51.2 & \\
\hline Total Hospitals with Oncology Services & & & & & $* * *$ \\
\hline High & 551 & 39.7 & 16,157 & 44.5 & \\
\hline Low & 837 & 60.3 & 20,119 & 55.5 & \\
\hline
\end{tabular}

Note: Based on 1,388 elderly WV-Medicare women and 36,276 elderly SEER-Medicare women, age 66 and above diagnosed with primary incident breast cancer from 2003 to 2006. FFS, Fee-for-service; WV, West Virginia; SEER, Surveillance, Epidemiology, and End Results; ER, Estrogen-receptor; PCP, Primary Care Physicians, BC, Breast Cancer; CE, College Education; pop., population; LE, Less than or equal to; GT, Greater than; LT, Less than; GE, Greater than or equal to; Sig, Significance. Asterisks represent statistically significant group differences based on $\chi 2$ tests: $* * * \mathrm{P}<0.001 ; * * 001<=\mathrm{P}<.01$; $* .01<=\mathrm{P}<.05$.

Table 3.2

Median Days in Diagnosis and Treatment for the Study Cohorts 2003-2006

\begin{tabular}{|c|c|c|c|c|c|c|}
\hline \multirow[b]{2}{*}{ Type of Delay } & \multicolumn{3}{|c|}{ WV-Medicare $(\mathrm{N}=1,388)$} & \multicolumn{3}{|c|}{ SEER-Medicare $(\mathrm{N}=36,276)$} \\
\hline & $\mathbf{N}$ & $\begin{array}{c}\text { Median } \\
\text { (Days) }\end{array}$ & $\begin{array}{c}\text { 25-75\% IQR } \\
\text { (Days) }\end{array}$ & $\mathbf{N}$ & $\begin{array}{c}\text { Median } \\
\text { (Days) }\end{array}$ & $\begin{array}{c}\text { 25-75\% IQR } \\
\text { (Days) }\end{array}$ \\
\hline Initial Consultation to Diagnosis & 892 & 26 & 12 to 50 & 35,717 & 20 & 8 to 41 \\
\hline Diagnosis to Treatment & 851 & 8 & 0 to 28 & 34,695 & 15 & 0 to 29 \\
\hline Diagnosis to Surgery & 738 & 0 & 0 to 25 & 31,779 & 14 & 0 to 28 \\
\hline Diagnosis to Chemotherapy & 39 & 20 & 15 to 29 & 1,329 & 25 & 14 to 45 \\
\hline Diagnosis to Radiation & 74 & 27 & 16 to 48 & 1,587 & 28 & 15 to 49 \\
\hline
\end{tabular}

Note: Based on 1,388 elderly WV-Medicare women and 36,276 elderly SEER-Medicare women, age 66 and above diagnosed with primary incident breast cancer from 2003 to 2006. WV, West Virginia; SEER, Surveillance, Epidemiology, and End Results; IQR, Inter Quartile Range. 
Table 3.3

Median Days (IQR) for Type of Initial Treatment by Stage at Diagnosis

For the Study Cohorts

2003-2006

\begin{tabular}{lcccccc}
\hline WV-Medicare & SEER-Medicare & WV-Medicare & SEER-Medicare & WV-Medicare & SEER-Medicare \\
\hline $\begin{array}{l}\text { Stage at } \\
\text { Diagnosis }\end{array}$ & $\begin{array}{c}\text { Diagnosis to } \\
\text { Surgery }\end{array}$ & $\begin{array}{c}\text { Diagnosis to } \\
\text { Surgery }\end{array}$ & $\begin{array}{c}\text { Diagnosis to } \\
\text { Chemotherapy }\end{array}$ & $\begin{array}{c}\text { Diagnosis to } \\
\text { Chemotherapy }\end{array}$ & $\begin{array}{c}\text { Diagnosis to } \\
\text { Radiation }\end{array}$ & $\begin{array}{c}\text { Diagnosis to } \\
\text { Radiation }\end{array}$ \\
\hline Insitu & $0(0$ to 20$)$ & $11(0$ to 28$)$ & $178(178$ to 178$)$ & $21(8$ to 34$)$ & $31(24$ to 64$)$ & $28(19$ to 46$)$ \\
Local & $0(0$ to 26$)$ & $14(0$ to 28$)$ & $20(15$ to 51$)$ & $29(15$ to 50$)$ & $27(16$ to 48$)$ & $30(17$ to 49$)$ \\
Regional & $9(0$ to 25$)$ & $15(0$ to 29$)$ & $21(11$ to 27$)$ & $25(14$ to 42$)$ & $17(14$ to 55$)$ & $29(15$ to 54$)$ \\
Distant & $10(0$ to 24$)$ & $14(0$ to 29$)$ & $17(15$ to 31$)$ & $24(14$ to 49$)$ & $25(4$ to 44$)$ & $13(4$ to 42$)$ \\
\hline
\end{tabular}

Note: Based on 1,388 elderly WV-Medicare women and 36,276 elderly SEER-Medicare women, age 66 and above diagnosed with primary incident breast cancer from 2003 to 2006. WV, West Virginia; SEER, Surveillance, Epidemiology, and End Results; IQR, Inter Quartile Range. 
Table 3.4

Median Days in Diagnosis and Treatment within Independent Variables for the Study Cohorts 2003-2006

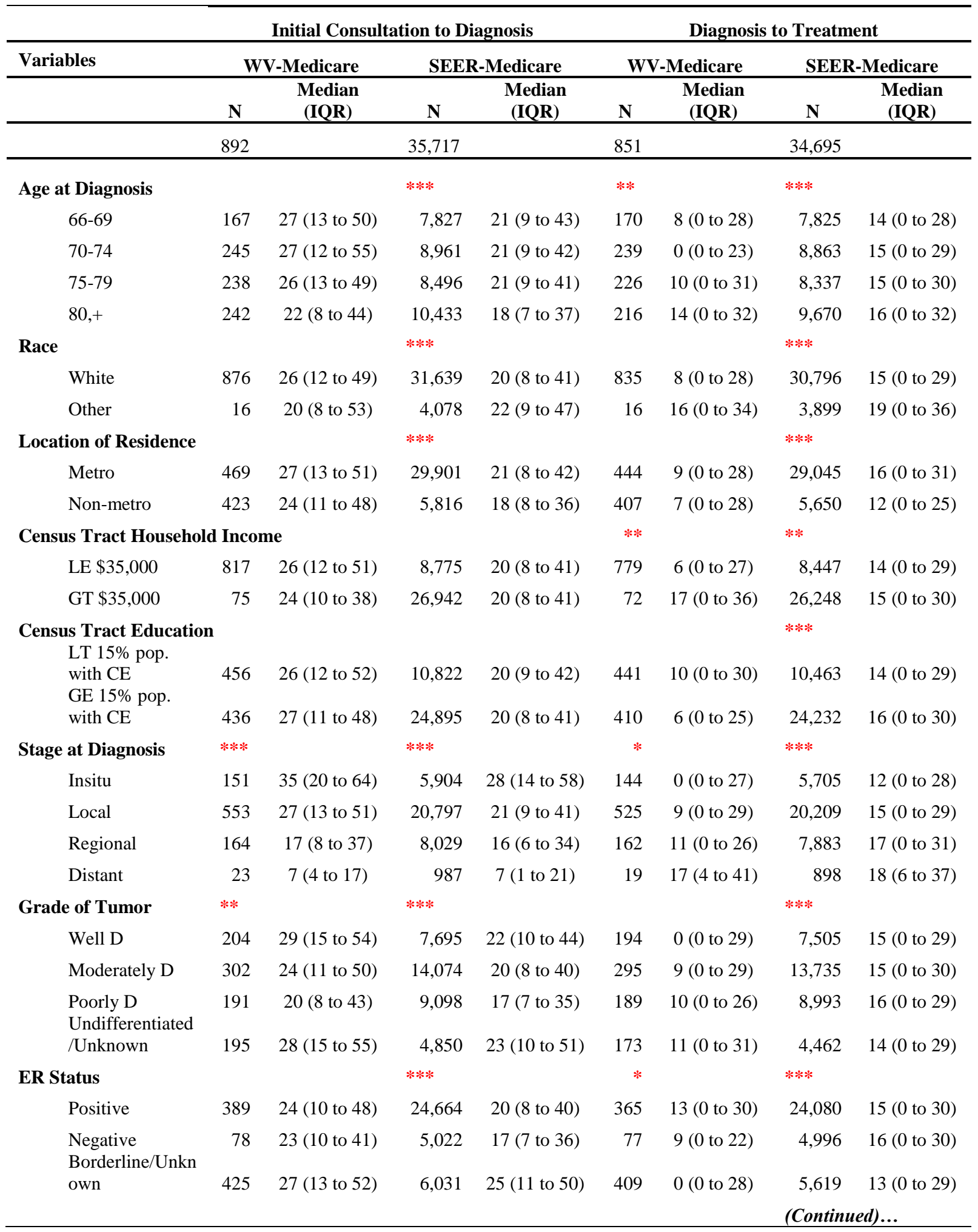


Table 3.4

Median Days in Diagnosis and Treatment within Independent Variables for the Study Cohorts 2003-2006

\begin{tabular}{|c|c|c|c|c|c|c|c|c|}
\hline \multirow{3}{*}{ Variables } & \multicolumn{4}{|c|}{ Initial Consultation to Diagnosis } & \multicolumn{4}{|c|}{ Diagnosis to Treatment } \\
\hline & \multicolumn{2}{|c|}{ WV-Medicare } & \multicolumn{2}{|c|}{ SEER-Medicare } & \multicolumn{2}{|c|}{ WV-Medicare } & \multicolumn{2}{|c|}{ SEER-Medicare } \\
\hline & $\mathbf{N}$ & $\begin{array}{c}\text { Median } \\
\text { (IQR) } \\
\end{array}$ & $\mathbf{N}$ & $\begin{array}{c}\text { Median } \\
\text { (IQR) }\end{array}$ & $\mathbf{N}$ & $\begin{array}{c}\text { Median } \\
(\text { IQR }) \\
\end{array}$ & $\mathbf{N}$ & $\begin{array}{c}\text { Median } \\
(\text { IQR }) \\
\end{array}$ \\
\hline & 892 & & 35,717 & & 851 & & 34,695 & \\
\hline Tumor Size & $* * *$ & & $* * *$ & & & & $* * *$ & \\
\hline$<1 \mathrm{~cm}$ & 191 & $29(17$ to 49$)$ & 7,921 & $26(12$ to 52$)$ & 185 & $0(0$ to 31$)$ & 7,824 & $13(0$ to 28$)$ \\
\hline $1-2 \mathrm{~cm}$ & 255 & $26(10$ to 48$)$ & 13,675 & 20 (8 to 39$)$ & 240 & $14(0$ to 29$)$ & 13,379 & $14(0$ to 29$)$ \\
\hline $2-3 \mathrm{~cm}$ & 99 & $19(8$ to 44$)$ & 5,430 & $16(7$ to 34$)$ & 90 & $12(0$ to 28$)$ & 5,279 & $16(0$ to 30$)$ \\
\hline$>3 \mathrm{~cm}$ & 75 & 13 (4 to 29$)$ & 7,753 & 17 (6 to 38$)$ & 72 & $12(0$ to 25$)$ & 7,341 & $17(0$ to 32$)$ \\
\hline Comorbidity & & & $* * *$ & & & & $* * *$ & \\
\hline 0 & 458 & $24(12$ to 47$)$ & 20,550 & $20(8$ to 40$)$ & 438 & $5(0$ to 28$)$ & 20,111 & 15 (0 to 29$)$ \\
\hline 1 & 268 & 27 (10 to 49) & 9,650 & 21 (9 to 42$)$ & 265 & $10(0$ to 29$)$ & 9,361 & 15 (0 to 29$)$ \\
\hline $2,+$ & 166 & $29(13$ to 60$)$ & 5,517 & $22(9$ to 45$)$ & 148 & $9(0$ to 29$)$ & 5,223 & $17(0$ to 33$)$ \\
\hline Mental Condition & & & $*$ & & & & & \\
\hline Yes & 87 & $23(11$ to 49$)$ & 2,227 & 21 (9 to 42$)$ & 83 & $9(0$ to 28$)$ & 2,104 & $14(0$ to 29$)$ \\
\hline No & 805 & $26(12$ to 50$)$ & 33,490 & $20(8$ to 41$)$ & 768 & $7(0$ to 28$)$ & 32,591 & 15 (0 to 29$)$ \\
\hline PCP visits & & & $* * *$ & & & & $* * *$ & \\
\hline High & 455 & 27 (12 to 53$)$ & 17,635 & $22(10$ to 45$)$ & 430 & $7(0$ to 28$)$ & 17,004 & $15(0$ to 29$)$ \\
\hline Low & 437 & 25 (11 to 48$)$ & 18,082 & 19 (7 to 37$)$ & 421 & $9(0$ to 28$)$ & 17,691 & $15(0$ to 30$)$ \\
\hline Total BC Screenin & ters & & & & $* *$ & & $* * *$ & \\
\hline High & 374 & $27(13$ to 52$)$ & 17,449 & 21 (8 to 42$)$ & 353 & $2(0$ to 22$)$ & 16,929 & $18(0$ to 33$)$ \\
\hline Low & 518 & 26 (11 to 48$)$ & 18,268 & $20(8$ to 40$)$ & 498 & 13 (0 to 32$)$ & 17,766 & 13 (0 to 27$)$ \\
\hline Total Hospitals wi & colog. & Services & $* * *$ & & $* *$ & & & \\
\hline High & 351 & $27(12$ to 51$)$ & 15,924 & 21 (8 to 43$)$ & 330 & $1(0$ to 23$)$ & 15,427 & $19(0$ to 33$)$ \\
\hline Low & 541 & $26(12$ to 48$)$ & 19,793 & $20(8$ to 40$)$ & 521 & $13(0$ to 31$)$ & 19,268 & 13 (0 to 27$)$ \\
\hline
\end{tabular}

Note: Based on 1,388 elderly WV-Medicare women and 36,276 elderly SEER-Medicare women, age 66 and above diagnosed with primary incident breast cancer from 2003 to 2006. WV, West Virginia; SEER, Surveillance, Epidemiology, and End Results; CE, College Education; pop., population; D, Differentiated; ER, Estrogen-receptor; PCP, Primary Care Physicians, BC, Breast Cancer; LE, Less than or equal to; GT, Greater than; LT, Less than; GE, Greater than or equal to; IQR, Inter Quartile Range; Sig, Significance. Asterisks represent statistically significant group differences based on Kruskal-Wallis tests: $* * * \mathrm{P}<0.001 ; * * 001<=\mathrm{P}<.01 ; * .01<=\mathrm{P}<.05$. 
Table 3.5

Factors Associated with Timely Diagnosis and Timely Treatment Separately for the Study Cohorts

Adjusted Odds Ratios and 95\% Confidence Intervals from Logistic Regressions

2003-2006

\begin{tabular}{|c|c|c|c|c|c|c|c|c|c|c|c|c|}
\hline & \multicolumn{3}{|c|}{ WV-Medicare } & \multicolumn{3}{|c|}{ SEER-Medicare } & \multicolumn{3}{|c|}{ WV-Medicare } & \multicolumn{3}{|c|}{ SEER-Medicare } \\
\hline & \multicolumn{3}{|c|}{ Timely Diagnosis } & \multicolumn{3}{|c|}{ Timely Diagnosis } & \multicolumn{3}{|c|}{ Timely Treatment } & \multicolumn{3}{|c|}{ Timely Treatment } \\
\hline \multirow[t]{2}{*}{ Variables } & \multicolumn{3}{|c|}{ Model 1} & \multicolumn{3}{|c|}{ Model 2} & \multicolumn{3}{|c|}{ Model 3} & \multicolumn{3}{|c|}{ Model 4} \\
\hline & AOR & $95 \% \mathrm{CI}$ & Sig & AOR & $95 \% \mathrm{CI}$ & Sig & AOR & $95 \% \mathrm{CI}$ & Sig & AOR & $95 \% \mathrm{CI}$ & Sig \\
\hline \multicolumn{13}{|l|}{ Age at Diagnosis } \\
\hline $66-69$ & 0.98 & {$[0.59,1.64]$} & & 0.81 & {$[0.76,0.87]$} & $* * *$ & 1.55 & {$[0.87,2.77]$} & & 1.23 & {$[1.14,1.32]$} & $* * *$ \\
\hline $70-74$ & 0.79 & {$[0.49,1.28]$} & & 0.83 & {$[0.78,0.89]$} & $* * *$ & 1.72 & {$[0.99,3.01]$} & & 1.17 & {$[1.09,1.25]$} & $* * *$ \\
\hline $75-79$ & 0.88 & {$[0.54,1.42]$} & & 0.87 & {$[0.81,0.93]$} & $* * *$ & 1.07 & {$[0.63,1.80]$} & & 1.07 & {$[1.00,1.14]$} & $*$ \\
\hline $80,+$ & 1 & & & 1 & & & 1 & & & 1 & & \\
\hline \multicolumn{13}{|l|}{ Race } \\
\hline White & 1.31 & {$[0.25,6.75]$} & & 1.21 & {$[1.12,1.30]$} & $* * *$ & 0.91 & {$[0.09,8.84]$} & & 1.36 & {$[1.26,1.47]$} & $* * *$ \\
\hline Other & 1 & & & 1 & & & 1 & & & 1 & & \\
\hline \multicolumn{13}{|l|}{ Location of Residence } \\
\hline Metro & 1 & & & 1 & & & 1 & & & 1 & & \\
\hline Non-metro & 1.40 & {$[0.91,2.17]$} & & 1.30 & {$[1.20,1.40]$} & $* * *$ & 1.47 & {$[0.90,2.40]$} & & 1.28 & {$[1.18,1.39]$} & $* * *$ \\
\hline \multicolumn{13}{|c|}{ Census Tract Household Income } \\
\hline LE $\$ 35,000$ & 1 & & & 1 & & & 1 & & & 1 & & \\
\hline GT $\$ 35,000$ & 3.33 & {$[1.41,7.83]$} & $* *$ & 1.03 & {$[0.96,1.10]$} & & 0.77 & {$[0.33,1.80]$} & & 1.07 & {$[1.00,1.15]$} & \\
\hline \multicolumn{13}{|l|}{ Census Tract Education } \\
\hline LT $15 \%$ pop. with CE & 1 & & & 1 & & & 1 & & & 1 & & \\
\hline GE $15 \%$ pop. with CE & 0.77 & {$[0.48,1.22]$} & & 1.07 & {$[1.01,1.14]$} & $*$ & 1.45 & {$[0.84,2.52]$} & & 0.94 & {$[0.88,1.00]$} & $*$ \\
\hline \multicolumn{13}{|l|}{ Stage at Diagnosis } \\
\hline Insitu & 0.19 & {$[0.02,1.57]$} & & 0.33 & {$[0.27,0.39]$} & $* * *$ & 0.74 & {$[0.14,4.02]$} & & 1.37 & {$[1.17,1.61]$} & $* * *$ \\
\hline Local & 0.23 & {$[0.03,1.86]$} & & 0.51 & {$[0.42,0.61]$} & $* * *$ & 0.76 & {$[0.15,3.77]$} & & 1.23 & {$[1.05,1.43]$} & $* *$ \\
\hline Regional & 0.28 & {$[0.03,2.28]$} & & 0.60 & {$[0.50,0.73]$} & $* * *$ & 0.91 & {$[0.18,4.71]$} & & 1.19 & {$[1.02,1.38]$} & $*$ \\
\hline Distant & 1 & & & 1 & & & 1 & & & 1 & & \\
\hline & & & & & & & & & & \multicolumn{2}{|c|}{ (Continued)... } & \\
\hline
\end{tabular}


Table 3.5

Factors Associated with Timely Diagnosis and Timely Treatment Separately for the Study Cohorts

Adjusted Odds Ratios and 95\% Confidence Intervals from Logistic Regressions

2003-2006

\begin{tabular}{|c|c|c|c|c|c|c|c|c|c|c|c|c|}
\hline & \multicolumn{3}{|c|}{ WV-Medicare } & \multicolumn{3}{|c|}{ SEER-Medicare } & \multicolumn{3}{|c|}{ WV-Medicare } & \multicolumn{3}{|c|}{ SEER-Medicare } \\
\hline & \multicolumn{3}{|c|}{ Timely Diagnosis } & \multicolumn{3}{|c|}{ Timely Diagnosis } & \multicolumn{3}{|c|}{ Timely Treatment } & \multicolumn{3}{|c|}{ Timely Treatment } \\
\hline \multirow[t]{2}{*}{ Variables } & \multicolumn{3}{|c|}{ Model 1} & \multicolumn{3}{|c|}{ Model 2} & \multicolumn{3}{|c|}{ Model 3} & \multicolumn{3}{|c|}{ Model 4} \\
\hline & AOR & $95 \% \mathrm{CI}$ & Sig & AOR & $95 \% \mathrm{CI}$ & Sig & AOR & $95 \% \mathrm{CI}$ & Sig & AOR & $95 \% \mathrm{CI}$ & Sig \\
\hline \multicolumn{13}{|l|}{ Grade of Tumor } \\
\hline Well D & 1 & & & 1 & & & 1 & & & 1 & & \\
\hline Moderately D & 1.34 & {$[0.85,2.11$} & & 1.09 & {$[1.02,1.16]$} & $* *$ & 1.07 & {$[0.64,1.78]$} & & 0.98 & {$[0.92,1.05]$} & \\
\hline Poorly D & 1.32 & {$[0.77,2.26]$} & & 1.26 & {$[1.17,1.36]$} & $* * *$ & 1.33 & {$[0.71,2.49]$} & & 1.04 & {$[0.96,1.12]$} & \\
\hline Undifferentiated/Unknown & 0.94 & {$[0.54,1.65]$} & & 0.93 & {$[0.85,1.01]$} & & 1.18 & {$[0.62,2.23]$} & & 1.00 & {$[0.91,1.10]$} & \\
\hline \multicolumn{13}{|l|}{ ER Status } \\
\hline Positive & 1 & & & 1 & & & 1 & & & 1 & & \\
\hline Negative & 0.97 & {$[0.52,1.78]$} & & 1.01 & {$[0.94,1.09]$} & & 1.95 & {$[0.88,4.32]$} & & 1.02 & {$[0.95,1.10]$} & \\
\hline Borderline/Unknown & 1.22 & {$[0.80,1.87]$} & & 0.85 & {$[0.79,0.91]$} & $* * *$ & 1.11 & {$[0.70,1.78]$} & & 1.07 & {$[0.99,1.16]$} & \\
\hline \multicolumn{13}{|l|}{ Tumor Size } \\
\hline$<1 \mathrm{~cm}$ & 0.48 & {$[0.23,0.97]$} & $*$ & 0.66 & {$[0.61,0.71]$} & $* * *$ & 0.59 & {$[0.27,1.31]$} & & 1.22 & {$[1.13,1.32]$} & $* * *$ \\
\hline $1-2 \mathrm{~cm}$ & 0.58 & {$[0.30,1.12]$} & & 0.90 & {$[0.84,0.96]$} & $* *$ & 0.63 & {$[0.30,1.34]$} & & 1.20 & {$[1.12,1.29]$} & $* * *$ \\
\hline $2-3 \mathrm{~cm}$ & 0.60 & {$[0.29,1.24]$} & & 1.06 & {$[0.98,1.16]$} & & 0.66 & {$[0.29,1.51]$} & & 1.12 & {$[1.03,1.21]$} & $* *$ \\
\hline$>3 \mathrm{~cm}$ & 1 & & & 1 & & & 1 & & & 1 & & \\
\hline \multicolumn{13}{|l|}{ Comorbidity } \\
\hline 0 & 1 & & & 1 & & & 1 & & & 1 & & \\
\hline 1 & 0.72 & {$[0.48,1.08]$} & & 0.93 & {$[0.88,0.98]$} & $* *$ & 0.67 & {$[0.43,1.05]$} & & 0.96 & {$[0.90,1.02]$} & \\
\hline $2,+$ & 0.65 & {$[0.41,1.04]$} & & 0.84 & {$[0.78,0.90]$} & $* * *$ & 0.92 & {$[0.53,1.60]$} & & 0.81 & {$[0.76,0.88]$} & $* * *$ \\
\hline \multicolumn{13}{|l|}{ Mental Condition } \\
\hline Yes & 1.16 & {$[0.65,2.08]$} & & 0.99 & {$[0.90,1.10]$} & & 1.05 & {$[0.54,2.02]$} & & 1.07 & {$[0.96,1.19]$} & \\
\hline No & 1 & & & 1 & & & 1 & & & 1 & & \\
\hline & & & & & & & & & & \multicolumn{3}{|c|}{ (Continued)... } \\
\hline
\end{tabular}


Table 3.5

Factors Associated with Timely Diagnosis and Timely Treatment Separately for the Study Cohorts

Adjusted Odds Ratios and 95\% Confidence Intervals from Logistic Regressions 2003-2006

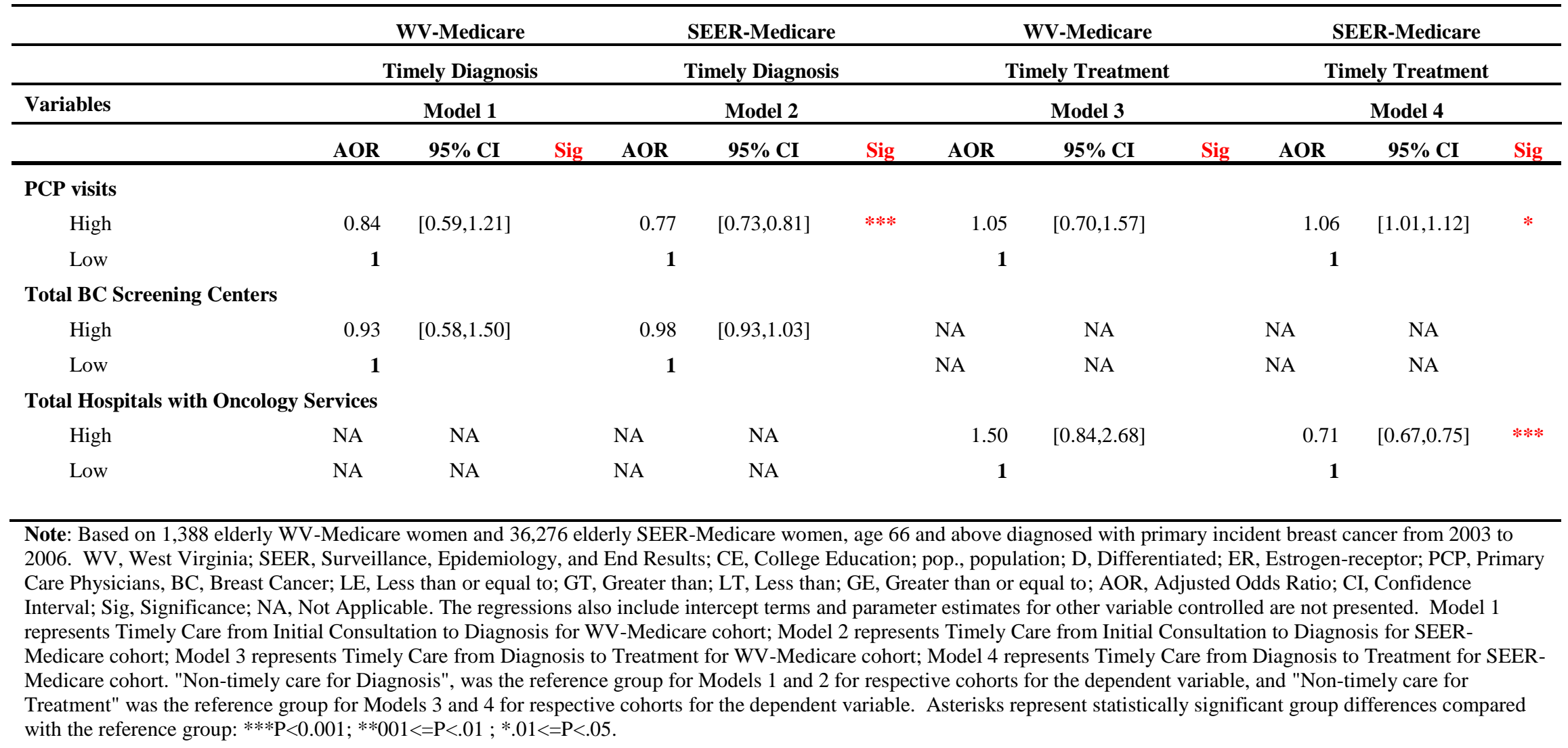


Table 3.6

Differences in Timely Diagnosis and Treatment between Study Cohorts In a Multivariate Framework

Adjusted Odds Ratios and 95\% Confidence Intervals from Logistic Regressions 2003-2006

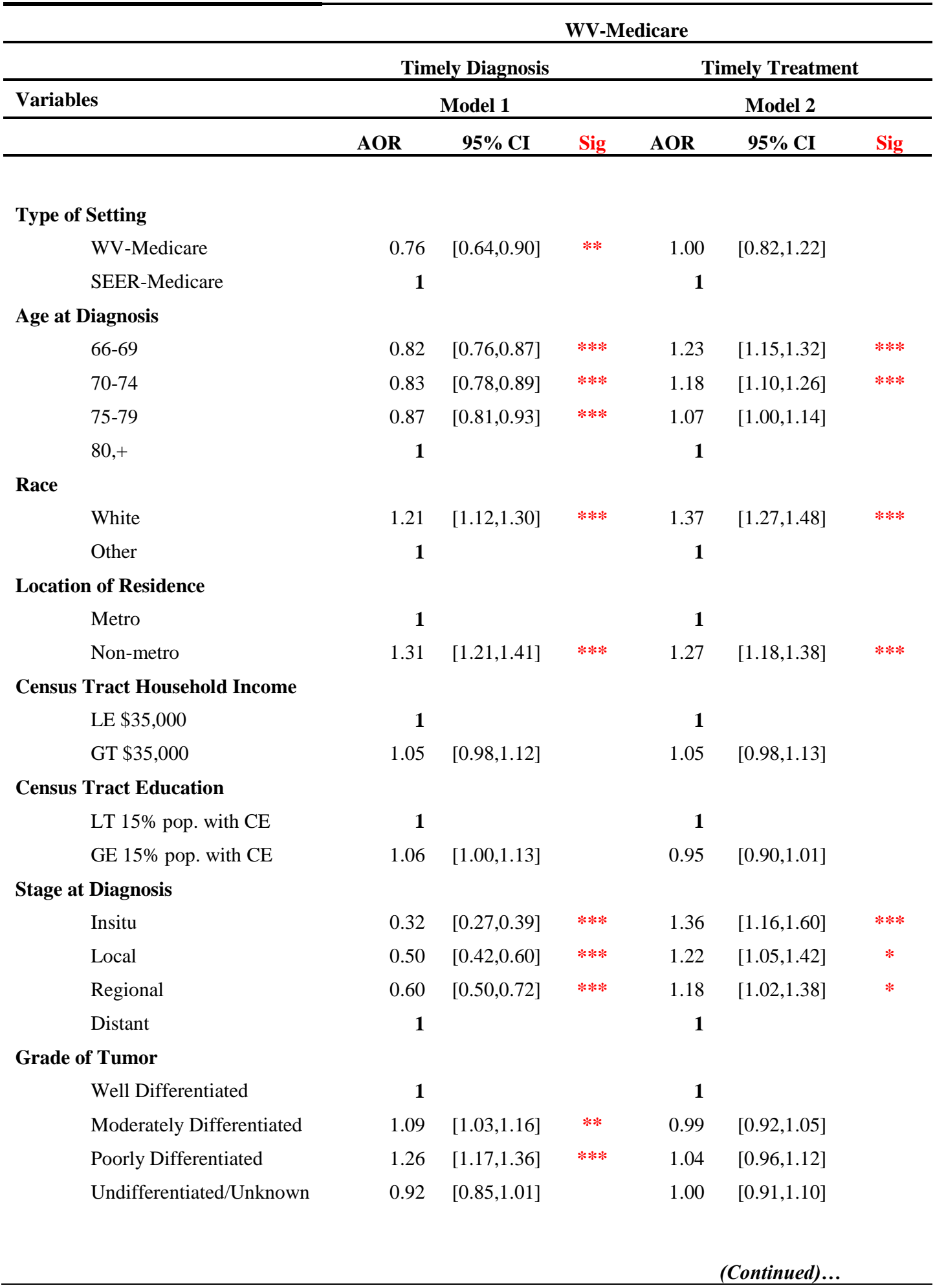


Table 3.6

Differences in Timely Diagnosis and Treatment between Study Cohorts

In a Multivariate Framework

Adjusted Odds Ratios and 95\% Confidence Intervals from Logistic Regressions

2003-2006

\begin{tabular}{|c|c|c|c|c|c|c|c|}
\hline & \multicolumn{7}{|c|}{ WV-Medicare } \\
\hline & \multicolumn{4}{|c|}{ Timely Diagnosis } & \multicolumn{3}{|c|}{ Timely Treatment } \\
\hline \multirow[t]{2}{*}{ Variables } & \multicolumn{4}{|c|}{ Model 1} & \multicolumn{3}{|c|}{ Model 2} \\
\hline & & & $95 \% \mathrm{CI}$ & Sig & AOR & $95 \% \mathrm{CI}$ & Sig \\
\hline \multicolumn{8}{|l|}{ ER Status } \\
\hline Positive & & 1 & & & 1 & & \\
\hline Negative & & 1.01 & {$[0.94,1.09]$} & & 1.03 & {$[0.95,1.11]$} & \\
\hline Borderline/Unknown & & 0.86 & {$[0.81,0.92]$} & $* * *$ & 1.07 & {$[0.99,1.15]$} & \\
\hline \multicolumn{8}{|l|}{ Tumor Size } \\
\hline$<1 \mathrm{~cm}$ & & 0.66 & {$[0.62,0.71]$} & $* * *$ & 1.21 & {$[1.12,1.31]$} & $* * *$ \\
\hline $1-2 \mathrm{~cm}$ & & 0.90 & {$[0.84,0.96]$} & $* *$ & 1.19 & {$[1.11,1.28]$} & $* * *$ \\
\hline $2-3 \mathrm{~cm}$ & & 1.06 & {$[0.97,1.15]$} & & 1.11 & {$[1.02,1.20]$} & $*$ \\
\hline$>3 \mathrm{~cm}$ & & 1 & & & 1 & & \\
\hline \multicolumn{8}{|l|}{ Comorbidity } \\
\hline 0 & & 1 & & & 1 & & \\
\hline 1 & & 0.92 & {$[0.88,0.98]$} & $* *$ & 0.96 & {$[0.90,1.01]$} & \\
\hline $2,+$ & & 0.83 & {$[0.78,0.89]$} & $* * *$ & 0.82 & {$[0.76,0.88]$} & $* * *$ \\
\hline \multicolumn{8}{|l|}{ Mental Condition } \\
\hline Yes & & 1.00 & {$[0.91,1.10]$} & & 1.07 & {$[0.96,1.18]$} & \\
\hline No & & 1 & & & 1 & & \\
\hline \multicolumn{8}{|l|}{ PCP visits } \\
\hline High & & 0.77 & {$[0.74,0.81]$} & $* * *$ & 1.06 & {$[1.01,1.12]$} & $*$ \\
\hline Low & & 1 & & & 1 & & \\
\hline \multicolumn{8}{|l|}{ Total BC Screening Centers } \\
\hline High & & 0.97 & {$[0.92,1.02]$} & $* *$ & NA & NA & \\
\hline Low & & 1 & & & NA & NA & \\
\hline \multicolumn{8}{|c|}{ Total Hospitals with Oncology Services } \\
\hline High & NA & & NA & & 0.72 & {$[0.68,0.76]$} & $* * *$ \\
\hline Low & NA & & NA & & 1 & & \\
\hline
\end{tabular}

Note: Based on 1,388 elderly WV-Medicare women and 36,276 elderly SEER-Medicare women, age 66 and above diagnosed with primary incident breast cancer from 2003 to 2006. WV, West Virginia; SEER, Surveillance, Epidemiology, and End Results; CE, College Education; pop., population; D, Differentiated; ER, Estrogen-receptor; PCP, Primary Care Physicians, BC, Breast Cancer; LE, Less than or equal to; GT, Greater than; LT, Less than; GE, Greater than or equal to; AOR, Adjusted Odds Ratio; CI, Confidence Interval; Sig, Significance; NA, Not Applicable. The regressions also include intercept terms and parameter estimates for other variable controlled are not presented. Model 1 represents Timely Care from Initial Consultation to Diagnosis; Model 2 represents Timely Care from Diagnosis to Treatment. "Non-timely care for Diagnosis" and "Non-timely care for Treatment" are the reference groups for Model 1 and Model 2, respectively for the dependent variables. Asterisks represent statistically significant group differences compared with the reference group: $* * * \mathrm{P}<0.001 ; * * 001<=\mathrm{P}<.01 ; * .01<=\mathrm{P}<.05$ 
Table 3.7

Differences in Survival between Study Cohorts with Receipt of Timely Diagnosis and Timely Treatment in a Multivariate Framework Adjusted Odds Ratios and $95 \%$ Confidence Intervals from Logistic Regressions

2003-2006

\begin{tabular}{|c|c|c|c|c|c|c|}
\hline \multirow{3}{*}{ Variables } & \multicolumn{6}{|c|}{ WV-Medicare } \\
\hline & \multicolumn{3}{|c|}{ Model 1} & \multicolumn{3}{|c|}{ Model 2} \\
\hline & AOR & $95 \% \mathrm{CI}$ & Sig & AOR & $95 \% \mathrm{CI}$ & Sig \\
\hline WV-Medicare & 7.79 & {$[3.33,18.20]$} & $* * *$ & 6.82 & {$[2.89,16.1]$} & $* * *$ \\
\hline SEER-Medicare & 1 & & & 1 & & \\
\hline \multicolumn{7}{|l|}{ Timely Diagnosis } \\
\hline Yes & 0.91 & {$[0.81,1.02]$} & & NA & NA & \\
\hline No & 1 & & & NA & NA & \\
\hline \multicolumn{7}{|l|}{ Timely Treatment } \\
\hline Yes & NA & NA & & 1.17 & {$[1.04,1.31]$} & $*$ \\
\hline No & NA & NA & & $\mathbf{1}$ & & \\
\hline \multicolumn{7}{|l|}{ Age at Diagnosis } \\
\hline $70-74$ & 3.10 & {$[2.70,3.56]$} & $* * *$ & 2.87 & {$[2.49,3.31]$} & $* * *$ \\
\hline $75-79$ & 2.45 & {$[2.15,2.80]$} & $* * *$ & 2.29 & {$[2.00,2.62]$} & $* * *$ \\
\hline $80,+$ & 1 & & & 1 & & \\
\hline \multicolumn{7}{|l|}{ Race } \\
\hline White & 0.95 & {$[0.81,1.12]$} & & 0.95 & {$[0.80,1.12]$} & \\
\hline Other & 1 & & & 1 & & \\
\hline \multicolumn{7}{|l|}{ Location of Residence } \\
\hline Metro & 1 & & & $\mathbf{1}$ & & \\
\hline Non-metro & 0.99 & {$[0.85,1.16]$} & & 1.01 & {$[0.86,1.19]$} & \\
\hline \multicolumn{7}{|l|}{ Census Tract Household Income } \\
\hline LE $\$ 35,000$ & 1 & & & $\mathbf{1}$ & & \\
\hline GT $\$ 35,000$ & 1.07 & {$[0.93,1.22]$} & & 1.07 & {$[0.92,1.23]$} & \\
\hline & & & & & (Cont & \\
\hline
\end{tabular}


Table 3.7

Differences in Survival between Study Cohorts with Receipt of Timely Diagnosis and Timely Treatment in a Multivariate Framework Adjusted Odds Ratios and $95 \%$ Confidence Intervals from Logistic Regressions

2003-2006

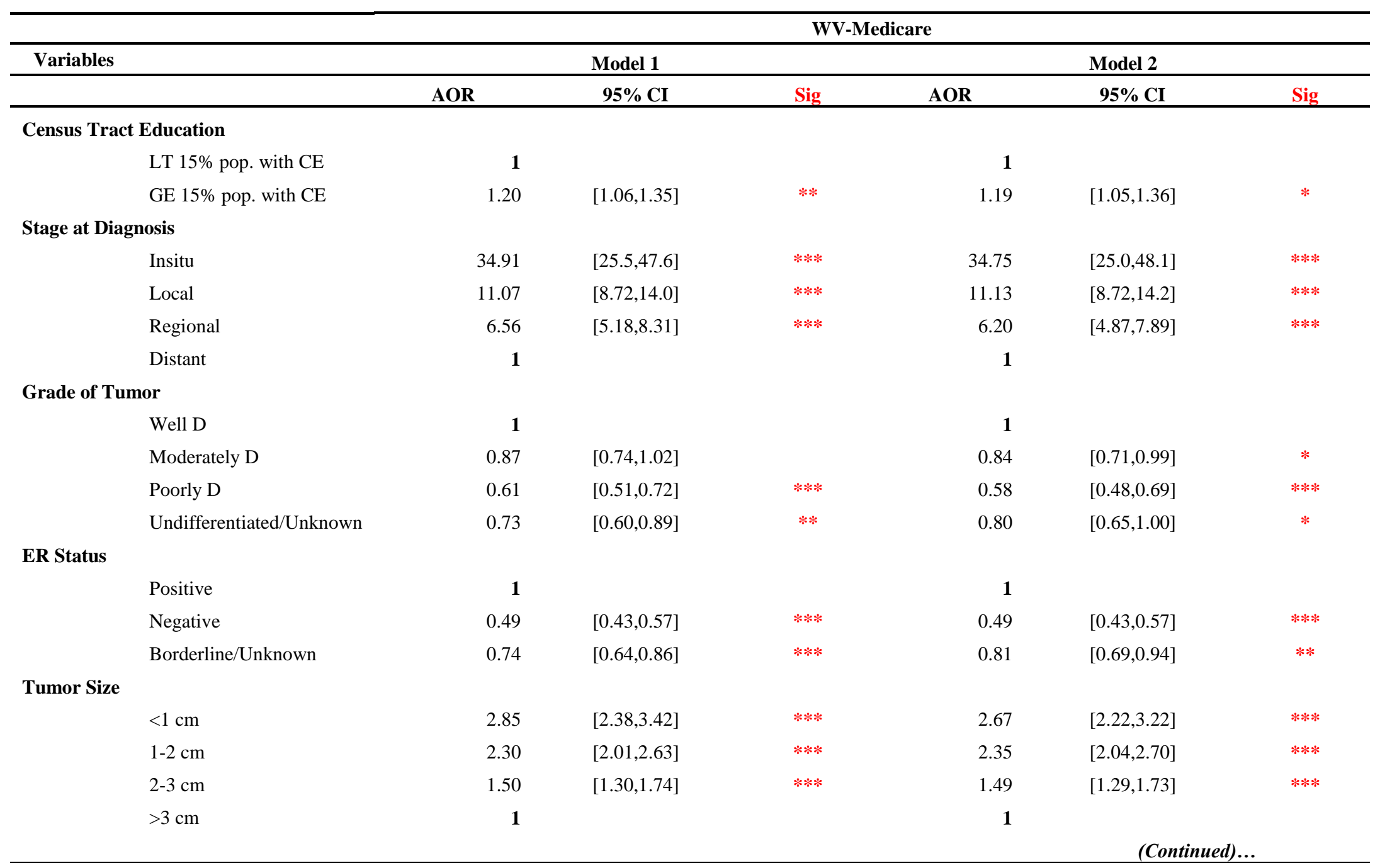


Table 3.7

Differences in Survival between Study Cohorts with Receipt of Timely Diagnosis and Timely Treatment in a Multivariate Framework Adjusted Odds Ratios and $95 \%$ Confidence Intervals from Logistic Regressions

2003-2006

\begin{tabular}{|c|c|c|c|c|c|c|}
\hline \multirow{3}{*}{ Variables } & \multicolumn{6}{|c|}{ WV-Medicare } \\
\hline & \multicolumn{3}{|c|}{ Model 1} & \multicolumn{3}{|c|}{ Model 2} \\
\hline & AOR & $95 \% \mathrm{CI}$ & Sig & AOR & $95 \% \mathrm{CI}$ & Sig \\
\hline 0 & 1 & & & 1 & & \\
\hline 1 & 0.64 & {$[0.57,0.72]$} & $* * *$ & 0.64 & {$[0.56,0.73]$} & $* * *$ \\
\hline $2,+$ & 0.36 & {$[0.32,0.41]$} & $* * *$ & 0.37 & {$[0.32,0.42]$} & $* * *$ \\
\hline \multicolumn{7}{|l|}{ Mental Condition } \\
\hline Yes & 0.64 & {$[0.53,0.77]$} & $* * *$ & 0.70 & {$[0.58,0.85]$} & $* * *$ \\
\hline No & 1 & & & 1 & & \\
\hline \multicolumn{7}{|l|}{ PCP visits } \\
\hline High & 0.84 & {$[0.75,0.93]$} & $* *$ & 0.87 & {$[0.78,0.97]$} & $* *$ \\
\hline Low & 1 & & & 1 & & \\
\hline High & 1.03 & {$[0.92,1.16]$} & & NA & NA & \\
\hline Low & 1 & & & NA & NA & \\
\hline \multicolumn{7}{|c|}{ Total Hospitals with Oncology Services } \\
\hline High & NA & NA & & 1.12 & {$[1.00,1.26]$} & \\
\hline Low & NA & NA & & 1 & & \\
\hline
\end{tabular}

Note: Based on 1,388 elderly WV-Medicare women and 36,276 elderly SEER-Medicare women, age 66 and above diagnosed with primary incident breast cancer from 2003 to 2006. WV, West Virginia; SEER, Surveillance, Epidemiology, and End Results; CE, College Education; pop., population; D, Differentiated; ER, Estrogen-receptor; PCP, Primary Care Physicians, BC, Breast Cancer; LE, Less than or equal to; GT, Greater than; LT, Less than; GE, Greater than or equal to; NA, Not Applicable; AOR, Adjusted Odds Ratio;

CI, Confidence Interval; Sig, Significance. The regressions also include intercept terms and parameter estimates for other variable controlled are not presented. Model 1 represents Survival After Controlling for Timely Diagnosis; Model 2 represents Survival after Controlling for Timely Treatment. "Death" is the reference group for the dependent variables for both the models. Asterisks represent statistically significant group differences compared with the reference group: $* * * \mathrm{P}<0.001 ; * * 001<=\mathrm{P}<.01 ; * .01<=\mathrm{P}<.05$. 
CHAPTER 4 


\section{CHAPTER 4}

TOTAL HEALTHCARE COSTS AMONG ELDERLY WOMEN WITH BREAST

CANCER IN THE INITIAL PERIOD OF ONE YEAR AFTER DIAGNOSIS: AN

\section{APPLICATION OF DECOMPOSITION TECHNIQUE}

\section{INTRODUCTION}

\section{Breast Cancer}

Breast cancer $(\mathrm{BC})$, the most common type of cancer, is the second leading cause of cancer death in women in the United States (US). It is estimated that approximately 232,670 new cases of invasive BC, and about 62,570 new cases of carcinoma in situ (CIS) will be diagnosed, and 40,000 women will die from BC in the US in $2014^{1}$. Based on Surveillance, Epidemiology and End Results (SEER) statistics for 2005-2009, the overall incidence of BC from 2005-2009 was 82.97 per 100,000 in women age below 65 years and was 421.30 per 100,000 in women age 65 and above ${ }^{2}$. The overall mortality from BC from 2005-2009 was 11.15 per 100,000 in women below 65 years of age and was 98.64 per 100,000 in women age 65 and above ${ }^{2}$.

\section{Total Healthcare Costs in the Initial Phase of One Year after Breast Cancer Diagnosis}

Due to rapid scientific and technological advances in the field of oncology and with increased adoption and utilization of more expensive cancer treatments as the standards of care, and due to an increasing aging population, the costs of cancer care is expected to increase enormously in the future. Based on a recent study, the national costs of cancer care in 2010 was estimated to be $\$ 124.6$ billion, out of which female BC comprised the highest proportion of $13 \%$ ( $\$ 16.5$ billion), which may increase by $32 \%$ in $2020^{3}$. In addition, BC had the highest expenditures in the initial phase of care (one year after diagnosis) among all other cancers ${ }^{3}$. 
From $\$ 16.5$ billion, $37 \%$ of the BC costs were for the initial phase of care, $41 \%$ were for the continuing phase of care and $22 \%$ were for the last year of life.

A descriptive review on the costs of cancer care in the US reported that studies vary widely with regards to study settings, methodology, cost perspective, stage at diagnosis, populations, measurements of costs, types of services included, time horizons, and databases ${ }^{4}$. Moreover, none of the studies included in the review followed any published standards of reporting costs analyses and hence called for future studies to follow these standards ${ }^{4}$. A systematic review of costs associated with BC in the US reported that the lifetime per-patient direct medical care cost estimates of $\mathrm{BC}$ ranged from $\$ 20,000$ to $\$ 100,000$ for a base cost year from 1984 to $2003^{5}$. Yet the authors of this review suggested that the majority of the studies included in the review were outdated, and hence the findings of the study did not reflect the changes in patterns of care due to technological advances and innovations in BC treatment ${ }^{5}$. Also, most of the studies included in the review focused on women with BC stages disease I or II 5

The costs to Medicare of BC care are substantially higher during the initial phase of care due to surgery, radiation and adjuvant therapy ${ }^{5-9}$. Despite the extensive cost to Medicare during the initial phase of care, there is inadequate information on costs incurred by types of specific services, and average costs by stage at diagnosis, type of treatment, and number of comorbidities, and the factors associated with higher costs of BC care. Recent studies on costs of cancer care in the initial phase of care for elderly BC patients in the US have been based on old data (2003), from fewer cancer registries, or for fewer disease stages ${ }^{3,6,7,10}$. In addition, the average costs by type of specific services, stage at diagnosis, type of initial treatment, and comorbidities have not been reported ${ }^{7,10}$. One study which determined the initial phase of care costs for Medicare 
beneficiaries in Virginia reported lower costs associated with BC care as compared to that from the SEER-Medicare data, and that comorbidity, hospital stay, and type of treatment were significant contributors of costs due to $\mathrm{BC}^{11}$. However, there is limited information available about the costs associated with $\mathrm{BC}$ care from rural settings and from non-SEER states. The costs estimates from the previous studies may not be representative of Medicare reimbursements for other geographic areas and across other populations in the US.

The population in WV is predominantly white and a considerable proportion reside in rural areas. WV also has high poverty rates, low levels of education, aging population, high rates of chronic diseases, and poor health behaviors ${ }^{12-15}$. With lower incidence of BC among WV women age 65 and older (372.8 per 100,000 vs. 410.6 per 100,000) but higher mortality (110.4 per 100,000 vs. 98.6 per 100,000$){ }^{16,17}$ than national estimates, and with higher rates of advanced and unstaged $\mathrm{BC}$ in these women ${ }^{18-22}$, it is likely that costs of $\mathrm{BC}$ care during the initial phase of care may be higher. These findings will help to determine the extent to which costs are higher in rural, underserved states such as WV with increasing median age.

Thus, the purpose of the study is to determine the average costs in the initial phase of care among WV-Medicare fee-for-service (FFS) women beneficiaries and compare it with national estimates derived from SEER-Medicare data, and to determine the factors associated with higher costs in WV-Medicare women and compare it with the national estimates, after controlling for predisposing factors (age, race), enabling factors (median household income, education level), need-related factors (stage at diagnosis, grade of tumor, estrogen-receptor (ER) status, cooccurring physical and mental chronic conditions), healthcare use factors (number of primary care physicians (PCP) visits in the year prior to $\mathrm{BC}$ diagnosis, type of initial cancer-related treatment, inpatient stay) and external healthcare environmental factors (location of residence 
and number of hospitals offering oncology services in the area of residence). The post hoc objective of the study is to utilize linear decomposition technique ${ }^{23,24}$ to determine the magnitude of differences in the average costs in the initial phase of care between WV-Medicare and the SEER-Medicare, and to understand extent to which the predisposing, enabling, need, healthcare use, and external healthcare environmental factors explain the differences in the average costs between WV-Medicare and the SEER-Medicare cohorts.

\section{METHODS}

\section{Data Source}

\section{West Virginia Cancer Registry-Medicare-Area Resource File linked dataset}

The West Virginia Cancer Registry (WVCR) was established by the West Virginia Department of Health and Human Resources in 1993 and it is a state-level cancer registry which provides information on cancer incidence and mortality in West Virginia (WV) ${ }^{25}$. The WVCR collects and provides data on primary site of cancer, tumor grade, date and stage of diagnosis, date and cause of mortality, and demographics such as age, gender, race, and also zip code (for location of residence). The de-identified linked WVCR-Medicare dataset was developed at West Virginia University (WVU) in full compliance with the WVU Institutional Review Board and HIPPA requirements ${ }^{26}$. The WVCR file served as the case source file from which the information about individuals aged $\geq 65$ years and diagnosed with cancer between the January 1 , 2002 and December 31, 2007 was obtained. The Social security numbers (SSN) for these individuals were provided to the CMS by the WVCR, using which the CMS identified the corresponding Health Insurance Claim (HIC) number. A “crosswalk" file created using the HIC allowed for linkage across the WVCR and the Medicare for extracting information on these individuals as Medicare beneficiaries. Individuals with a missing SSN were excluded from the 
linkage. The Area Resource File (ARF) was linked to the WVCR-Medicare dataset using the state and county FIPS codes for each beneficiary to extract the county level information on the availability of healthcare facilities, healthcare providers, and socioeconomic characteristics of the region's population.

\section{SEER-Medicare-Area Resource File linked dataset}

The SEER-Medicare linked dataset provides population-based information on cancerrelated epidemiologic and health services research. The SEER-Medicare program collects information on newly diagnosed cases of cancer from 17 population-based tumor registries which collect information from several sources including hospitals, outpatient clinics, laboratories, private practitioners, hospices, autopsy reports and death certificates. The SEERMedicare data represents approximately $26 \%$ of the US population. It is in the form of a customized file known as the Patient Entitlement and Diagnosis Summary File (PEDSF) which contains one record per person for individuals in the SEER database who have been matched with Medicare enrollment records. It provides diagnostic information for up to 10 diagnosed cancer cases (including date of cancer diagnosis, cancer sub-site, cancer stage at diagnosis, tumor size, histology, grade), and information on the first course of cancer related treatment (surgery and radiation provided in the first 4 months after diagnosis) for each individual. The PEDSF additionally includes information on the median household income and education level for each individual based on their census tract and zip code data.

The Medicare files that are a part of the SEER-Medicare linked dataset provide information about any health care utilized in the inpatient, outpatient, physician, home health, and hospice care by individuals age 65 and above who are enrolled in and are covered under the Medicare program. All Medicare files include specific dates of service and codes for specific 
diagnosis and procedures using the International Classification of Disease, Ninth Edition (ICD-9) codes or Common Procedure Terminology codes. The linkage of the SEER data with the Medicare data, and formation of the SEER case number involves matching individuals across the two files using an algorithm based on a match of SSN, name, sex, and date of birth. The linkage process is described elsewhere ${ }^{27}$. The Area Resource File (ARF) was linked to the SEERMedicare dataset using the state and county Federal Information Processing Standards (FIPS) code for each beneficiary to get the county level information on the availability of healthcare facilities and healthcare providers.

\section{Study Design}

This study utilized a retrospective observational cohort design to assess healthcare costs during initial phase of care in Medicare FFS beneficiaries diagnosed with BC.

\section{Study Cohorts}

The two study cohorts comprised of women from WVCR-Medicare-ARF linked dataset and SEER-Medicare-ARF linked dataset, age 66 and above at the first primary diagnosis of incident BC between January 1, 2003 to December 31, 2006. These women were required to be continuously enrolled in Medicare parts A and B at least 12 months prior to the $\mathrm{BC}$ diagnosis to identify chronic conditions to measure comorbidity and till the follow up period of 12 months after $\mathrm{BC}$ diagnosis to determine average total costs, and not enrolled in health maintenance organizations (HMOs) at any time during this period. Women with a previous cancer diagnosis, having an unknown or missing BC stage information, and who were diagnosed via death certificate or autopsy were excluded from the study. Also women who died during the first 12 months after BC diagnosis were excluded from the study as these women may have dramatically higher total average costs which may affect the estimates ${ }^{9,11}$. Each beneficiary was followed for 
up to 12 months after $\mathrm{BC}$ diagnosis, to determine healthcare costs during the initial phase of care. $\mathrm{BC}$ diagnosis codes were based on the primary site and International Classification of Diseases, 9th edition Clinical Modification (ICD-9-CM) codes 174.xx, 233.0x, 238.3x, and 239.3x.

The WVCR-Medicare-ARF linked dataset identified 2,814 women diagnosed with BC from January 1, 2003 to December 31, 2006. The following women were excluded from the final study cohort: 152 women who were below 66 years at diagnosis, 13 women who died during the first 12 months after BC diagnosis, 526 women with any previous cancer diagnosis, 24 women who were diagnosed with BC during death or autopsy, 245 women with unknown or missing BC stage, 234 women who were not continuously enrolled in Medicare parts A and B in the 12 months before and 12 months after diagnosis, and 232 women who were members of a HMO at any time during the study period. From the remaining 1,388 women, only 1 woman $(0.07 \%)$ had zero total expenditure in the initial period after BC diagnosis and hence was removed from the analyses. Thus, a sample of 1,387 women was included in the final analyses.

The SEER-Medicare-ARF linked dataset had 112,719 women diagnosed with BC from January 1, 2003 to December 31, 2006. The following women were excluded from the final study cohort: 44,869 women who were below 66 years at diagnosis, 6,137 women who died during the first 12 months after $\mathrm{BC}$ diagnosis, 3,123 women with any previous cancer diagnosis, 2 women who were diagnosed with BC during death or autopsy, 1,299 women with unknown or missing BC stage, 3,292 women who were not continuously enrolled in Medicare parts A and B in the 12 months before and 12 months after diagnosis, and 14,296 women who were members of a $\mathrm{HMO}$ at any time during the study period. From the remaining 39,701 women, 176 women $(0.44 \%)$ had zero total costs in the initial phase of care and hence were removed from the analyses. Thus, a sample of 39,525 women was included in the final analyses. 


\section{Measures}

Cost Estimates: Costs of care in the initial phase of care were separately calculated for both the study cohorts. All Medicare files including Inpatient (Medicare Analysis and Procedure), Hospital Outpatient, Carrier/NCH, Hospice, Skilled Nursing Facility, Home Health Agency, and Durable Medical Equipment, were used to estimate average direct medical costs in the initial phase of care. In addition to total direct medical costs of care, average direct medical costs within the categories of care such as inpatient services, outpatient services, physician services, and other services (costs related to durable medical equipment, hospice care and home health agency) were determined for both the study cohorts. The prescription drug costs were not included in the analysis as data pertaining to prescription drugs was not available for the years of the study.

The initial phase of care was defined as the year following BC diagnosis, based on the following reasons cited by previous studies: initial course of treatment including adjuvant therapy to be completed within one year of diagnosis, initial phase of care is also based on the consensus from a group of clinical oncologists, and it could be used for comparison purposes with previous literature ${ }^{6,8,9,11,28}$.

Defining direct medical costs: Direct medical costs were defined as the amount reimbursed by Medicare. Reimbursement rather than charges has been used as a proxy for medical care costs in previous cost studies ${ }^{\mathbf{8 - 1 0}}$. Moreover, charges reflect price setting rather than resource consumption and hence are not necessarily related to the cost of providing services ${ }^{29}$. Reimbursements are actual payments derived from reimbursement formulas which reflect the average resource utilization for each healthcare service ${ }^{29}$. Apart from calculating average total direct medical costs, costs by type of specific services such as inpatient services, outpatient 
services, physician services, and other services were also calculated separately for both the study cohorts to identify which Medicare component contributes substantially to the average total costs of care. To account for variation in the costs of medical care services over time, consumer price indices (CPI) for medical care services were utilized to convert costs to 2007 US dollars ${ }^{\mathbf{3 0}}$ and hence all the costs are reported in 2007 US dollars. The Medicare reimbursement formulae for all the services already include geographic factors which may affect geographic variations in the costs, and hence the costs were not adjusted for any geographic variations.

Independent Variables: To identify the factors associated with healthcare costs in elderly Medicare FFS with first primary incident BC, the Andersen behavioral healthcare services utilization model was utilized $^{31,32}$. Based on this model, the independent variables were grouped into predisposing factors, enabling factors, need-related factors, healthcare use factors and external healthcare environmental factors (Figure 4.1).

Predisposing factors comprised of age at BC diagnosis (66-69, 70-74, 75-79, 80 and older), and race (white, other), while enabling factors consisted of census tract median household income $(=<\$ 35,000 ;>\$ 35,000)$, and census tract percentage of people age $>=25$ years with at least 4 years of college education $(<15 \%\rangle=,15 \%)$. Since person-level information on household income and education level are not available with both the SEER-Medicare and WV-Medicare cohorts, census tract information for these two variables were used in this study. Need-related factors included clinical factors such as stage at diagnosis (insitu, local, regional, distant), grade of tumor (well-differentiated, moderately differentiated, poorly differentiated, undifferentiated/unknown), estrogen-receptor status (positive, negative, borderline/unknown), comorbidity scores and mental conditions (depression and/or anxiety) derived from co-occurring chronic conditions during the twelve months before BC diagnosis identified from the Medicare 
files using the ICD-9-CM diagnosis codes. BC stage at diagnosis was determined according to the SEER Summary staging system which uses all information available in the medical record. It is a combination of the most precise clinical and pathological documentation of the extent of disease $^{33}$. Comorbidity scores were calculated using Charlson comorbidity index with macros provided by the National Cancer Institute ${ }^{34-36}$ and were categorized as 0 (no comorbidity), 1, 2+. Mental conditions included depression and/or anxiety and was dichotomized as presence or absence of a mental condition. Factors associated with healthcare use were the number of PCP visits in the 12 months prior to the $\mathrm{BC}$ diagnosis, type of initial treatment in the year subsequent to $\mathrm{BC}$ diagnosis, and inpatient use. Similar to previous research, PCP visits were derived from the National Claims History $(\mathrm{NCH})$ files using the Medicare provider specialty field found in $\mathrm{NCH}$ claims and the PCP included those in general practice (01), family practice (08), internal medicine (11), geriatric medicine (38), and multi-specialty group practice (70) ${ }^{37}$. The PCP visits were categorized into two groups (high or low) based on the median value. Type of initial treatment was categorized as definitive surgery only, non-surgical treatment (chemotherapy or radiation therapy or both), definitive surgery plus non-surgical therapy, and no treatment. Claims related to surgical procedures, chemotherapy, radiation therapy were identified from the appropriate Medicare files using a combination of ICD-9-CM diagnosis and procedure codes, CPT codes, HCPCS codes and revenue center codes. Inpatient use during the 12 months after $\mathrm{BC}$ diagnosis was derived from the inpatient claims file and was dichotomized as presence or absence of inpatient use. External healthcare environmental factors included location of residence based on US Department of Agriculture rural-urban continuum codes (metro, nonmetro) and ARF-derived number of hospitals offering oncology-related services in the area of 
residence. The hospitals offering oncology-related services were categorized into two groups (high or low) based on the median value.

\section{Statistical Analyses}

Descriptive statistics and chi-square statistics were used to describe the characteristics and the significant differences in characteristics between the two study cohorts. CPI adjusted average total direct medical costs during the initial period after $\mathrm{BC}$ diagnosis and average total costs by types of specific services were estimated for both the study populations and were statistically compared using t-tests and ratio-of-means. Ratio-of-means is obtained by dividing average total costs of WV-Medicare cohort by average total costs of SEER-Medicare cohort. In addition, average total costs by type of specific services among users of the respective services were determined and reported. Adjusted average total direct medical costs were estimated for clinically relevant variables such as stage at $\mathrm{BC}$ diagnosis, type of initial treatment and comorbidity scores for both the study populations and their ratio-of-means were reported. Data on adjusted average total costs and average costs by types of specific services for both WVMedicare and SEER-Medicare cohorts were positively skewed and with high kurtosis (>3). Hence transformation of these costs data was required. Breusch-Pagan/Cook-Weisberg test and simplified White test were performed to check for heteroscedasticity and kurtosis of log-scale residuals in the costs data ${ }^{38}$. Due to presence of distributional problems such as skewness, kurtosis of log-scale residuals and heteroscedasticity, Park tests ${ }^{39}$ were conducted for total costs, and for costs by types of specific service for both the study populations to determine the most appropriate model which may produce the most precise estimates for the costs data. The results of the Park tests suggested that Generalized Linear Model (GLM) with log link function and gamma distribution was the most appropriate regression to model costs in this study. 
GLM regressions with log transformation for adjusted total costs and gamma distribution as the link function were conducted separately for both the study populations to determine the predictors of total healthcare costs incurred during the initial period after BC diagnosis in elderly women, after controlling for all the independent variables. GLM regressions were also conducted on total, inpatient, outpatient, and physician services costs after controlling for setting (WV-Medicare vs. SEER-Medicare) and other independent variables, to determine the significant differences between total costs and costs by services between WV-Medicare and SEER-Medicare cohorts. The independent variables, predisposing factors, enabling factors, need-related factors, factors affecting healthcare use and external environmental healthcare access factors were entered in sequential blocks in the regression models. Model 1 included only 'type of setting (WV-Medicare vs SEER-Medicare)' as an independent variable. Model 2 added predisposing and enabling factors in addition to setting variable. Model 3 added need-related factors and factors affecting healthcare use in addition to the variables specified in Model 2. Model 4 included external healthcare environmental factors in addition to the variables specified in Model 3. From the GLM regressions, the parameter estimates (beta coefficients), betas transformed into corresponding average costs, and standard errors were examined. The findings that were significant with p-values less than or equal to 0.05 levels were discussed. All analyses were conducted within statistical analysis system software SAS 9.3 (SAS ${ }^{\circledR}$ version 9.3, SAS Institute Inc., Cary, NC, USA) and Stata 13 (StataCorp.2013.Stata Statistical Software:Release 13.College Station,TX:StataCorp LP).

\section{Blinder-Oaxaca Decomposition Technique}

To determine the extent to which independent variables explained the differences in total average costs in the initial year between WV-Medicare and SEER-Medicare, a post-regression 
linear decomposition technique was utilized ${ }^{23,24}$. This technique helps in examining the proportion of total setting difference (WV-Medicare vs SEER-Medicare) being explained by different independent variables included in the model, and also in identifying how much of the setting differences in total average costs were explained by these independent variables. The decomposition method utilizes the parameter estimates (beta coefficients) from the regressions and the means of independent variables to generate two components: 'explained' component (also known as characteristics effect) which provides differences in the total costs due to differences in observed characteristics between WV and SEER-Medicare, and 'unexplained' component (also known as coefficients effect) which provides differences in the total costs between WV-Medicare and SEER-Medicare cohorts that could not be explained, either because of differences in the regression parameter estimates between the two groups or differences in unobservable or unmeasured independent variables (e.g. provider level, organizational level variables) which were not captured and included in the model.

The explained portion was calculated by multiplying the differences in the average characteristics between the WV-Medicare and SEER-Medicare cohorts with the pooled regression weights. The pooled regression weights are the coefficients of the characteristics from the regression model which used data from the WV-Medicare and SEER-Medicare cohorts. The pooled regression model included type of setting as one of the independent variables in the regression model.

\section{RESULTS}

\section{Description of the Study Cohorts}

Table 4.1 describes the WV-Medicare and SEER-Medicare cohorts age 66 and above, diagnosed with the first primary incident BC in 2003-2006. Twenty-five percent of the women 
in the WV-Medicare cohort were age 80 and above as compared to $29 \%$ in SEER-Medicare cohort. Majority of WV-Medicare cohort (97.6\%) was white as compared to $89 \%$ from the SEER-Medicare cohort. A higher proportion of WV-Medicare cohort had a household income below $\$ 35,000$ (91\%), resided in areas with less than $15 \%$ population with some college education (51\%), had lower PCP visits (51\%) and resided in areas with lower number of hospitals with oncology services $(60 \%)$. However, a majority of the SEER-Medicare cohort resided in metro areas (84\%), had household income above $\$ 35,000(75 \%)$, resided in areas with greater than $15 \%$ of population with some college education (70\%), had lower PCP visits (54\%), and resided in areas with a lower number of hospitals with oncology services (55\%).

\section{Average Total Costs and Average Costs by Types of Services}

Table 4.3 describes the CPI adjusted total average costs and average costs by types of specific services during the initial phase of care for both the WV-Medicare and SEER-Medicare cohorts, and also presents the ratio-of-means between the WV-Medicare and SEER-Medicare cohorts. The average total costs for WV-Medicare cohort during initial phase of care was $\$ 19,875$ ( $\mathrm{SE}=483$ ), while the average total costs for those belonging to the SEER-Medicare cohort was $\$ 22,881(\mathrm{SE}=100)$. The ratio-of-means was 0.87 and the total average costs for the WV-Medicare cohort was significantly lower than that of the SEER-Medicare cohort. Total average inpatient costs for WV-Medicare cohort \$4,707 ( $\mathrm{SE}=255)$ was also significantly lower

than the costs for SEER-Medicare cohort $\$ 5,254(\mathrm{SE}=59)$ with ratio-of-means of 0.90 . The total average outpatient costs for the WV-Medicare cohort and the SEER-Medicare cohort were $\$ 5,767(\mathrm{SE}=237)$ and $\$ 5,806(\mathrm{SE}=34)$ respectively, with ratio-of-means 0.99 . The total average costs for physician services were significantly lower for the WV-Medicare cohort $(\$ 8,684$, $\mathrm{SE}=261)$ as compared to the SEER-Medicare cohort $(\$ 10,800, \mathrm{SE}=57)$, with ratio-of-means of 
0.80. Also the total average costs for other services were significantly lower for the WVMedicare cohort $(\$ 716, \mathrm{SE}=60)$ as compared to the SEER-Medicare cohort $(\$ 1,020, \mathrm{SE}=16)$.

Among users of the specific services, total average inpatient costs were significantly lower for the WV-Medicare cohort $(\$ 9,745)$ as compared to the SEER-Medicare cohort $(\$ 11,239)$, and ratio-of-means was 0.87 . The total average costs among users of physician services were also significantly lower for the WV-Medicare cohort $(\$ 8,684)$ as compared to the SEER-Medicare cohort $(\$ 10,814)$ with a ratio-of-means of 0.80 .

\section{Average Total Costs for Clinically Important Variables}

Table 4.4 describes the average total costs for clinically important variables such as stage at diagnosis, type of initial treatment, and comorbidity score. Average total costs in the WVMedicare women with distant stage at $\mathrm{BC}$ diagnosis was $\$ 27,073(\mathrm{SE}=3,635)$ as compared to $\$ 43,431$ ( $\mathrm{SE}=973$ ) in the SEER-Medicare women with distant stage, and the ratio-of-means was 0.62. WV-Medicare cohort who had adjuvant therapy only as the initial treatment had average total expenditures of $\$ 26,498$ as compared to $\$ 33,786$ for the SEER-Medicare cohort, with ratioof-means of 0.78. Average total costs were lower for the WV-Medicare cohort with 2 or more comorbidities as compared to the SEER-Medicare cohort with two or comorbidities $(\$ 22,018$ vs. $\$ 27,593)$, with a ratio-of-means of 0.80 .

\section{Factors Associated with Average Total Costs}

Table 4.5 summarizes the results from the separate GLM regression models on total average costs during the initial phase of care in the WV-Medicare and the SEER-Medicare cohorts. In the WV-Medicare cohort, women who had regional or distant stage of BC, who had surgery with adjuvant therapy or who had adjuvant therapy only, who had inpatient visits, who had two or more comorbidities, and who had either depression or anxiety had significantly 
higher total average costs. Also, WV-Medicare cohort who was age 75 or older had significantly lower total average costs. In the SEER-Medicare cohort, women who resided in areas with higher education, who were diagnosed at advanced stages of $\mathrm{BC}$, who did not have a welldifferentiated tumor grade, who had negative ER tumor status, who had any kind of treatment in form of surgery or adjuvant therapy, who had inpatient visits and PCP visits, and who had any comorbidity had significantly higher total average costs. In addition, the SEER-Medicare cohort who was age 70 or older, and who resided in non-metro areas had significantly lower total average costs. The beta estimates and exponentiated average costs for all the independent variables within each GLM regression are reported in Table 4.4.

\section{Differences in Average Total Costs and Average Costs by Types of Services}

Table 4.6 summarizes the results from the separate multivariate GLM regression models on total average costs, average costs for types of specific services during the initial phase of care, to identify any significant differences in these costs between WV-Medicare cohort and SEERMedicare cohort. As compared to the SEER-Medicare cohort, total average costs were significantly lower for the WV-Medicare cohort. In Model 1 without adjusting for other independent variables, the WV-Medicare cohort had lower total average healthcare costs as compared to the SEER-Medicare cohort by $\$ 3,006$. However, this difference shrunk to $\$ 549$ in Model 4 after adjusting for all the independent variables. The total average costs for inpatient and physician services were also significantly lower for the WV-Medicare cohort as compared to the average costs for these services for the SEER-Medicare cohort. 
Factors Explaining Lower Average Total Costs in the WV-Medicare Cohort Using BlinderOaxaca Linear Decomposition Analysis

Table 4.7 summarizes the results from the Blinder-Oaxaca linear decomposition analysis. The total average costs for WV-Medicare cohort for the initial phase of care was $\$ 19,875$ and that for the SEER-Medicare cohort was $\$ 22,881$, a difference of $\$ 3,006$ in total average costs between these two cohorts. Using the pooled weights, $15.82 \%$ of the difference in the total average costs between the two cohorts was explained by the beneficiary characteristics.

Enabling resources (census tract income and education) contributed 6.85\%, healthcare use (PCP visits, type of initial treatment, inpatient use) contributed $7.53 \%$, and external healthcare environmental factors (location of residence, hospital visits) contributed 3.33\% to the total explained portion of $15.82 \%$. Detailed examination of the decomposition results revealed that the differences in the type of initial treatment explained $11.52 \%$ of the differences in the total average costs between the two groups. This can be interpreted as follows: keeping all the other characteristics same, if WV-Medicare cohort had the same course of initial treatment as the SEER-Medicare cohort, then the WV-Medicare cohort would have had a lower total average costs. A total of $84.14 \%$ of the differences in the total average costs in the initial phase of care between WV-Medicare and SEER-Medicare cohorts remained unexplained.

Since only $16 \%$ of the differences between WV-Medicare and SEER-Medicare cohorts were explained by the beneficiary characteristics discussed above, it was hypothesized that other factors related to healthcare utilization such as number of radiation visits, number of chemotherapy visits, and type of surgeon seen (general surgeon vs. oncology surgeon) may explain a portion of lower total average costs in the WV-Medicare cohort. The post-hoc analyses was conducted to evaluate significant differences between the study cohorts for the additional 
healthcare use factors such as number of radiation visits, number of chemotherapy visits and type of surgeon seen by the Medicare beneficiaries and its results are reported in Table 4.2. A higher proportion of the WV-Medicare cohort had no radiation visits as compared to the SEERMedicare cohort (51\% vs. 47\%). However, among those who had radiation visits, WV-Medicare cohort had higher proportion of women with at least 10 radiation visits in the year following BC diagnosis as compared to the SEER-Medicare cohort. There were no significant differences between the two study cohorts for number of chemotherapy visits and type of surgeon seen in the year following BC diagnosis. Another post-hoc Blinder-Oaxaca decomposition analyses was also conducted to identify the extent to which the previously included independent variables and the additional healthcare use factors explained the magnitude of differences in these study cohorts. Using the pooled weights, only $11 \%$ of the difference in the total average costs between the two cohorts was explained by the beneficiary characteristics (data not shown). Healthcare use contributed $61 \%$, enabling resources contributed $28 \%$ and external healthcare environmental factors contributed $29 \%$ to the total explained portion (data not shown).

\section{DISCUSSION}

As the costs of $\mathrm{BC}$ constitute a substantial portion of the overall national costs of cancer care and as these costs are likely to increase tremendously in the coming years ${ }^{3}$, estimating the $\mathrm{BC}$ costs and the costs by types of specific services is vital for the Medicare program to focus on controlling these costs and setting priorities for the effective allocation of the resources.

Previous studies which estimated total average costs in the initial phase of care in BC patients

have been outdated and utilized data from SEER-Medicare registries only ${ }^{3,6,7,10}$. This study is first of its kind to identify costs by types of specific services and the factors associated with higher costs in $\mathrm{BC}$ patients, from a non-SEER-Medicare and rural geographic region and 
compared it with the national estimates derived from SEER-Medicare data, and to examine the which factors explained the differences in the average costs between the WV-Medicare and SEER-Medicare cohorts. The study findings indicate that the two populations were statistically different in terms of most of their characteristics. The total average costs, and the average costs for inpatient services, physician services and other services in the initial phase of care in elderly BC patients from WV-Medicare cohort was significantly lower than that for the SEER-Medicare cohort. The total average costs, average costs for inpatient services and physician services were 13\%, 13\% and 20\% higher, respectively, for SEER-Medicare cohort than for WV-Medicare cohort as seen in Table 2. These findings did not change even after controlling for the comprehensive list of covariates in the multivariate framework. A part of the lower costs in a rural state such as WV as compared to the SEER-Medicare regions may be due to the differences in the Medicare spending across various geographic regions in the US ${ }^{40}$. In addition, average costs by stage at diagnosis, type of initial treatment, and comorbidity scores were also lower for the BC patients in WV than that for the SEER-Medicare elderly women.

In contrast to study by Warren et al., it was found that physician services was the major contributor to the total average costs in the initial phase of care among the elderly WV-Medicare and SEER-Medicare beneficiaries with $\mathrm{BC}^{10}$, followed by outpatient costs and inpatient costs. Average costs for physician services, inpatient services, and outpatient services were lower for WV-Medicare cohort as compared to their national counterparts. Among users of specific services, average costs due to inpatient services was the highest for both the groups, followed by average costs due to physician services. However, these costs were lower for WV-Medicare cohort as compared to their national counterparts. These findings are surprising given the fact 
that elderly WV women with BC have higher comorbidity burden and possibly greater proportion of negative health-outcomes which may increase their total average costs.

In elderly WV women with $\mathrm{BC}$, the factors associated with higher costs during the initial phase of care were advanced stages of the cancer, surgery with adjuvant therapy or adjuvant therapy only, any hospitalization, presence of two or more physical chronic conditions, and presence of depression and/or anxiety. But older age was associated with lower average costs in these women. These findings were consistent with those reported in the previous study on Virginia population ${ }^{11}$. These findings highlight the importance of encouraging women to utilize preventive screenings to get them diagnosed at earlier stages of BC. In addition, the findings also emphasize the importance of better co-management of physical and mental chronic conditions in elderly women with BC, to lower overall costs to Medicare in a rural state such as WV. Emerging healthcare delivery models such as 'medical homes' which emphasize carecoordination for management of the elderly Medicare beneficiaries with multiple chronic conditions are a step in the right direction.

The differences in the total average costs for elderly women with $\mathrm{BC}$ were also examined between the two cohorts in a multivariable setting. There were statistically significant difference in the total average costs between the two groups after controlling for the predisposing, enabling, need-related, healthcare use, and external healthcare environmental factors. The difference in total average costs in the initial phase of care reduced from $\$ 3,006$ to $\$ 549$ after adjusting for all the covariates.

The study also utilized the unique Blinder-Oaxaca linear decomposition technique to examine the extent to which the differences in the various factors explained the difference in the total average costs between the two cohorts. Enabling resources (household income and 
education), and healthcare use (PCP visits, type of initial treatment, inpatient use) primarily explained the differences in the total average costs between the two populations. These findings are consistent to the findings from previous studies which reported that the differences in healthcare spending is largely explained by the differential treatment pattern owing to the supply of physicians and hospital resources in the area, and also household income and education ${ }^{41-44}$. Hence, if both the study populations have similar household income and education, PCP visits, initial treatment and inpatient use then the difference in the total average costs would shrink. A noteworthy finding of this study is that around $84 \%$ of the difference in total average expenditures between the two populations remained unexplained. It is plausible that some portion of this difference may be due to unmeasured factors such as health status, severity of comorbid conditions, body mass index, patient preferences and propensity to seek care. The results of the post-hoc decomposition analyses after adding additional healthcare use factors such as number of radiation visits, number of chemotherapy visits and type of surgeon seen by the beneficiaries did not increase the 'explained' portion of the differences in the total average costs between the two study cohorts. Hence, healthcare utilization may not be a contributing factor for lower total average costs in the initial phase for the WV-Medicare cohort as compared to the national averages.

Since the analyses of the costs for $\mathrm{BC}$ utilized the data from administrative claims, the results of this study should be interpreted with caution. Any healthcare services obtained outside of Medicare settings may not be captured, hence the costs may be underestimated. The costs of adjuvant therapy with prescription drugs were not captured in the analyses as these costs were not covered by Medicare prior to 2007. Also, indirect medical costs (e.g. cost due to lost productivity), indirect non-medical costs, and out-of-pocket costs borne by patients were not 
included and hence the findings do not represent the total costs during the initial phase of care. Certain patient characteristics such as annual household income, education level, access to total of $\mathrm{BC}$ screening centers at patient level are not available in the cancer registries-Medicare linked databases and hence census tract information for these variables have been utilized ${ }^{45}$. Data on some important variables such as health status, severity of comorbidities, and patient preferences which may be important predictors of their cancer prognosis, or selection of type of treatment were not available. Moreover, the findings of this study are generalizable to elderly BC patients only covered by Medicare. Also the findings are not generalizable to other rural populations. Costs may vary in a younger population due to differences in their age and insurance coverage.

\section{CONCLUSION}

The difference in the total average expenditures between the elderly beneficiaries with $\mathrm{BC}$ from a rural state such as WV and their national counterparts narrowed but remained significantly lower after multivariate adjustment, and is mainly driven by enabling factors and healthcare use factors. Further research focusing on the incremental costs among elderly beneficiaries with $\mathrm{BC}$ with combination of different comorbid conditions from rural areas is suggested. 


\section{REFERENCES}

1. American Cancer Society. Breast Cancer Facts and Figures 2013-2014. Atlanta, GA. http://www.cancer.org/acs/groups/content/@ research/documents/document/acspc-040951.pdf. Updated 2013. Accessed 02/19, 2014.

2. Howlader N, Noone A, Krapcho M, et al. SEER cancer statistics review, 1975-2009 (Vintage 2009 populations), National Cancer Institute. Bethesda, MD. Based on november 2011 SEER data submission. http://seer.cancer.gov/csr/1975_2009_pops09/. Updated April 2012. Accessed 02/19, 2014.

3. Mariotto AB, Yabroff KR, Shao Y, Feuer EJ, Brown ML. Projections of the cost of cancer care in the United States: 2010-2020. J Natl Cancer Inst. 2011;103(2):117-128.

4. Yabroff KR, Warren JL, Brown ML. Costs of cancer care in the USA: A descriptive review. Nat Clin Pract Oncol. 2007;4(11):643-656.

5. Campbell JD, Ramsey SD. The costs of treating breast cancer in the US: A synthesis of published evidence. Pharmacoeconomics. 2009;27(3):199-209.

6. Brown ML, Riley GF, Schussler N, Etzioni R. Estimating health care costs related to cancer treatment from SEER-Medicare data. Med Care. 2002;40(8 Suppl):IV-104-17.

7. Yabroff KR, Lamont EB, Mariotto A, et al. Cost of care for elderly cancer patients in the United States. J Natl Cancer Inst. 2008;100(9):630-641.

8. Warren JL, Brown ML, Fay MP, Schussler N, Potosky AL, Riley GF. Costs of treatment for elderly women with early-stage breast cancer in fee-for-service settings. J Clin Oncol. 2002;20(1):307-316.

9. Riley GF, Potosky AL, Lubitz JD, Kessler LG. Medicare payments from diagnosis to death for elderly cancer patients by stage at diagnosis. Med Care. 1995;33(8):828-841.

10. Warren JL, Yabroff KR, Meekins A, Topor M, Lamont EB, Brown ML. Evaluation of trends in the cost of initial cancer treatment. J Natl Cancer Inst. 2008;100(12):888-897.

11. Penberthy L, Retchin SM, McDonald MK, et al. Predictors of Medicare costs in elderly beneficiaries with breast, colorectal, lung, or prostate cancer. Health Care Manag Sci. 1999;2(3):149-160.

12. U.S. Census Bureau. Persons 25 years old and over with a bachelor's degree or more, 2008. Washington, DC: U.S. Census Bureau. http://www.census.gov/compendia/statab/2010/ranks/rank19.html. Updated 2010. Accessed 02/24, 2014. 
13. U.S. Census Bureau. Persons below the poverty level, 2008. Washington, DC: U.S. Census Bureau. http://www.census.gov/compendia/statab/2010/ranks/rank34.html. Updated 2010. Accessed 02/24, 2014.

14. Kaiser State Health Facts. Overweight and obesity rates for adults by sex, 2009. Menlo Park, CA: Kaiser Family Foundation. http://www.statehealthfacts.org. Updated 2009. Accessed 02/24, 2014.

15. Kaiser State Health Facts. Percent of adults who smoke by sex, 2008. Menlo Park, CA: Kaiser Family Foundation. http://www.statehealthfacts.org. Updated 2008. Accessed 02/24, 2014.

16. SEER State Cancer Profiles 2009.

http://statecancerprofiles.cancer.gov/map/map.withimage.php?00\&157\&055\&00\&2\&01\&1\&1\& 6\&0\#map. Updated 2009. Accessed 02/19, 2014.

17. SEER State Cancer Profiles 2009.

http://statecancerprofiles.cancer.gov/map/map.withimage.php?00\&157\&055\&00\&2\&02\&1\&1\& 6\&0\#map. Updated 2009. Accessed 02/19, 2014.

18. Wingo PA, Tucker TC, Jamison PM, et al. Cancer in Appalachia, 2001-2003. Cancer. 2008;112(1):181-192.

19. Lengerich EJ, Chase GA,Beiler J, Darnell M. Increased risk of unknown stage cancer from residence in a rural area: Health disparities with poverty and minority status. Hershey, PA:

Pennsylvania State University and the Penn State Cancer Institute, Department of Health Evaluation Sciences. 2006.

20. State Cancer Profiles. Incidence and mortality rate reports for West Virginia by county, 2010. Bethesda, MD: National Cancer Institute. http://statecancerprofiles.cancer.gov/. Updated 2010. Accessed 02/24, 2014.

21. United States Cancer Statistics. State vs. National Rates: 2006, female, West Virginia. Atlanta, GA: Centers for Disease Control and Prevention (CDC). http://apps.nccd.cdc.gov/uscs/. Updated 2010. Accessed 02/24, 2014.

22. United States Cancer Statistics. Rankings by state: 2006, male and female, all cancer sites combined. Atlanta, GA: Centers for Disease Control and Prevention (CDC). http://apps.nccd.cdc.gov/uscs/. Updated 2010. Accessed 02/24, 2014.

23. Blinder AS. Wage discrimination: Reduced form and structural estimates. J Hum Resour. 1973;8(4):436-455. http://search.ebscohost.com/login.aspx?direct=true \&db=22h\&AN=5080767\&site=ehost-live.

24. Oaxaca R. Male-female wage differentials in urban labor markets. International economic review. 1973:693-709. 
25. Cancer Incidence in West Virginia, 1993-2009, West Virginia Cancer Registry, Charleston WV, 2012.

26. Nadpara PA, Madhavan SS. Linking Medicare, Medicaid, and cancer registry data to study the burden of cancers in West Virginia. Medicare and Medicaid Research Review. 2012;2(4):02/25/2014.

27. Warren JL, Klabunde CN, Schrag D, Bach PB, Riley GF. Overview of the SEER-Medicare data: Content, research applications, and generalizability to the united states elderly population. Med Care. 2002;40(8 Suppl):IV-3-18.

28. Taplin SH, Barlow W, Urban N, et al. Stage, age, comorbidity, and direct costs of colon, prostate, and breast cancer care. J Natl Cancer Inst. 1995;87(6):417-426.

29. Finkler SA. The distinction between cost and charges. Ann Intern Med. 1982;96(1):102-109.

30. Consumer price index: Bureau of labor statistics, medical care services, 1982-84.

http://www.bls.gov/cpi/data.htm. Updated 2014. Accessed 02/27, 2014.

31. Andersen RM. Revisiting the behavioral model and access to medical care: Does it matter? $J$ Health Soc Behav. 1995;36(1):1-10.

32. Andersen R, Newman JF. Societal and individual determinants of medical care utilization in the united states. Milbank Mem Fund Q Health Soc. 1973;51(1):95-124.

33. Young,J.LJr., Roffers,S.D., Ries,L.A.G., Fritz,A.G., Hurlbut,A.A. (eds). SEER summary staging manual-2000: Codes and coding instructions, National Cancer Institute, NIH pub. no. 014969. 2001.

34. Klabunde CN, Potosky AL, Legler JM, Warren JL. Development of a comorbidity index using physician claims data. J Clin Epidemiol. 2000;53(12):1258-1267.

35. Charlson ME, Pompei P, Ales KL, MacKenzie CR. A new method of classifying prognostic comorbidity in longitudinal studies: Development and validation. J Chronic Dis.

1987;40(5):373-383.

36. National Cancer Institute: SEER-Medicare: Calculation of comorbidity weights. . http://healthservices.cancer.gov/seermedicare/program/comorbidity.html. Updated 2013. Accessed 02/25, 2014.

37. Yu X, McBean AM, Virnig BA. Physician visits, patient comorbidities, and mammography use among elderly colorectal cancer survivors. J Cancer Surviv. 2007;1(4):275-282.

38. Manning WG. The logged dependent variable, heteroscedasticity, and the retransformation problem. J Health Econ. 1998;17(3):283-295. 
39. Manning WG, Mullahy J. Estimating log models: To transform or not to transform? J Health Econ. 2001;20(4):461-494.

40. Super $\mathrm{N}$. The geography of medicare: Explaining differences in payment and costs. NHPF Issue Brief. 2003;(792)(792):1-19.

41. Brooks GA, Li L, Sharma DB, et al. Regional variation in spending and survival for older adults with advanced cancer. J Natl Cancer Inst. 2013;105(9):634-642.

42. Fisher ES, Wennberg DE, Stukel TA, Gottlieb DJ, Lucas FL, Pinder EL. The implications of regional variations in Medicare spending. Part 1: The content, quality, and accessibility of care. Ann Intern Med. 2003;138(4):273-287.

43. Fisher ES, Wennberg DE, Stukel TA, Gottlieb DJ, Lucas FL, Pinder EL. The implications of regional variations in Medicare spending. Part 2: Health outcomes and satisfaction with care. Ann Intern Med. 2003;138(4):288-298.

44. Zuckerman S, Waidmann T, Berenson R, Hadley J. Clarifying sources of geographic differences in Medicare spending. $N$ Engl J Med. 2010;363(1):54-62.

45. Krieger N. Overcoming the absence of socioeconomic data in medical records: Validation and application of a census-based methodology. Am J Public Health. 1992;82(5):703-710. 


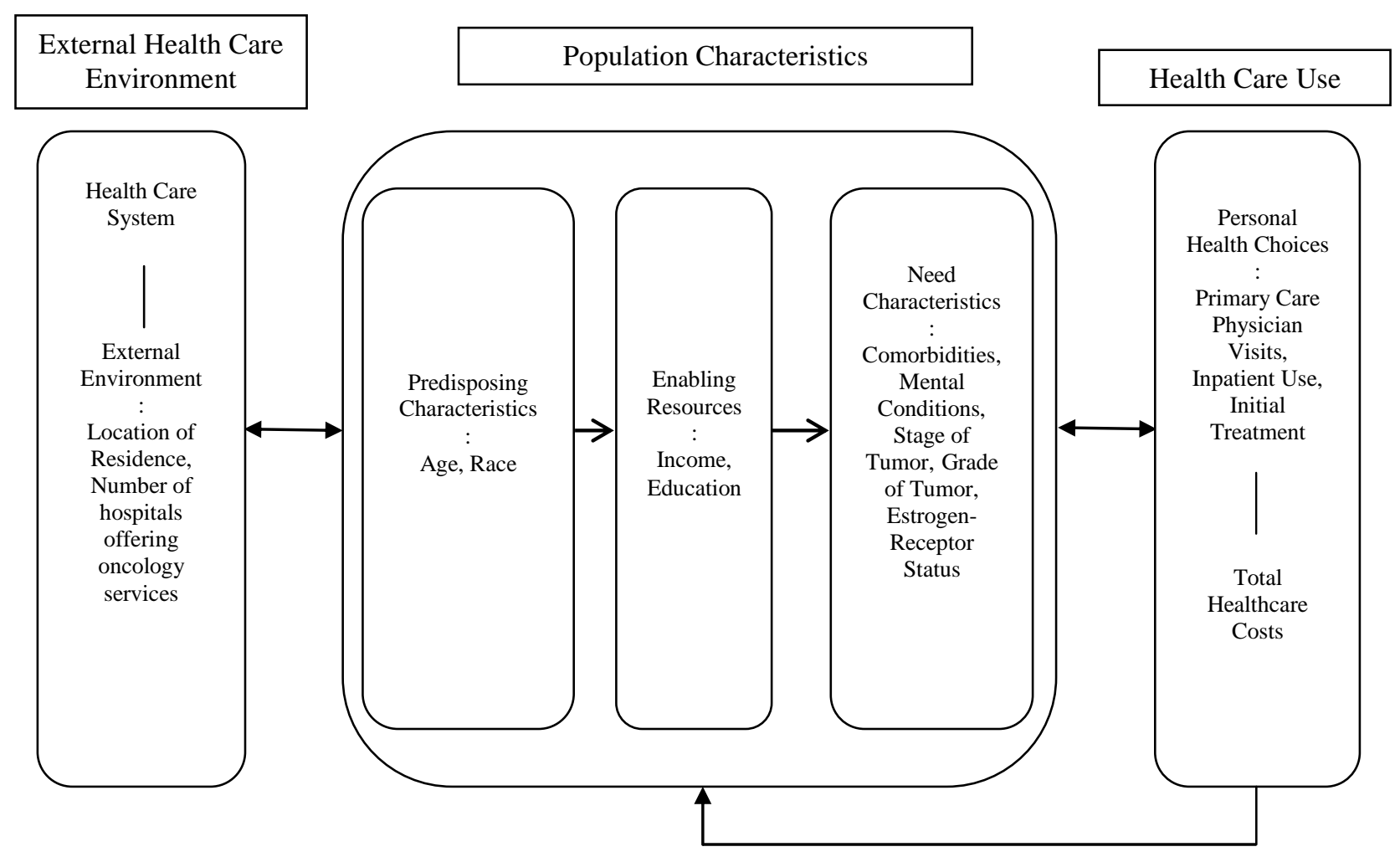

Figure 4.1: The Andersen Behavioral Model for Health Care Utilization (Aim 3) 
Table 4.1

Description of the Study Cohorts

2003-2006

\begin{tabular}{|c|c|c|c|c|c|}
\hline \multirow[t]{2}{*}{ Variables } & \multicolumn{2}{|c|}{$\begin{array}{c}\text { WV-Medicare } \\
(\mathrm{N}=\mathbf{1 , 3 8 7})\end{array}$} & \multicolumn{2}{|c|}{$\begin{array}{c}\text { SEER-Medicare } \\
(\mathbf{N}=\mathbf{3 9}, \mathbf{5 2 5})\end{array}$} & \multirow[b]{2}{*}{ Sig } \\
\hline & $\mathbf{N}$ & $\%$ & $\mathbf{N}$ & $\%$ & \\
\hline Age at Diagnosis & & & & & $* * *$ \\
\hline $66-69$ & 275 & 19.8 & 8,799 & 22.3 & \\
\hline $70-74$ & 384 & 27.7 & 9,868 & 25.0 & \\
\hline $75-79$ & 379 & 27.3 & 9,331 & 23.6 & \\
\hline $80,+$ & 349 & 25.2 & 11,527 & 29.2 & \\
\hline Race & & & & & $* * *$ \\
\hline White & 1,354 & 97.6 & 34,992 & 88.5 & \\
\hline Other & 33 & 2.4 & 4,533 & 11.5 & \\
\hline Location of Residence & & & & & $* * *$ \\
\hline Metro & 761 & 54.9 & 32,989 & 83.5 & \\
\hline Non-metro & 626 & 45.1 & 6,536 & 16.5 & \\
\hline Census Tract Household Income & & & & & $* * *$ \\
\hline LE $\$ 35,000$ & 1,267 & 91.4 & 9,764 & 24.7 & \\
\hline GT $\$ 35,000$ & 120 & 8.6 & 29,761 & 75.3 & \\
\hline Census Tract Education & & & & & $* * *$ \\
\hline LT $15 \%$ pop. with CE & 703 & 50.7 & 12,056 & 30.5 & \\
\hline GE $15 \%$ pop. with CE & 684 & 49.3 & 27,469 & 69.5 & \\
\hline Stage at Diagnosis & & & & & $* *$ \\
\hline Insitu & 209 & 15.1 & 6,610 & 16.7 & \\
\hline Local & 866 & 62.5 & 22,738 & 57.5 & \\
\hline Regional & 273 & 19.7 & 8,985 & 22.7 & \\
\hline Distant & 39 & 2.7 & 1,192 & 3.0 & \\
\hline Grade of Tumor & & & & & $* * *$ \\
\hline Well Differentiated & 325 & 23.4 & 8,459 & 21.4 & \\
\hline Moderately Differentiated & 472 & 34.0 & 15,524 & 39.3 & \\
\hline Poorly Differentiated & 306 & 22.1 & 9,969 & 25.2 & \\
\hline Undifferentiated/Unknown & 284 & 20.5 & 5,573 & 14.1 & \\
\hline ER Status & & & & & $* * *$ \\
\hline Positive & 627 & 45.2 & 27,260 & 69.0 & \\
\hline Negative & 126 & 9.1 & 5,412 & 13.7 & \\
\hline Borderline/Unknown & 634 & 45.7 & 6,853 & 17.3 & \\
\hline Initial Treatment & & & & & $* *$ \\
\hline Surgery Only & 560 & 40.4 & 14,478 & 36.6 & \\
\hline Surgery+Adjuvant Therapy & 765 & 55.2 & 23,494 & 59.4 & \\
\hline Adjuvant Therapy Only & 16 & 1.2 & 581 & 1.5 & \\
\hline No Treatment & 46 & 3.3 & 972 & 2.5 & \\
\hline \multicolumn{6}{|l|}{ Inpatient Use } \\
\hline Yes & 681 & 49.1 & 18,621 & 47.1 & \\
\hline No & 706 & 50.9 & 20,904 & 52.9 & \\
\hline Comorbidity & & & & & $* * *$ \\
\hline $1-10$ conditions & 715 & 51.6 & 23,039 & 58.3 & \\
\hline 11 to 20 conditions & 416 & 30.0 & 10,629 & 26.9 & \\
\hline$>20$ conditions & 256 & 18.4 & 5,857 & 14.8 & \\
\hline Mental Condition & & & & & $* * *$ \\
\hline Yes & 134 & 9.7 & 2,411 & 6.1 & \\
\hline \multirow[t]{2}{*}{ No } & 1,253 & 90.3 & 37,114 & 93.9 & \\
\hline & & & \multicolumn{2}{|c|}{ (Continued)... } & \\
\hline
\end{tabular}


Table 4.1

Description of the Study Cohorts

2003-2006

\begin{tabular}{|c|c|c|c|c|c|}
\hline \multirow[t]{2}{*}{ Variables } & \multicolumn{2}{|c|}{$\begin{array}{c}\text { WV-Medicare } \\
(\mathrm{N}=\mathbf{1 , 3 8 7})\end{array}$} & \multicolumn{2}{|c|}{$\begin{array}{c}\text { SEER-Medicare } \\
(\mathrm{N}=\mathbf{3 9 , 5 2 5})\end{array}$} & \multirow[b]{2}{*}{ Sig } \\
\hline & $\mathbf{N}$ & $\%$ & $\mathbf{N}$ & $\%$ & \\
\hline PCP visits & & & & & $*$ \\
\hline High & 681 & 49.1 & 18,051 & 45.7 & \\
\hline Low & 706 & 50.9 & 21,474 & 54.3 & \\
\hline Total Hospitals with Oncology Services & & & & & $* * *$ \\
\hline High & 551 & 39.7 & 17,613 & 44.6 & \\
\hline Low & 836 & 60.3 & 21,912 & 55.4 & \\
\hline
\end{tabular}

Note: Based on 1,387 elderly WV-Medicare women and 39,525 elderly SEER-Medicare women, age 66 and above diagnosed with primary incident breast cancer from 2003 to 2006. WV, West Virginia; SEER, Surveillance, Epidemiology, and End Results; ER, Estrogen-receptor; PCP, Primary Care Physicians; CE, College Education; pop., population; LE, Less than or equal to; GT, Greater than; LT, Less than; GE, Greater than or equal to; Sig, Significance. Asterisks represent statistically significant group differences based on $\chi 2$ tests: $* * * \mathrm{P}<0.001 ; * * 001<=\mathrm{P}<.01 ; * .01<=\mathrm{P}<.05$.

Table 4.2

Description of the Study Cohorts for Differences in the Healthcare Utilization 2003-2006

\begin{tabular}{|c|c|c|c|c|c|}
\hline \multirow[t]{2}{*}{ Variables } & \multicolumn{2}{|c|}{$\begin{array}{c}\text { WV-Medicare } \\
(\mathrm{N}=\mathbf{1 , 3 8 7})\end{array}$} & \multicolumn{2}{|c|}{$\begin{array}{c}\text { SEER-Medicare } \\
(\mathrm{N}=\mathbf{3 9 , 5 2 5})\end{array}$} & \multirow[b]{2}{*}{ Sig } \\
\hline & $\mathbf{N}$ & $\%$ & $\mathbf{N}$ & $\%$ & \\
\hline Radiation Visits & & & & & $* * *$ \\
\hline No visit & 700 & 50.5 & 18,475 & 46.7 & \\
\hline Low visits (1-10) & 201 & 14.5 & 11,563 & 29.3 & \\
\hline High visits $(10,+)$ & 486 & 35.0 & 9,487 & 24.0 & \\
\hline \multicolumn{6}{|l|}{ Chemotherapy Visits } \\
\hline No & 1,084 & 78.2 & 30,545 & 77.3 & \\
\hline Yes & 303 & 21.8 & 8,980 & 22.7 & \\
\hline \multicolumn{6}{|l|}{ Type of Surgeon Seen } \\
\hline No surgeon seen & 31 & 2.2 & 752 & 1.9 & \\
\hline General Surgeon & 355 & 25.6 & 9,287 & 23.5 & \\
\hline Oncology Surgeon & 73 & 5.3 & 2,320 & 5.9 & \\
\hline Both & 928 & 66.9 & 27,166 & 68.7 & \\
\hline
\end{tabular}

Note: Based on 1,387 elderly WV-Medicare women and 39,525 elderly SEER-Medicare women, age 66 and above diagnosed with primary incident breast cancer from 2003 to 2006. WV, West Virginia; SEER, Surveillance, Epidemiology, and End Results; Sig, Significance. Asterisks represent statistically significant group differences based on $\chi 2$ tests: $* * * \mathrm{P}<0.001$; $* * 001<=\mathrm{P}<.01 ; * .01<=\mathrm{P}<.05$. 
Table 4.3

Average Total Healthcare Costs and Average Healthcare Costs by Type of Service For the Study Cohorts

2003-2006

\begin{tabular}{|c|c|c|c|c|c|c|c|}
\hline & \multicolumn{7}{|c|}{ Among All Users } \\
\hline & \multicolumn{3}{|c|}{ WV-Medicare $(\mathrm{N}=1,387)$} & \multicolumn{3}{|c|}{ SEER-Medicare $(\mathrm{N}=39,525)$} & \multirow[t]{2}{*}{$\begin{array}{c}\text { Ratio-of- } \\
\text { Means } \\
\end{array}$} \\
\hline & Average (\$) & SE & $\%$ & Average (\$) & SE & $\%$ & \\
\hline Total $* * *$ & 19,875 & 483 & $100 \%$ & 22,881 & 100 & $100 \%$ & 0.87 \\
\hline Inpatient* & 4,707 & 255 & $24 \%$ & 5,254 & 59 & $23 \%$ & 0.90 \\
\hline Outpatient & 5,767 & 237 & $29 \%$ & 5,806 & 34 & $25 \%$ & 0.99 \\
\hline Physician Services*** & 8,684 & 261 & $44 \%$ & 10,800 & 57 & $47 \%$ & 0.80 \\
\hline \multirow[t]{4}{*}{ Other (HHA, HSP, DME) $* * *$} & 716 & 60 & $4 \%$ & 1,020 & 16 & $4 \%$ & 0.70 \\
\hline & \multicolumn{6}{|c|}{ Among Users of Specific Services } & \\
\hline & \multicolumn{3}{|c|}{ WV-Medicare } & \multicolumn{3}{|c|}{ SEER-Medicare } & \\
\hline & $\mathbf{N}$ & Average (\$) & SE & $\mathbf{N}$ & Average (\$) & SE & \\
\hline Inpatient* & 670 & 9,745 & 454 & 18,479 & 11,239 & 111 & \\
\hline Outpatient & 1,372 & 5,830 & 239 & 38,531 & 5,956 & 34 & \\
\hline Physician Services*** & 1,387 & 8,684 & 261 & 39,474 & 10,814 & 57 & \\
\hline Other (HHA, HSP, DME) ${ }^{* * *}$ & 727 & 1,366 & 110 & 19,579 & 2,060 & 31 & \\
\hline
\end{tabular}

Note: Based on 1,387 elderly WV-Medicare women and 39,525 elderly SEER-Medicare women, age 66 and above diagnosed with primary incident breast cancer from 2003 to 2006. WV, West Virginia; SEER, Surveillance, Epidemiology, and End Results; CPI, Consumer Price Index; HHA, Home Health Agency; HSP, Hospice; DME, Durable Medical Equipment; SE, Standard Error. Asterisks represent statistically significant group differences based on t-tests: $* * * \mathrm{P}<0.001 ; * * 001<=\mathrm{P}<.01$; $* .01<=\mathrm{P}<.05$. 
Table 4.4

Average Total Healthcare Costs for Clinically Important Variables For the Study Cohorts 2003-2006

\begin{tabular}{|c|c|c|c|c|c|c|c|}
\hline & \multicolumn{7}{|c|}{ Among All Users } \\
\hline & \multicolumn{3}{|c|}{ WV-Medicare } & \multicolumn{3}{|c|}{ SEER-Medicare } & \multirow[t]{2}{*}{ Ratio-of-Means } \\
\hline & $\mathbf{N}$ & $\begin{array}{l}\text { Average } \\
\text { costs }(\$)\end{array}$ & SE & $\mathbf{N}$ & $\begin{array}{l}\text { Average } \\
\text { costs }(\$) \\
\end{array}$ & SE & \\
\hline \multicolumn{8}{|l|}{ Stage at Diagnosis } \\
\hline Insitu & 209 & 13,148 & 871 & 6,610 & 14,872 & 169 & 0.88 \\
\hline Local & 866 & 17,484 & 514 & 22,738 & 20,124 & 107 & 0.87 \\
\hline Regional & 273 & 31,592 & 1,401 & 8,985 & 33,024 & 255 & 0.96 \\
\hline Distant & 39 & 27,073 & 3,635 & 1,192 & 43,431 & 973 & 0.62 \\
\hline \multicolumn{8}{|l|}{ Initial Treatment } \\
\hline Surgery Only & 560 & 12,306 & 593 & 14,478 & 15,119 & 137 & 0.81 \\
\hline Surgery+Adjuvant Therapy & 765 & 25,664 & 660 & 23,494 & 27,774 & 129 & 0.92 \\
\hline Adjuvant Therapy Only & 16 & 26,498 & 3,832 & 581 & 33,786 & 1,254 & 0.78 \\
\hline No Treatment & 46 & 13,422 & 3,160 & 972 & 13,699 & 751 & 0.98 \\
\hline \multicolumn{8}{|l|}{ Comorbidity } \\
\hline 0 & 715 & 18,432 & 625 & 23,039 & 21,438 & 119 & 0.86 \\
\hline 1 & 416 & 21,034 & 954 & 10,629 & 23,412 & 199 & 0.90 \\
\hline $2,+$ & 256 & 22,018 & 1,171 & 5,857 & 27,593 & 324 & 0.80 \\
\hline
\end{tabular}

Note: Based on 1,387 elderly WV-Medicare women and 39,525 elderly SEER-Medicare women, age 66 and above diagnosed with primary incident breast cancer from 2003 to 2006. WV, West Virginia; SEER, Surveillance, Epidemiology, and End Results; CPI, Consumer Price Index; SE, Standard Error. 
Table 4.5

Factors Associated with Average Total Healthcare Costs Separately for the Study Cohorts Using Generalized Linear Model Regressions 2003-2006

\begin{tabular}{|c|c|c|c|c|c|c|c|c|}
\hline \multirow[t]{2}{*}{ Variables } & \multicolumn{4}{|c|}{ WV-Medicare $(\mathrm{N}=1,387)$} & \multicolumn{4}{|c|}{ SEER-Medicare $(\mathrm{N}=39,525)$} \\
\hline & Beta & $\begin{array}{l}\text { Average } \\
\text { costs }(\$)\end{array}$ & SE & Sig & Beta & $\begin{array}{l}\text { Average } \\
\text { costs (\$) }\end{array}$ & SE & Sig \\
\hline Intercept (Baseline Costs) & 8.6015 & 5,440 & 0.1342 & $* * *$ & 8.6028 & 5,447 & 0.0252 & $* * *$ \\
\hline \multicolumn{9}{|l|}{ Age at Diagnosis } \\
\hline \multicolumn{9}{|l|}{$66-69$} \\
\hline $70-74$ & -0.0666 & 5,089 & 0.0503 & & -0.0349 & 5,260 & 0.0086 & $* * *$ \\
\hline $75-79$ & -0.1678 & 4,599 & 0.0507 & $* * *$ & -0.0836 & 5,010 & 0.0088 & $* * *$ \\
\hline $80,+$ & -0.1121 & 4,863 & 0.0538 & $*$ & -0.1376 & 4,747 & 0.0088 & $* * *$ \\
\hline \multicolumn{9}{|l|}{ Race } \\
\hline \multicolumn{9}{|l|}{ White } \\
\hline Other & -0.0233 & 5,315 & 0.1120 & & -0.0096 & 5,395 & 0.0096 & \\
\hline \multicolumn{9}{|l|}{ Location of Residence } \\
\hline \multicolumn{9}{|l|}{ Metro } \\
\hline Non-metro & -0.0762 & 5,041 & 0.0440 & & -0.0814 & 5,021 & 0.0092 & $* * *$ \\
\hline \multicolumn{9}{|l|}{ Census Tract Household Income } \\
\hline \multicolumn{9}{|l|}{ LE $\$ 35,000$} \\
\hline GT $\$ 35,000$ & 0.0208 & 5,554 & 0.0755 & & 0.0150 & 5,529 & 0.0084 & \\
\hline \multicolumn{9}{|l|}{ Census Tract Education } \\
\hline \multicolumn{9}{|l|}{ LT $15 \%$ pop. with CE } \\
\hline GE $15 \%$ pop. with CE & -0.0075 & 5,399 & 0.0477 & & 0.0285 & 5,604 & 0.0076 & $* * *$ \\
\hline \multicolumn{9}{|l|}{ Stage at Diagnosis } \\
\hline \multicolumn{9}{|l|}{ Insitu } \\
\hline Local & 0.0940 & 5,976 & 0.0508 & & 0.1625 & 6,408 & 0.0091 & $* * *$ \\
\hline Regional & 0.4257 & 8,327 & 0.0617 & $* * *$ & 0.4081 & 8,192 & 0.0106 & $* * *$ \\
\hline Distant & 0.5909 & 9,822 & 0.1220 & $* * *$ & 0.7389 & 11,404 & 0.0203 & $* * *$ \\
\hline \multicolumn{9}{|l|}{ Grade of Tumor } \\
\hline \multicolumn{9}{|l|}{ Well Differentiated } \\
\hline Moderately Differentiated & -0.0061 & 5,407 & 0.0462 & & 0.0282 & 5,603 & 0.0080 & $* * *$ \\
\hline Poorly Differentiated & 0.0118 & 5,504 & 0.0538 & & 0.0977 & 6,006 & 0.0093 & $* * *$ \\
\hline Undifferentiated/Unknown & -0.0504 & 5,172 & 0.0539 & & 0.0365 & 5,649 & 0.0108 & $* * *$ \\
\hline \multicolumn{9}{|l|}{ ER Status } \\
\hline Positive & & & & & & & & \\
\hline Negative & 0.1061 & 6,049 & 0.0649 & & 0.0976 & 6,005 & 0.0094 & $* * *$ \\
\hline Borderline/Unknown & -0.0402 & 5,225 & 0.0369 & & 0.0111 & 5,508 & 0.0087 & \\
\hline
\end{tabular}


Table 4.5

Factors Associated with Average Total Healthcare Costs Separately for the Study Cohorts Using Generalized Linear Model Regressions

2003-2006

\begin{tabular}{|c|c|c|c|c|c|c|c|c|}
\hline \multirow[t]{2}{*}{ Variables } & \multicolumn{4}{|c|}{ WV-Medicare $(\mathrm{N}=1,387)$} & \multicolumn{4}{|c|}{ SEER-Medicare $(\mathrm{N}=39,525)$} \\
\hline & Beta & $\begin{array}{l}\text { Average } \\
\text { costs }(\$)\end{array}$ & SE & Sig & Beta & $\begin{array}{l}\text { Average } \\
\text { costs (\$) }\end{array}$ & SE & Sig \\
\hline \multicolumn{9}{|l|}{ Initial Treatment } \\
\hline Surgery Only & 0.1165 & 6,112 & 0.1040 & & 0.1843 & 6,549 & 0.0201 & $* * *$ \\
\hline Surgery+Adjuvant Therapy & 1.0199 & 15,084 & 0.1051 & $* * *$ & 0.9223 & 13,699 & 0.0202 & $* * *$ \\
\hline Adjuvant Therapy Only & 0.7929 & 12,021 & 0.1867 & $* * *$ & 0.7776 & 11,854 & 0.0317 & $* * *$ \\
\hline No Treatment & & & & & & & & \\
\hline \multicolumn{9}{|l|}{ Inpatient Use } \\
\hline Yes & 0.7829 & 11,901 & 0.0370 & $* * *$ & 0.7065 & 11,040 & 0.0065 & $* * *$ \\
\hline No & & & & & & & & \\
\hline \multicolumn{9}{|l|}{ Comorbidity } \\
\hline 0 & & & & & & & & \\
\hline 1 & 0.0726 & 5,849 & 0.0395 & & 0.0668 & 5,823 & 0.0070 & $* * *$ \\
\hline $2,+$ & 0.1904 & 6,581 & 0.0478 & $* * *$ & 0.2105 & 6,723 & 0.0090 & $* * *$ \\
\hline \multicolumn{9}{|l|}{ Mental Condition } \\
\hline Yes & 0.2480 & 6,971 & 0.0581 & $* * *$ & 0.0841 & 5,925 & 0.0125 & $* * *$ \\
\hline No & & & & & & & & \\
\hline \multicolumn{9}{|l|}{ PCP visits } \\
\hline High & 0.0138 & 5,515 & 0.0353 & & 0.0786 & 5,892 & 0.0062 & $* * *$ \\
\hline Low & & & & & & & & \\
\hline \multicolumn{9}{|l|}{ Total Hospitals with Oncology Services } \\
\hline High & 0.0654 & 5,807 & 0.0498 & & 0.0738 & 5,864 & 0.0066 & $* * *$ \\
\hline Low & & & & & & & & \\
\hline
\end{tabular}

Note: Based on average costs in initial phase of care, in 1,387 elderly WV-Medicare women and 39,525 elderly SEER-Medicare women, age 66 and above from 2003 to 2006 diagnosed with first primary incident breast cancer from 2003 to 2006 . FFS, Feefor-service; WV, West Virginia; SEER, Surveillance, Epidemiology, and End Results; CPI, Consumer Price Index; SE, Standard Error; ER, Estrogen-receptor; PCP, Primary Care Physicians; CE, College Education; pop., population; LE, Less than or equal to; GT, Greater than; LT, Less than; GE, Greater than or equal to; Sig, Significance. Asterisks represent statistically significant group differences based on Generalized Linear Model with gamma distribution and log link function: $* * * \mathrm{P}<0.001$; $* * 001<=\mathrm{P}<.01 ; * .01<=\mathrm{P}<.05$. 
Table 4.6

Differences in Average Total Costs between the Study Cohorts

Using Generalized Linear Model Regressions

2003-2006

\begin{tabular}{|c|c|c|c|c|c|c|c|c|c|c|c|c|c|c|c|c|}
\hline & \multicolumn{4}{|c|}{ Model 1} & \multicolumn{4}{|c|}{ Model 2} & \multicolumn{4}{|c|}{ Model 3} & \multicolumn{4}{|c|}{ Model 4} \\
\hline & Beta & $\begin{array}{l}\text { Average } \\
\text { costs }(\$)\end{array}$ & SE & Sig & Beta & $\begin{array}{l}\text { Average } \\
\text { costs }(\$)\end{array}$ & SE & Sig & Beta & $\begin{array}{l}\text { Average } \\
\text { costs }(\$)\end{array}$ & SE & Sig & Beta & $\begin{array}{l}\text { Average } \\
\text { costs }(\$)\end{array}$ & SE & Sig \\
\hline \multicolumn{17}{|l|}{ Total Costs } \\
\hline Intercept & 10.0381 & 22,882 & 0.0039 & $* * *$ & 10.1151 & 24,713 & 0.0111 & $* * *$ & 8.5944 & 5,401 & 0.0244 & $* * *$ & 8.6060 & 5,464 & 0.0248 & $* * *$ \\
\hline WV-Medicare & -0.1410 & 19,873 & 0.0210 & $* * *$ & -0.1107 & 22,124 & 0.0218 & $* * *$ & -0.1029 & 4,873 & 0.0170 & $* * *$ & -0.1059 & 4,915 & 0.0170 & $* * *$ \\
\hline \multicolumn{17}{|l|}{ SEER-Medicare } \\
\hline \multicolumn{17}{|l|}{ Inpatient Costs } \\
\hline Intercept & 9.3271 & 11,238 & 0.0065 & $* * *$ & 9.1568 & 9,479 & 0.0187 & $* * *$ & 9.6841 & 16,060 & 0.4973 & $* * *$ & 9.7625 & 17,370 & 0.4948 & $* * *$ \\
\hline WV-Medicare & -0.1436 & 9,735 & 0.0349 & $* * *$ & -0.0819 & 8,733 & 0.0361 & $*$ & -0.0915 & 14,656 & 0.0353 & $* *$ & -0.0917 & 15,848 & 0.0351 & $* *$ \\
\hline \multicolumn{17}{|l|}{ SEER-Medicare } \\
\hline \multicolumn{17}{|l|}{ Outpatient Costs } \\
\hline Intercept & 8.6922 & 5,956 & 0.0051 & $* * *$ & 8.7953 & 6,603 & 0.0145 & $* * *$ & 7.3029 & 1,485 & 0.0374 & $* * *$ & 7.2181 & 1,364 & 0.0380 & $* * *$ \\
\hline WV-Medicare & -0.0209 & 5,833 & 0.0275 & & 0.0092 & 6,664 & 0.0284 & & 0.0508 & 1,562 & 0.0245 & $*$ & 0.0328 & 1,409 & 0.0244 & \\
\hline \multicolumn{17}{|l|}{ SEER-Medicare } \\
\hline \multicolumn{17}{|c|}{ Physician Services Costs } \\
\hline Intercept & 9.2886 & 10,814 & 0.0042 & $* * *$ & 9.4193 & 12,324 & 0.0116 & $* * *$ & 7.5664 & 1,932 & 0.0262 & $* * *$ & 7.6349 & 2,069 & 0.0266 & $* * *$ \\
\hline WV-Medicare & -0.2191 & 8,686 & 0.0228 & $* * *$ & -0.1406 & 10,708 & 0.0230 & $* * *$ & -0.1531 & 1,658 & 0.0183 & $* * *$ & -0.1377 & 1,803 & 0.0183 & $* * *$ \\
\hline SEER-Medicare & & & & & & & & & & & & & & & & \\
\hline
\end{tabular}

Note: Based on average costs in initial phase of care, in 1,387 elderly WV-Medicare women and 39,525 elderly SEER-Medicare women, age 66 and above from 2003 to 2006 diagnosed with first primary incident breast cancer from 2003 to 2006. WV, West Virginia; SEER, Surveillance, Epidemiology, and End Results; CPI, Consumer Price Index; SE, Standard Error; Sig, Significance. Asterisks represent statistically significant group differences based on Generalized Linear Model with gamma distribution and log link function: $* * * \mathrm{P}<0.001 ; * * 001<=\mathrm{P}<.01 ; * .01<=\mathrm{P}<.05$.

Model 1 includes only WV-Medicare/SEER-Medicare groups and no other independent variables

Model 2 includes WV-Medicare/SEER-Medicare groups, and adjusts for predisposing (age, race) and enabling (census tract income and education) as independent variables Model 3 includes WV-Medicare/SEER-Medicare groups, and adjusts for predisposing (age, race), enabling (census tract income and education), need-related (stage at diagnosis, grade of tumor, estrogen receptor status, comorbidities, mental conditions) and healthcare use (Primary care physician visits, type of initial treatment, inpatient use) as independent variables

Model 4 includes WV-Medicare/SEER-Medicare groups, and adjusts for the independent variables listed above in addition to external healthcare environmental factors (location of residence, number of hospitals with oncology services) 
Table 4.7

Factors Explaining Lower Total Average Costs in WV-Medicare Cohort

Using Blinder-Oaxaca Linear Decomposition Analysis 2003-2006

\begin{tabular}{lrr}
\hline Variables & $\begin{array}{c}\text { Pooled } \\
\text { Weights }\end{array}$ & $\begin{array}{c}\text { \% Contribution to the } \\
\text { 'Explained' Portion }\end{array}$ \\
\hline $\begin{array}{l}\text { Predisposing characteristics (Age, Race) } \\
\text { Enabling resources (Census tract Annual Household Income and } \\
\text { Education) }\end{array}$ & $-0.40 \%$ & $-2.53 \%$ \\
$\begin{array}{l}\text { Need-Related Variables (Stage at Diagnosis, Grade of Tumor, ER } \\
\text { status, Comorbidity, Mental Conditions) }\end{array}$ & $6.85 \%$ & $43.30 \%$ \\
$\begin{array}{l}\text { Healthcare Use (PCP visits, Type of Initial Treatment, Inpatient } \\
\text { use) }\end{array}$ & $-1.50 \%$ \\
$\begin{array}{l}\text { External Healthcare Environmental Factors (Location of Residence, } \\
\text { Number of Hospitals with Oncology Services) }\end{array}$ & $7.53 \%$ \\
Total Difference Explained & $3.33 \%$ & $-9.48 \%$ \\
\end{tabular}


CHAPTER 5 


\section{CHAPTER 5}

\section{SUMMARY AND CONCLUSIONS}

\section{RATIONALE AND OBJECTIVES}

Breast cancer (BC) is the most common cancer among women and is the second leading cause of cancer death in women in the United States (US). Based on 2005-2009 Surveillance, Epidemiology and End Results (SEER) statistics, $41 \%$ of the new BC cases and $57.4 \%$ of the BC deaths occur in women age 65 and above ${ }^{1}$. The overall incidence of $\mathrm{BC}$ in women below 65 years of age is 82.97 per 100,000 women and is 421.30 per 100,000 women in those above age $65^{1}$. The overall mortality from BC is 11.15 per 100,000 women for those less than 65 years of age and is 98.64 per 100,000 women in those above age $65^{1}$. Besides, elderly women age 65 and above have a greater burden of $\mathrm{BC}$ as they are diagnosed at more advanced stages and with larger tumors impacting their survival ${ }^{2}$.

In a rural state such as WV which is medically underserved with rates of chronic disease and poor health behaviors ${ }^{3-6}$, rates of advanced and unstaged BC are high ${ }^{7-11}$ owing to lower mammography screening rates in women in this state ${ }^{8-12}$. Also, WV have lower incidence of BC (372.8 per 100,000 vs. 411.7 per 100,000) but higher BC-related mortality (110.4 per 100,000 vs. 98.6 per 100,000$)$ as compared to the national estimates ${ }^{13,14}$. These may be because of low mammography screening rates ${ }^{9-11,15}$, limited physical access to services, shortage of healthcare professionals and services ${ }^{16}$, and untimely $\mathrm{BC}$ care. These disparities also indicate that elderly women diagnosed with $\mathrm{BC}$ in WV may have higher healthcare costs after cancer diagnosis.

There is no clear evidence about the beneficial effects of mammography screening in elderly women age 65 and above due to lack of inclusion of these women in clinical trials ${ }^{17}$ and discrepancy about evidence-based guidelines for mammography screening in these women. 
Previous published studies which reported benefits of mammography screening on representation of stage of BC in elderly women have been limited in terms of including women of certain age groups only, utilizing data from fewer cancer registries, not capturing persistent mammography utilization before $\mathrm{BC}$ diagnosis, and not distinguishing screening from diagnostic mammography claims which is an inherent issue with Medicare claims data ${ }^{18-21}$. Moreover, very limited information is available about the association between mammography screening and stage of disease in elderly Medicare beneficiaries with BC from a rural setting and from non-SEERMedicare states.

Although timely care in BC patients is highly crucial, the US-based guidelines have not yet defined an appropriate time frame for diagnosis and treatment. Previous published studies on timeliness of $\mathrm{BC}$ care ${ }^{22-30}$ have no consensus in regards to an appropriate time for diagnosis and treatment. Also none of these studies have followed any published opinion-based guidelines to appropriately define timely diagnosis and treatment. With lower incidence of $\mathrm{BC}$ but higher $\mathrm{BC}$ related mortality in elderly women in WV as compared to national estimates, it is highly likely that timeliness of $\mathrm{BC}$ care may be one of the important contributors to these disparities.

Female $\mathrm{BC}$ comprises the highest proportion of national cancer care costs which is expected to increase by $32 \%$ in $2020^{31}$. In addition, $\mathrm{BC}$ has the highest costs in the initial phase of care (one year after diagnosis) among all the cancers ${ }^{31}$. A systematic review on BC costs in the US suggested that majority of the studies included in the review were outdated and/or focused on women with selected stages only ${ }^{32}$. Few recent studies on costs have utilized data only till 2003 and from fewer cancer registries ${ }^{31,33-35}$. Moreover, very limited information is available about $\mathrm{BC}$ costs from a rural setting and from non-SEER states. 
To address these gaps in the literature and to identify the factors associated with higher BC-mortality in the elderly WV women, a series of retrospective observational cohort studies were conducted using data from the elderly fee-for-service (FFS) Medicare beneficiaries with first incident primary BC from the West Virginia Cancer Registry (WVCR)-Medicare linked dataset and the results were compared with national estimates derived from the SEER-Medicare linked dataset. In study one, the proportion of Medicare FFS beneficiaries in WV with incident $\mathrm{BC}$ persistent with mammography screening and the association between persistence with mammography screening and stage at $\mathrm{BC}$ diagnosis in a multivariate framework was determined and compared with the national estimates derived from the SEER-Medicare dataset. In study two, timeliness of $\mathrm{BC}$ care in terms of timely diagnosis and timely treatment based on published opinion-based guidelines, factors associated with timeliness and the effect of timely care on the probability of being alive were examined in elderly WV women with BC and compared with the national estimates derived from the SEER-Medicare dataset. In study three, total average healthcare utilization and costs in the initial period of one year after $\mathrm{BC}$ diagnosis and average utilization and costs by types of services and the factors associated with higher healthcare costs in initial period were evaluated in elderly WV women and these estimates were compared with the national estimates derived from the SEER-Medicare dataset.

\section{SUMMARY OF FINDINGS}

Overall, the study findings indicated that the elderly FFS Medicare beneficiaries with first primary incident $\mathrm{BC}$ from WV were statistically different from the nationally representative population from SEER-Medicare. The WV-Medicare study cohort was relatively younger, predominantly white, lived in non-metro areas, with lower median household income and mainly belonged to the areas with lower percentage of people with college education as compared to the 
SEER-Medicare cohort. In addition, the WV-Medicare cohort was mostly diagnosed at local stage of BC, had higher primary care physicians (PCP) visits, and had two or more comorbid chronic conditions.

\section{Persistence with Mammography Screening and Stage at Diagnosis among Elderly Women}

\section{Diagnosed with Breast Cancer}

In the retrospective observational cohort study, $51 \%$ of women in WV-Medicare cohort were persistent with mammography screening as compared to $45.4 \%$ in the SEER-Medicare cohort. In the WV-Medicare cohort, of those not persistent with mammography screening, $31 \%$ were diagnosed with late stage $\mathrm{BC}$ while among those who were persistent with mammography screening, only $12 \%$ were diagnosed with late stage BC. However, in the SEER-Medicare cohort, of those not persistent with mammography screening, 39\% were diagnosed with late stage $\mathrm{BC}$ while $17 \%$ were diagnosed with late stage $\mathrm{BC}$ among those who were persistent with mammography screening. In the multivariate framework for the WV study cohort, persistence with mammography screening was significantly associated with early stage $\mathrm{BC}$. While for the SEER-Medicare cohort, persistence with mammography screening, higher household income and higher PCP visits were significantly associated with earlier stage at BC diagnosis. This study also showed that elderly FFS Medicare beneficiaries with BC in WV were equally likely to be diagnosed at an early stage of BC as compared to their national counterparts from SEERMedicare after controlling for persistence with mammography screening. The study findings

contradict reports of lower mammography utilization in $\mathrm{WV}^{8,9,12,36}$ as the contributor of late stage BC leading to higher BC-related mortality. This also indicates that there may be other factors such as poor health status, family history of BC, BRCA gene mutation, untimely or 
inappropriate care that may be responsible for higher rates of late stage $\mathrm{BC}$ in elderly women in WV, which affect their survival.

\section{Timeliness of Care among Elderly Women Diagnosed with Breast Cancer}

In this retrospective observational cohort study, the median days from initial consultation for abnormality to BC diagnosis was 26 (Interquartile Range (IQR)=12-50 days) for the WVMedicare cohort as compared to 20 (IQR=8 to 41 days) for the SEER-Medicare cohort. The overall median days from $\mathrm{BC}$ diagnosis to any $\mathrm{BC}$ treatment was 8 (IQR=0-28 days) for the WVMedicare cohort as compared to 15 (IQR=0-29 days) for the SEER-Medicare cohort. Approximately, only $63 \%$ of women in the WV-Medicare cohort received timely diagnosis of BC (i.e. consistent with the published opinion-based EUSOMA recommendations) as compared to $71 \%$ of the SEER-Medicare cohort. Also, $76 \%$ of the WV-Medicare cohort received timely BC treatment (i.e. consistent with the published opinion-based NICE recommendations) as compared to $73 \%$ from the SEER-Medicare cohort. For the WV-Medicare cohort, census tract household income above $\$ 35,000$ and tumor size $>3 \mathrm{~cm}$ was significantly associated with timely diagnosis of BC; however, no factors were significantly associated with timely treatment of BC. In addition, the WV-Medicare cohort was significantly less likely to receive timely diagnosis of BC but it was equally likely as the SEER-Medicare cohort to receive timely treatment for BC. Furthermore, the WV-Medicare cohort was significantly more likely to be alive at the follow-up period of three years as compared to the SEER-Medicare cohort. It is possible that other factors such as WV women's social and cultural barriers including fear, sense of fatalism, knowledge

and beliefs, perceived risk, physicians' characteristics, and health system factors ${ }^{24,37-43}$ which are not measured in this study may be contributing to the higher BC-mortality rate among WV women. The higher probability of being alive at the end of follow-up period for WV-Medicare 
cohort compared to the SEER-Medicare cohort indicates that a three years follow-up period may not produce sufficient robust statistical estimates as compared to longer follow up period to make any conclusions in this regards due to higher five-year survival in women with BC.

\section{Total Healthcare Costs of Breast Cancer in the Initial Phase (12-months) After Diagnosis}

In this retrospective observational cohort study, the average total healthcare costs, the average total inpatient costs, and the average total costs for physician services in the initial phase of one year following BC diagnosis for the WV-Medicare cohort was significantly lower than that for the SEER-Medicare cohort. In the multivariate framework, these differences shrunk but continued to remain significant. In the WV-Medicare cohort, women who had regional or distant stage of BC, who had surgery with adjuvant therapy or who had adjuvant therapy only, who had inpatient visits, who had two or more comorbidities, and who had either depression or anxiety had significantly higher total average costs. Also, in the WV-Medicare cohort women who were of age 75 or older had significantly lower total average costs. In the Blinder-Oaxaca decomposition analyses, only $15.82 \%$ of the difference in the total average costs between the WV-Medicare and SEER-Medicare cohorts was explained by the beneficiary characteristics. Enabling resources (census tract income and education) contributed 6.85\%, healthcare use (PCP visits, type of initial treatment, inpatient use) contributed $7.53 \%$, and external healthcare environmental factors (location of residence, hospital visits) contributed 3.33\% to the total explained portion of $15.82 \%$. A total of $84.14 \%$ of the differences in the total average costs in the initial phase of care between WV-Medicare and SEER-Medicare cohorts remained unexplained. The study findings indicate that a portion of the lower costs in a rural state such as WV as compared to the SEER-Medicare regions may be due to the differences in the Medicare spending across various geographic regions in the US ${ }^{44}$. Also, these findings are surprising 
given the higher comorbidity burden which should increase the total average costs in the initial phase following BC diagnosis. Furthermore, the study findings highlight the importance of encouraging elderly WV women to utilize preventive screenings to get $\mathrm{BC}$ diagnosis at earlier stages. These also emphasize the importance of better co-management of physical and mental chronic conditions in this rural and elderly population, to lower overall costs to Medicare in a rural WV state. The findings from the Blinder-Oaxaca decomposition analyses indicate that a larger portion of 'unexplained' differences may be due to unmeasured factors such as health status, severity of comorbid conditions, BMI, patient preferences and propensity to seek care.

\section{CONCLUSION}

This project laid the foundation or larger studies aimed at reducing and eliminating BC disparities in a rural and geographically challenged state such as WV whose population is aging and has lower socio-economic status. Given that the elderly WV women had lower incidence of BC but higher BC-related mortality as compared to the national estimates ${ }^{13,14}$, various factors such as mammography screening, timeliness of care, appropriateness of care, physical access to healthcare services and healthcare professionals need to be studied to determine if these factors are the contributors to these disparities. In this project, the association between persistence with mammography screening and stage at $\mathrm{BC}$ diagnosis, timeliness of $\mathrm{BC}$ care based on published opinion-based recommendations, and total average costs in the initial phase were evaluated and estimated to identify if these factors contributed to the higher BC-related mortality in the rural state and if these rural women bore higher costs in the initial phase. The study findings directed that only timely diagnosis of $\mathrm{BC}$ as per published recommendations is an issue in rural $\mathrm{WV}$, however the chances of survival were better in this population as compared to the estimates from their national counterparts. Various unmeasured factors such as health status, BMI, severity of 
comorbid conditions, patient preferences, social and cultural barriers to care and several physician related and health system factors may be contributing to higher BC-related mortality in elderly WV women.

\section{FUTURE RESEARCH}

Studies investigating the effect of long term persistence with mammography screening (e.g. 10-years) on stage at BC diagnosis after controlling for important covariates such as health status, BMI, patient preferences, and beliefs knowledge about mammography screening that may generate a clear picture about the beneficial effects of mammography screening in this rural and elderly population are suggested. In addition, studies which controls for various factors such as fear, sense of fatalism, knowledge and beliefs about BC, perceived risk, physicians’ characteristics, and health system factors which may affect timely BC care are advocated. Furthermore, studies evaluating the effect of timely BC care on survival in elderly women should include longer follow-up period of at least five to ten years to produce accurate conclusions about this association. Future research focusing on the incremental costs due to presence of various co-occurring chronic conditions among elderly population with $\mathrm{BC}$ from rural areas is also recommended. Moreover, studies estimating indirect medical costs, indirect non-medical costs, out-of-pocket costs and caregiver burden in elderly women with BC in a rural setting are suggested. 


\section{REFERENCES}

1. Howlader N, Noone A, Krapcho M, et al. SEER cancer statistics review, 1975-2009 (Vintage 2009 populations), National Cancer Institute. Bethesda, MD. Based on November 2011 SEER data submission. http://seer.cancer.gov/csr/1975_2009_pops09/. Updated April 2012. Accessed 02/19, 2014.

2. Hillner BE, Penberthy L, Desch CE, McDonald MK, Smith TJ, Retchin SM. Variation in staging and treatment of local and regional breast cancer in the elderly. Breast Cancer Res Treat. 1996;40(1):75-86.

3. Kaiser State Health Facts. Percent of adults who smoke by sex, 2008. Menlo Park, CA: Kaiser Family Fundation. http://www.statehealthfacts.org. Updated 2008. Accessed 02/24, 2014.

4. Kaiser State Health Facts. Overweight and obesity rates for adults by sex, 2009. Menlo Park, CA: Kaiser Family Foundation. http://www.statehealthfacts.org. Updated 2009. Accessed 02/24, 2014.

5. U.S. Census Bureau. Persons 25 years old and over with a bachelor's degree or more, 2008. Washington, DC: U.S. Census Bureau.

http://www.census.gov/compendia/statab/2010/ranks/rank19.html. Updated 2010. Accessed 02/24, 2014.

6. U.S. Census Bureau. Persons below the poverty level, 2008. Washington, DC: U.S. Census Bureau. http://www.census.gov/compendia/statab/2010/ranks/rank34.html. Updated 2010. Accessed 02/24, 2014.

7. Wingo PA, Tucker TC, Jamison PM, et al. Cancer in Appalachia, 2001-2003. Cancer. 2008;112(1):181-192.

8. Lengerich EJ, Chase GA,Beiler J, Darnell M. Increased risk of unknown stage cancer from residence in a rural area: Health disparities with poverty and minority status. Hershey, PA: Pennsylvania State University and the Penn State Cancer Institute, Department of Health Evaluation Sciences. 2006.

9. State Cancer Profiles. Incidence and mortality rate reports for West Virginia by county, 2010. Bethesda, MD: National Cancer Institute. http://statecancerprofiles.cancer.gov/. Updated 2010. Accessed 02/24, 2014.

10. United States Cancer Statistics. Rankings by state: 2006, male and female, all cancer sites combined. Atlanta, GA: Centers for Disease Control and Prevention (CDC). http://apps.nccd.cdc.gov/uscs/. Updated 2010. Accessed 02/24, 2014. 
11. United States Cancer Statistics. State vs. National Rates: 2006, female, West

Virginia. Atlanta, GA: Centers for Disease Control and Prevention (CDC).

http://apps.nccd.cdc.gov/uscs/. Updated 2010. Accessed 02/24, 2014.

12. Khanna R, Bhanegaonkar A, Colsher P, Madhavan SS, Halverson J. Breast cancer screening, incidence, and mortality in west virginia. W V Med J. 2009;105 Spec No:24-32.

13. SEER State Cancer Profiles 2009.

http://statecancerprofiles.cancer.gov/map/map.withimage.php?00\&157\&055\&00\&2\&01\&1\&1\& 6\&0\#map. Updated 2009. Accessed 02/19, 2014.

14. SEER State Cancer Profiles 2009.

http://statecancerprofiles.cancer.gov/map/map.withimage.php?00\&157\&055\&00\&2\&02\&1\&1\& 6\&0\#map. Updated 2009. Accessed 02/19, 2014.

15. Hall HI, Uhler RJ, Coughlin SS, Miller DS. Breast and cervical cancer screening among Appalachian women. Cancer Epidemiol Biomarkers Prev. 2002;11(1):137-142.

16. Wingo PA, Howe HL, Thun MJ, et al. A national framework for cancer surveillance in the United States. Cancer Causes Control. 2005;16(2):151-170.

17. Walter LC, Covinsky KE. Cancer screening in elderly patients: A framework for individualized decision making. JAMA. 2001;285(21):2750-2756.

18. McCarthy EP, Burns RB, Freund KM, et al. Mammography use, breast cancer stage at diagnosis, and survival among older women. J Am Geriatr Soc. 2000;48(10):1226-1233.

19. Randolph WM, Mahnken JD, Goodwin JS, Freeman JL. Using Medicare data to estimate the prevalence of breast cancer screening in older women: Comparison of different methods to identify screening mammograms. Health Serv Res. 2002;37(6):1643-1657.

20. Badgwell BD, Giordano SH, Duan ZZ, et al. Mammography before diagnosis among women age 80 years and older with breast cancer. J Clin Oncol. 2008;26(15):2482-2488.

21. Galit W, Green MS, Lital KB. Routine screening mammography in women older than 74 years: A review of the available data. Maturitas. 2007;57(2):109-119.

22. Gorin SS, Heck JE, Cheng B, Smith SJ. Delays in breast cancer diagnosis and treatment by racial/ethnic group. Arch Intern Med. 2006;166(20):2244-2252.

23. Gwyn K, Bondy ML, Cohen DS, et al. Racial differences in diagnosis, treatment, and clinical delays in a population-based study of patients with newly diagnosed breast carcinoma. Cancer. 2004;100(8):1595-1604. 
24. Elmore JG, Nakano CY, Linden HM, Reisch LM, Ayanian JZ, Larson EB. Racial inequities in the timing of breast cancer detection, diagnosis, and initiation of treatment. Med Care. 2005;43(2):141-148.

25. Lobb R, Allen JD, Emmons KM, Ayanian JZ. Timely care after an abnormal mammogram among low-income women in a public breast cancer screening program. Arch Intern Med. 2010;170(6):521-528.

26. Bilimoria KY, Ko CY, Tomlinson JS, et al. Wait times for cancer surgery in the United States: Trends and predictors of delays. Ann Surg. 2011;253(4):779-785.

27. Richardson LC, Royalty J, Howe W, Helsel W, Kammerer W, Benard VB. Timeliness of breast cancer diagnosis and initiation of treatment in the national breast and cervical cancer early detection program, 1996-2005. Am J Public Health. 2010;100(9):1769-1776.

28. McLaughlin JM, Anderson RT, Ferketich AK, Seiber EE, Balkrishnan R, Paskett ED. Effect on survival of longer intervals between confirmed diagnosis and treatment initiation among lowincome women with breast cancer. J Clin Oncol. 2012;30(36):4493-4500.

29. Halpern MT, Holden DJ. Disparities in timeliness of care for U.S. Medicare patients diagnosed with cancer. Curr Oncol. 2012;19(6):e404-13.

30. Bleicher RJ, Ruth K, Sigurdson ER, et al. Preoperative delays in the US Medicare population with breast cancer. J Clin Oncol. 2012;30(36):4485-4492.

31. Mariotto AB, Yabroff KR, Shao Y, Feuer EJ, Brown ML. Projections of the cost of cancer care in the United States: 2010-2020. J Natl Cancer Inst. 2011;103(2):117-128.

32. Campbell JD, Ramsey SD. The costs of treating breast cancer in the US: A synthesis of published evidence. Pharmacoeconomics. 2009;27(3):199-209.

33. Yabroff KR, Lamont EB, Mariotto A, et al. Cost of care for elderly cancer patients in the United States. J Natl Cancer Inst. 2008;100(9):630-641.

34. Warren JL, Yabroff KR, Meekins A, Topor M, Lamont EB, Brown ML. Evaluation of trends in the cost of initial cancer treatment. J Natl Cancer Inst. 2008;100(12):888-897.

35. Brown ML, Riley GF, Schussler N, Etzioni R. Estimating health care costs related to cancer treatment from SEER-Medicare data. Med Care. 2002;40(8 Suppl):IV-104-17.

36. United States Cancer Statistics: 1999-2004 Incidence WONDER on-line database. United States Department of Health and Human Services, Centers for Disease Control and Prevention and National Cancer Institute. http://wonder.cdc.gov/cancer-v2004.html. Updated 2010. Accessed 02/24, 2014. 
37. Facione NC. Delay versus help seeking for breast cancer symptoms: A critical review of the literature on patient and provider delay. Soc Sci Med. 1993;36(12):1521-1534.

38. Facione NC, Miaskowski C, Dodd MJ, Paul SM. The self-reported likelihood of patient delay in breast cancer: New thoughts for early detection. Prev Med. 2002;34(4):397-407.

39. Dennis CR, Gardner B, Lim B. Analysis of survival and recurrence vs. patient and doctor delay in treatment of breast cancer. Cancer. 1975;35(3):714-720.

40. Kerner JF, Yedidia M, Padgett D, et al. Realizing the promise of breast cancer screening: Clinical follow-up after abnormal screening among black women. Prev Med. 2003;37(2):92-101.

41. Lyttle NL, Stadelman K. Assessing awareness and knowledge of breast and cervical cancer among Appalachian women. Prev Chronic Dis. 2006;3(4):A125.

42. Leslie NS, Deiriggi P, Gross S, DuRant E, Smith C, Veshnesky JG. Knowledge, attitudes, and practices surrounding breast cancer screening in educated Appalachian women. Oncol Nurs Forum. 2003;30(4):659-667.

43. Schoenberg NE, Kruger TM, Bardach S, Howell BM. Appalachian women's perspectives on breast and cervical cancer screening. Rural Remote Health. 2013;13(3):2452.

44. Super N. The geography of Medicare: Explaining differences in payment and costs. NHPF Issue Brief. 2003;(792)(792):1-19. 